
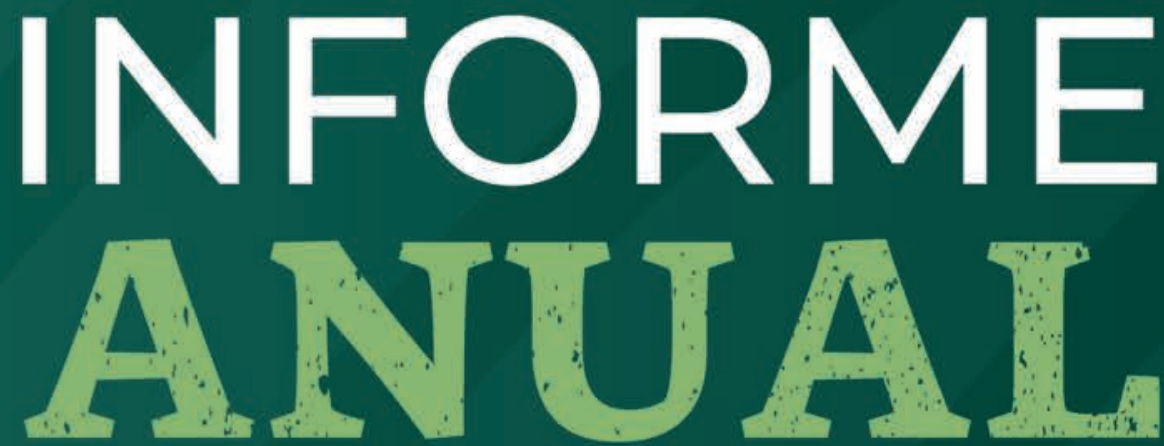

INSTITUTO MEXICANO DE TECNOLOGÍA DEL AGUA

DOI: https://doi.org/10.24850/i-imta-2020-01
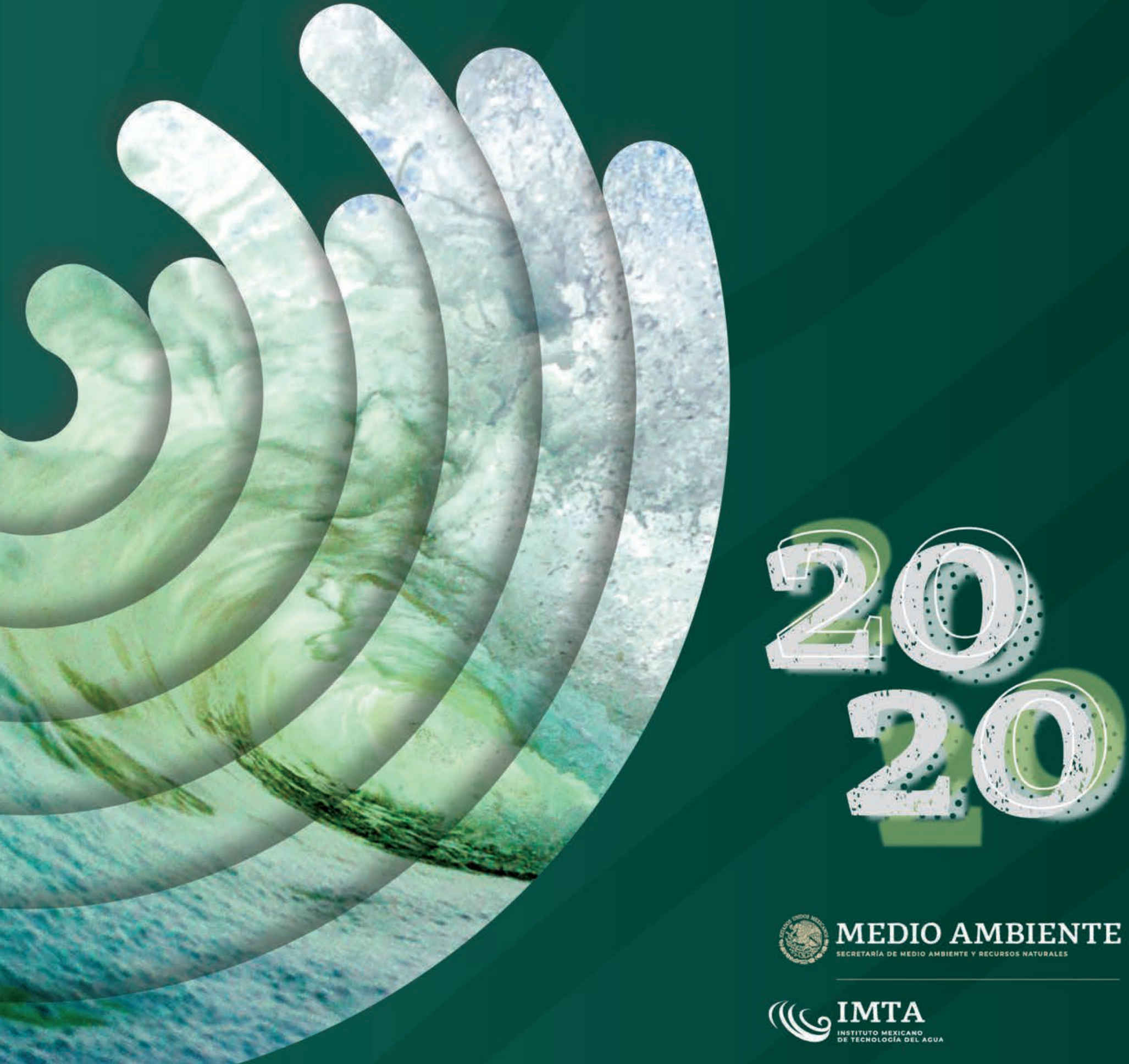

(2.) MEDIO AMBIENTE

( (GIMTA 

INFORME ANUAL 2020

(4. MEDIO AMBIENTE $\mid((6)$ IMTA 



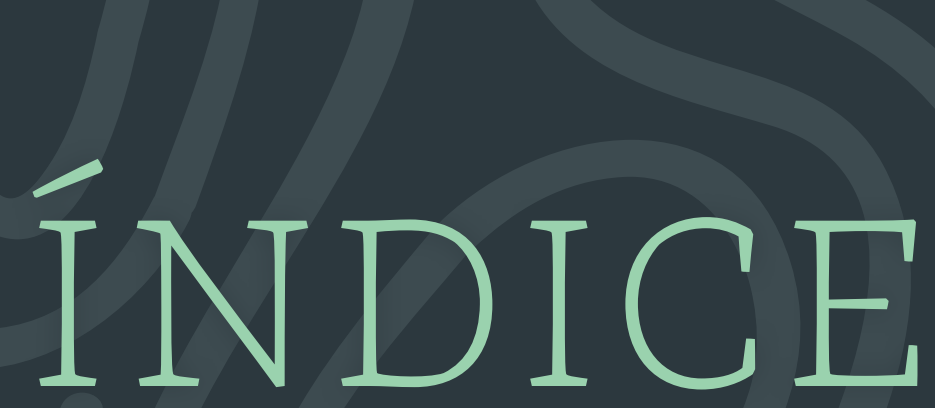

PRESENTACIÓN. .06

RESUMEN EJECUTIVO

AGUA Y AMBIENTE .42

4.1 BosQue DE ChapultepeC .45

4.2. MESETA P'URHÉPECHA 46

AGUA Y GOBIERNO

1.1 CENTRO DE EDUCACIÓN AMBIENTAL Y CULTURAL "MUROS DE AGUA-JOSÉ REVUELTAS" ............15

1.2 PLAN DE JUSTICIA DEL PUEBLO YAQUI...................................16

1.3 SERVIDORES DE LA NACIÓN, CAMPECHE ............................17

1.4 LEY GENERAL DE AGUAS .18

1.5 INDICADORES DE DERECHOS HUMANOS AL AGUA Y AL SANEAMIENTO 19

AGUA Y SOCIEDAD 22

2.1 AtLAS de CAlidAd del Agua en MÉXICO .25

2.2 REACTIVACIÓN DE LA RED PIEZOMÉTRICA Y DE CALIDAD DEL AGUA DEL ACUÍFERO VALLE DEL MEZQUitaL .26

2.3 BASES PARA CONFORMACIÓN DE UN ATLAS DE ORGANIZACIONES LOCALES

2.4 RED DE DISTRIBUCIÓN DE AGUA POTABLE DE CHIHUAHUA, CHIH.

2.5 PROGRAMA DE INDICADORES DE GESTIÓN DE ORGANISMOS OPERADORES Y SISTEMA DE INFORMACIÓN DE TARIFAS DE AGUA POTABLE

AGUA Y PRODUCTIVIDAD 32

3.1 MINITURBINA 35

3.2 PROGRAMA HídRICO PARA LA SEGURIDAD ALIMENTARIA Y ENERGÉTICA DEL SUR-SURESTE.

3.3 ESTIMACIÓN DE VARIABLES HIDROAGRÍCOLAS CON SENSORES REMOTOS PARA MEJORAR LA GESTIÓN DE RECURSOS HÍDRICOS

3.4 SISTEMAS DE DESALINIZACIÓN MEDIANTE TECNOLOGÍA FOTOVOLTAICA Y NANOFILTRACIÓN.

3.5 USOS DEL AGUA EN LA AGRICULTURA NACIONAL

4.3. RESTAURACIÓN ECOLÓGICA: PRESA ENDHÓ ..................... 47

4.4. MONITOREO DE PARÁMETROS AMBIENTALES .................. 49

4.5. INFRAESTRUCTURA VERDE .........................................................5 50

IMTA TRANSVERSAL 54

5.1 PROGRAMA INSTITUCIONAL ......................................................57

5.2 TZOLKIN: MONITOR MESOAMERICANO dE SEQUÍA........58

5.3 LEY MODELO DE SISTEMAS COMUNITARIOS DE AGUA Y SANEAMIENTO PARA AMÉRICA LATINA $Y$ EL CARIBE .59

5.4 TRANSPARENCIA HÍDRICA 60

5.5 CONACYT. 60

5.6 CONSEJO DE CIENCIA Y TECNOLOGíA DEL ESTADO DE MORELOS. 63

IMTA GLOBAL 66

6.1 SEMINARIO VIRTUAL SOLUCIONES BASADAS EN LA NATURALEZA PARA LA GESTIÓN HÍDRICA EN LATINOAMÉRICA.

6.2. COOPERACIÓN INTERNACIONAL PARA EL DESARROLLO............................................................... 70

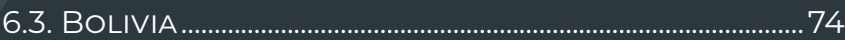

6.4. NICARAGUA ................................................................................. 75

CAPACIDADES PARA EL FUTURO ...........................78

7.1 POSGRADO Y NUEVO PROGRAMA EN SEGURIDAD HÍDRICA. 81

7.2 ESPACIO DE CONOCIMIENTO IMTA ....................................... 82

7.3 DIÁSPORA HÍDRICA.......................................................................... 83

7.4 EL ACUEDUCTO_................................................................................ 84 7.5 PROGRAMA JÓVENES CONSTRUYENDO EL FUTURO .......85 

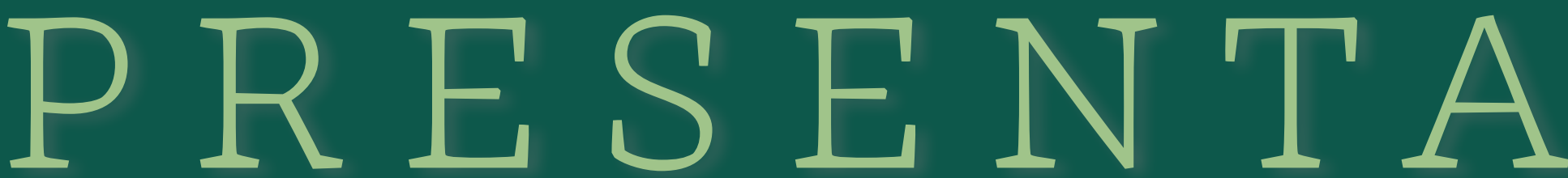

\section{DEL DIRECTOR GENERAL}

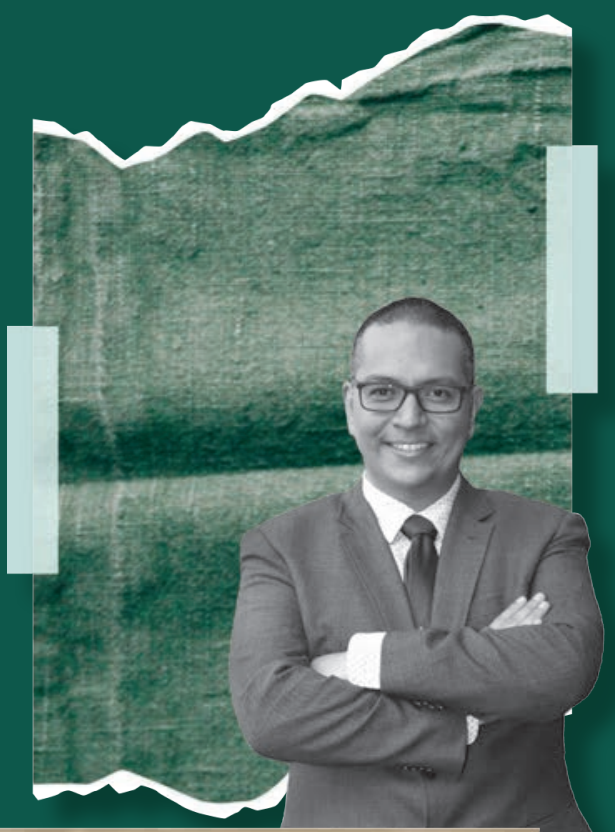

Adrian Pedrozo Acuña

Director General del Instituto

Mexicano de Tecnología del Agua

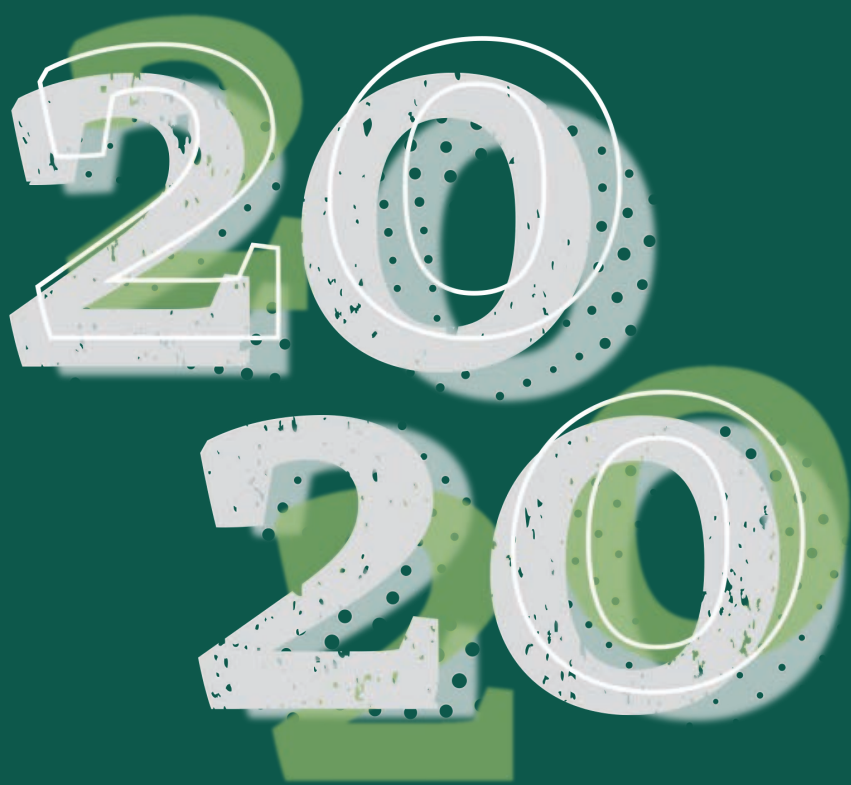

Los cambios repentinos detonados por el acelerado desarrollo económico global han impuesto una fuerte presión sobre nuestro planeta, lo cual ha resultado en desequilibrios del ciclo hidrológico global, que hoy se manifiestan en eventos extremos, como sequías e inundaciones, pero más importante durante este año 2020 fue la propagación espacial de un virus que pone en riesgo el aseguramiento de la salud y prosperidad de todas las naciones. La pandemia de COVID-19 es una llamada de atención planetaria que nos señala que cuando parecía estar todo bien por el desarrollo económico del mundo, en realidad no lo estaba. Este virus es una manifestación natural que - además de someter a prueba la capacidad de organización y fraternidad de todas las familias, sociedades, instituciones y gobiernos del planeta- pone en pausa el crecimiento económico de todas las naciones. La lección es simple: el planeta nos dice, a través de un virus con propagación global, que nuestra salud personal sí se relaciona y afecta con la salud del planeta, y que con la degradación ecológica se entrelazan la salud humana y el crecimiento económico global.

En el IMTA estamos ciertos de que es necesario y posible producir desarrollo y movernos hacia un mundo sin pobreza e injusticia de la mano del agua, pero, a la vez, debemos respetar los límites de la sustentabilidad. De esta forma, se detona una transición hídrica que tiene su base en la ética por la vida y que busca asegurar la prosperidad de largo plazo para todos. Nuestra misión, como especialistas del agua, consiste en mantener la habilidad de todos los ecosistemas para dar soporte al mundo moderno y su desarrollo. Esto requiere una transformación total en economías, sociedades, culturas y patrones de consumo y producción. El futuro estará cimentado en principios de equidad, responsabilidad, distribución sostenible del espacio y los recursos, y en el respeto de unos por otros de los que vivimos hoy y por quienes vivirán mañana.

La pandemia ha hecho evidente la visión incompleta que tenemos del agua. En todos los países, su administración ha estado fundada en una perspectiva técnica de eficiencia económica y productividad, soslayando equidad, justicia y participación ciudadana. El mundo que nace deberá reconocer que en lo relativo al agua, la mejor decisión ya no es necesariamente la más eficiente desde una perspectiva exclusivamente económica. Por el contrario, las decisiones deberán ser resultado de un análisis con base en evidenca científica, considerando siempre 
una lente de ética en lo local. Por si este razonamiento fuera poco, el número y nivel de conflictos hídricos que se aprecian en el mundo nos indican que es importante agregar a los conceptos de eficiencia y sustentabilidad hídrica consideraciones relativas a la justicia y equidad en la distribución del vital líquido.

Es posible un desarrollo económico impulsado por una agricultura e industria que utilicen el agua de forma responsable, pero necesitamos reconocer que para ello, uno de los grandes retos consiste en mover la voluntad $y$ el dinero de aquellos grandes usuarios para dirigirse hacia una mayor eficiencia y un reciclado completo de agua. Por otro lado, debemos también reconocer dos cosas: 1, que el modelo de producción extractivo no es sustentable y está agotado y 2 , que requerimos de la ética tanto en el servicio público como en el quehacer agrícola e industrial, de tal suerte que hacer lo correcto por el bien de todos se convierta en un impulso que motive nuestras acciones. Esto nos permitirá caminar como sociedad hacia un desarrollo económico equitativo, soportado por un uso sustentable e inteligente del agua.

Hoy día es vital que la transformación que vive nuestro país en diversos ámbitos de la vida nacional se dé también en el sector hídrico nacional. El agua es parte del territorio y de la identidad local, a través de ella se vinculan valores culturales, éticos y morales de las comunidades en el país. Por ello, la responsabilidad que tiene el IMTA de generar el mejor conocimiento disponible en el mundo y ponerlo al servicio de la nación, consituye una herramienta poderosísima para la transformación hídrica nacional.

En 2020, el IMTA trabajó de la mano de la Secretaría de Medio Ambiente y Recursos Naturales en la ciudadanización de la política ambiental. Participamos juntos en todas las mesas de díalogo con las comunidades afectadas e ignoradas en el pasado. Por ejemplo, en el Plan de Justicia Yaqui, en Sonora, y en la Restauración de la zona de Tula, en Hidalgo, dando así los primeros pasos a la construcción de nuevos acuerdos y de un nuevo México.

A pesar de las condiciones críticas que impuso la pandemia, nuestro informe da cuenta del gran compromiso institucional y nos presenta un año lleno de esfuerzos colaborativos con otras instituciones de gobierno. En este documento resumimos las intervenciones más significativas, considerando las interacciones del agua con decisiones de gobierno, sociedad, productividad y medio ambiente. Además, incluímos iniciativas que dan cuenta de la solidaridad regional, a través del intercambio de conocimiento con otras naciones hermanas de América Latina, en la búsqueda de un desarrollo humano regional y bajo un espíritu de cooperación internacional.

Durante este año, un hecho digno de mencionarse en la arena global es que nuestro trabajo resonó en el Parlamento Latinoamericano, organismo multilateral y regional, el cual aprobó la Ley Modelo de Sistemas Comunitarios de Agua y Saneamiento propuesta por parlamentarias mexicanas, quienes contaron con el apoyo técnico del IMTA. Esta labor permite reconocer el papel estratégico de estos sistemas para garantizar el cumplimiento de los derechos humanos al agua y al saneamiento, y es relevante para alcanzar las metas previstas en la Agenda 2030.

El Instituto Mexicano de Tecnología del Agua acompaña a la Secretaría de Medio Ambiente y Recursos Naturales en la atención de problemas hídricos locales en todo el territorio nacional, donde las comunidades expresan sus preocupaciones legítimas sobre la calidad y cantidad del agua de cuencas y acuíferos. Lo hacemos por que es lo correcto, y por esta razón no es gratuito que nuestros principios rectores sean la ética hídrica, la generación de evidencia científica para las decisiones, y la transparencia de los datos y la información que proporcionamos a la sociedad. Somos la inteligencia hídrica de México y estamos aquí para hacer la diferencia. 


\section{RESUMEN EJECUTIVO}

El presente informe presenta los proyectos más destacados que este Instituto llevó a cabo durante el 2020, un año en el que todo el mundo fue puesto a prueba por la presencia de un virus, que demostró de manera directa la relación que guardan la salud ambiental y la salud humana.

En el caso del agua, ya desde hace mucho tiempo, vivir en la pobreza rural o urbana es sinónimo de un limitado acceso a ella y de una precaria seguridad hídrica, que a su vez se relacionan con la limitada garantía de los derechos humanos al agua y saneamiento de la población que se encuentra en esta situación.

Hoy, la pandemia de COVID-19 hace evidente la visión incompleta con la que miramos el agua. Por esta razón, las acciones del IMTA, resumidas en este documento, incorporan un nuevo enfoque para atender la problemática hídrica nacional, que tiene su base en la utilización de tres principios axiológicos: 1) ética por la vida, 2) evidencia científica como base de las decisiones y 3) transparencia en los datos y la información para la reconstrucción de confianza entre gobierno y sociedad.

La información aquí presentada se organiza en siete secciones: cuatro que representan vínculos que las decisiones relativas al agua tienen con los entornos social y físico: "Agua y gobierno», "Agua y sociedad», «Agua y productividad», y «Agua y medio ambiente», así como dos que se relacionan con el entorno institucional: «IMTA transversal» e «IMTA global», además de una sección prospectiva denominada «Capacidades para el futuro».

Durante este año, bajo una lógica de trabajo en equipo, el IMTA redobló esfuerzos de cooperación participando en proyectos importantes del sector ambiental, entre los que destaca el Centro de Educación Ambiental y Cultural "Muros de Agua-José Revueltas". Asimismo, de la mano de la Semarnat y bajo el liderazgo del Instituto Nacional de Pueblos Indígenas, proporcionamos evidencia científica relativa a la calidad del agua del pueblo yaqui, dentro del marco del Plan de Justicia para el Pueblo Yaqui, y lideramos un trabajo interinstitucional dedicado al desarrollo de indicadores de derechos humanos al agua y al saneamiento.

Comprometidos con el mantra de que lo que no se mide no se puede administrar, reportamos nuestro esfuerzo en la reactivación de la red piezométrica y de calidad del agua del acuífero del valle del Mezquital e iniciamos la construcción de un atlas nacional de calidad del agua. Igualmente, reportamos el trabajo relativo al proyecto del bosque de Chapultepec, a la restauración ecológica de la presa Endhó y al monitoreo de parámetros ambientales y de soluciones basadas en la naturaleza. Trabajamos para generar información confiable y actualizada sobre el uso del agua en la agricultura nacional de riego, apoyada en imágenes satelitales y muestreo en campo. 
En cuanto a la colaboración con otros actores nacionales e internacionales destacan Tzolkin: Monitor Mesoamericano de Sequía, la Ley Modelo de Sistemas Comunitarios de Agua y Saneamiento para América Latina y el Caribe, y los proyectos desarrollados con fondos del Consejo Nacional de Ciencia y Tecnología. De igual manera, mantenemos la cooperación internacional con el apoyo de la Agencia Mexicana de Cooperación Internacional para el Desarrollo, principalmente para intercambiar conocimiento y experiencias con países de Centroamérica y el Caribe.

La formación de capacidades se lleva a cabo a través del Posgrado IMTA, que en 2020 impulsó la creación del nuevo Programa de Doctorado en Seguridad Hídrica. En este año complicado, el intercambio de conocimiento no se detuvo y - haciendo uso de las tecnologías de la información y la comunicación-, el Espacio de Conocimiento IMTA, el Editorial Perspectivas de nuestra página web y la gaceta El Acueducto se consolidaron como nuestros principales medios para compartir conocimientos y experiencias de manera abierta y con mayor alcance.

El IMTA, como la inteligencia hídrica del gobierno y del pueblo de México, trabaja y continuará dedicándose a desarrollar una ciencia profundamente humanista, que utilice el conocimiento científico-tecnológico en beneficio de toda la ciudadanía mexicana, siempre de la mano de una conducta ética que busque como fin la sustentabilidad del agua y, por ende, la continuidad de la vida.

EL CONOCIMIENTO DEL AGUA AL SERVICIO DE MÉXICO 


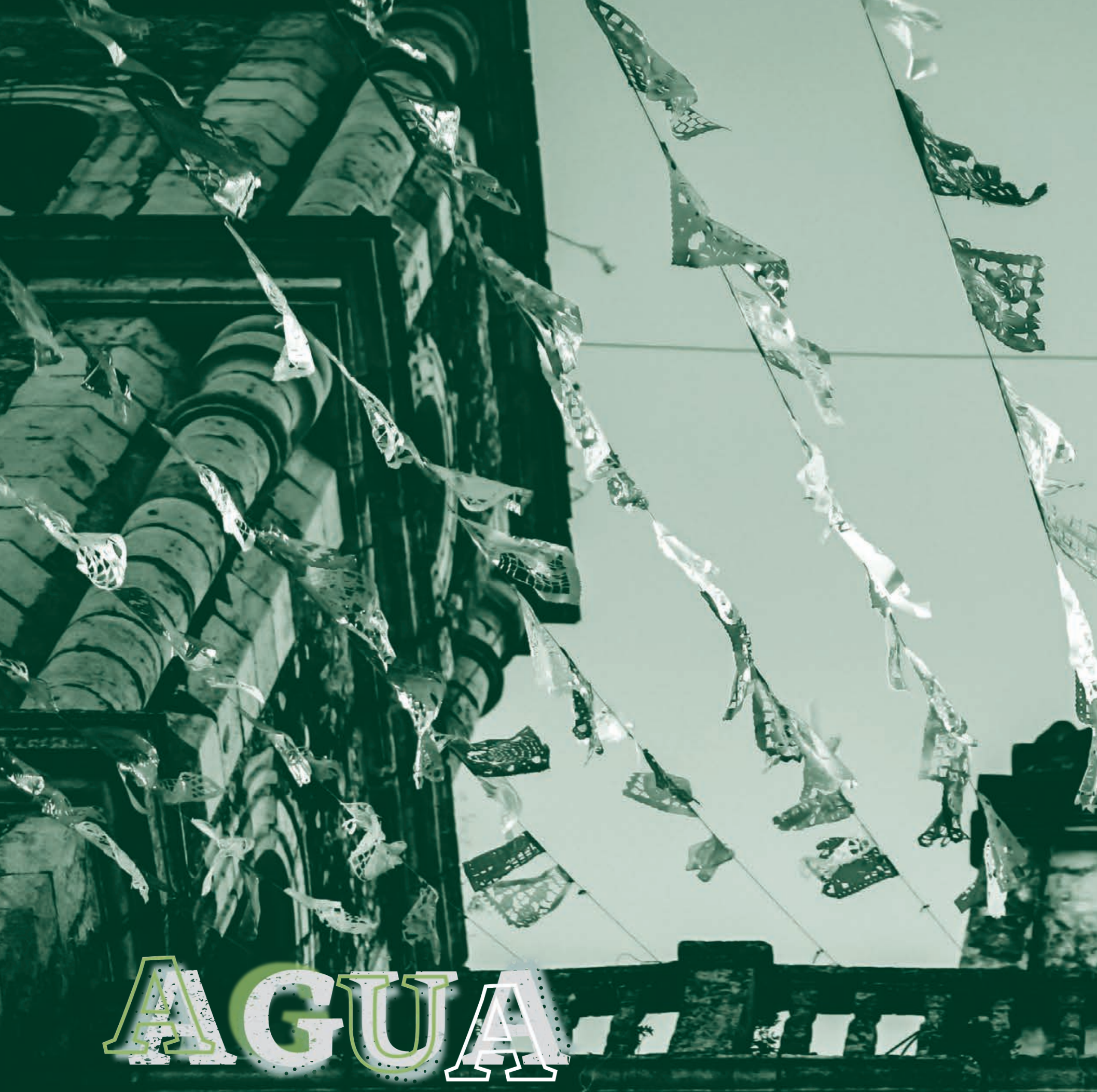




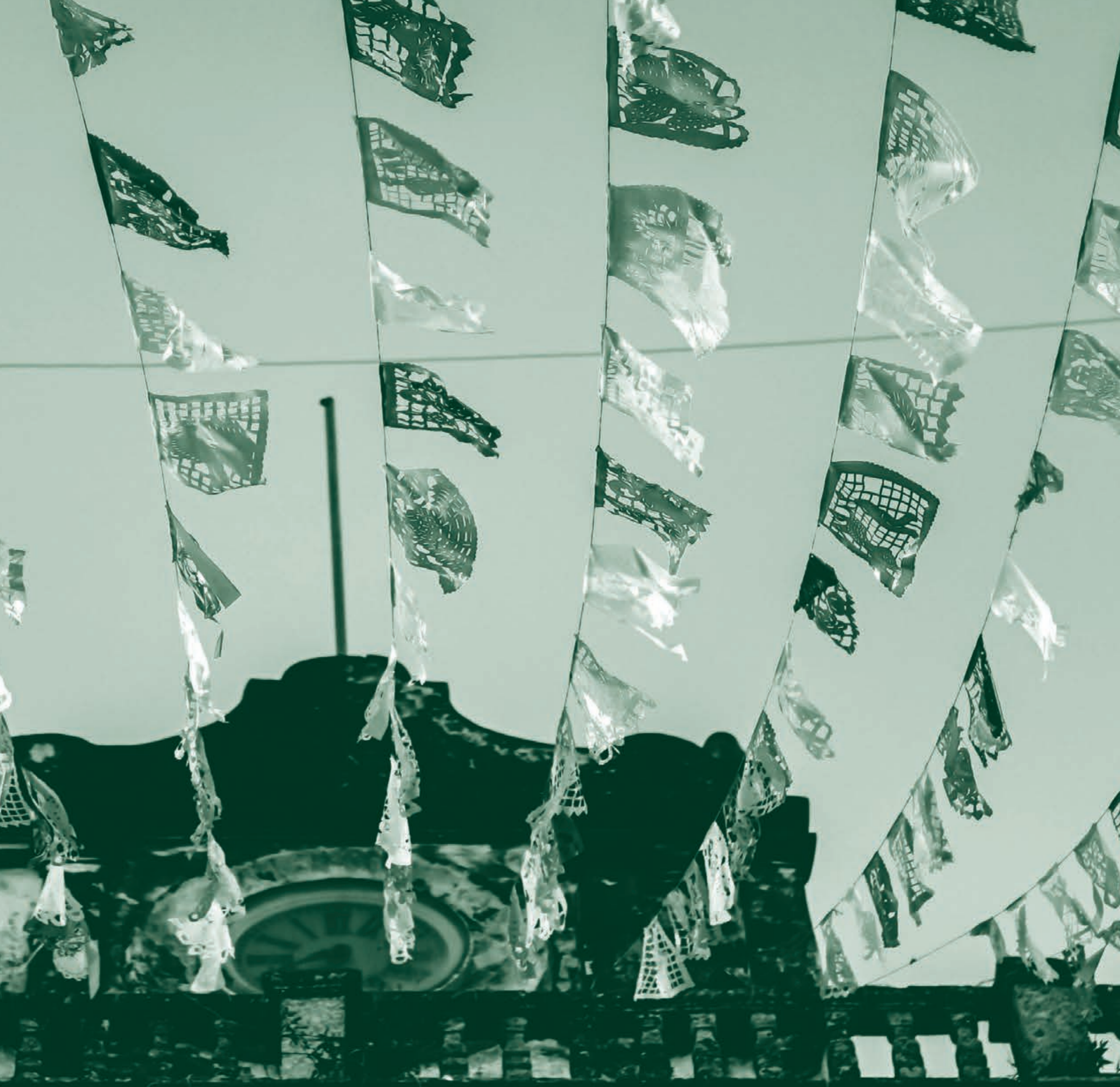




\section{AGUA Y GOBIERNO}

EVIDENCIA CIENTÍFICA DISPONIBLE PARA LAS DECISIONES DE NUESTRO GOBIERNO

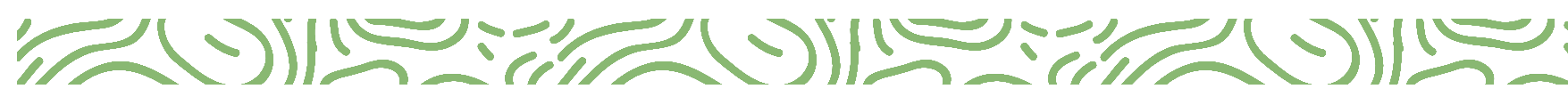

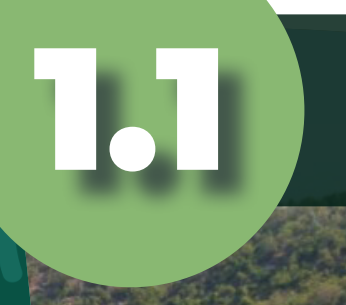

CENTRO DE EDUCACIÓN AMBIENTAL Y CULTURAL "MUROS DE AGUA-JOSÉ REVUELTAS"

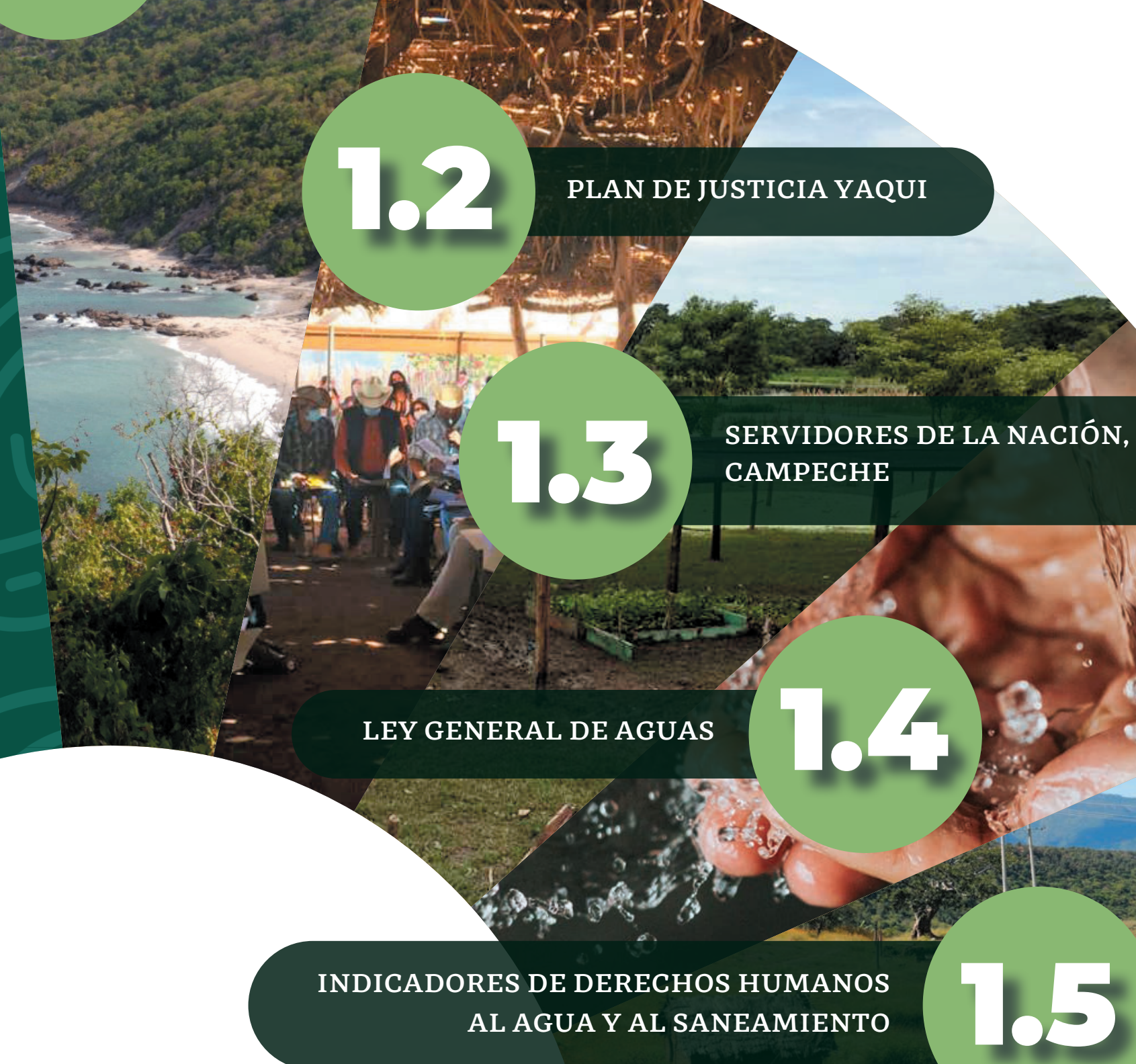

AL AGUA Y AL SANEAMIENTO 


\section{AGUA Y GOBIERNO}

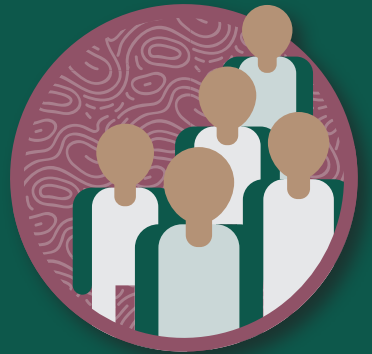

\section{El Gobierno de México}

asumió el compromiso de garantizar a las comunidades tradicionales los derechos fundamentales a la tierra y al agua.

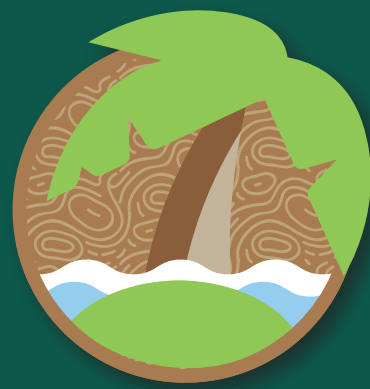

CEAC "Muros de Agua-José Revueltas"

Este centro educativo se ubica en la isla María Madre.

Inició operaciones el 20 de noviembre de 2020.

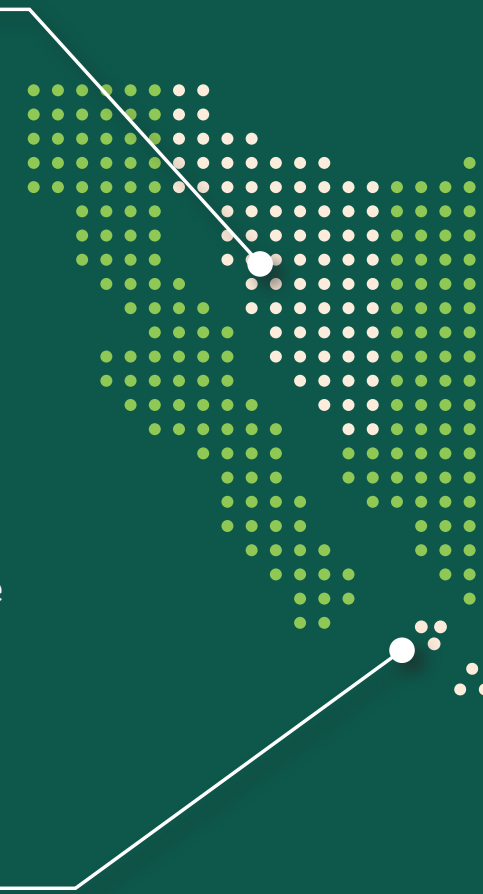

0

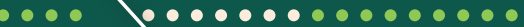

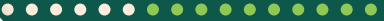
00000000000000000 0.0000000000000 0.000000000000 0.0000000000

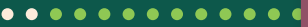
$000 \bullet \bullet \bullet$

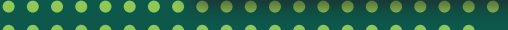

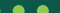

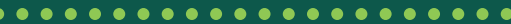
० 0 ०

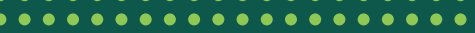

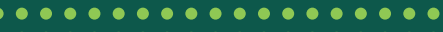

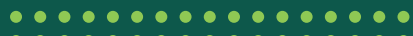
$\bullet \bullet \bullet \bullet \bullet \bullet \bullet \bullet \bullet \bullet \bullet \bullet \bullet \bullet \bullet \bullet ०$

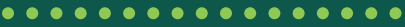

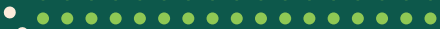
00000000000000

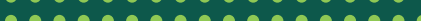

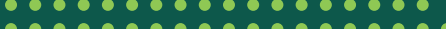
$\bullet \bullet \bullet \bullet \bullet \bullet \bullet \bullet \bullet \bullet ० ० \bullet \bullet ० \bullet \bullet \bullet$ $\bullet \bullet \bullet \bullet \bullet \bullet \bullet \bullet \bullet \bullet \bullet \bullet \bullet \bullet \bullet \bullet \bullet \bullet \bullet$

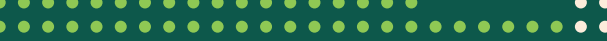

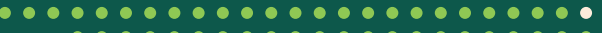

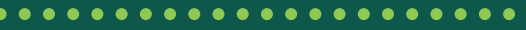

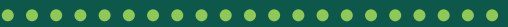
0.0000000000000000

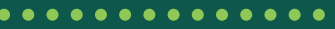
10.0 ?

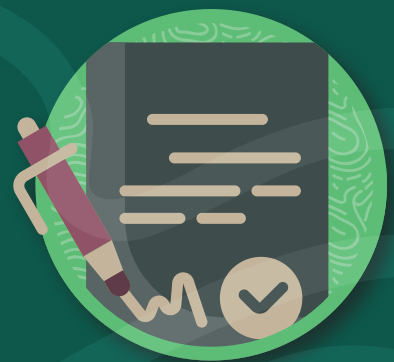

Ley General de Aguas

Participación en la construcción de un nuevo marco jurídico para la gestión integral del agua en México mediante el apoyo técnico y jurídico.
Derechos humanos al agua y al saneamaiento

EI IMTA impulsa el proyecto para generar los indicadores de derechos humanos al agua y al saneamiento.

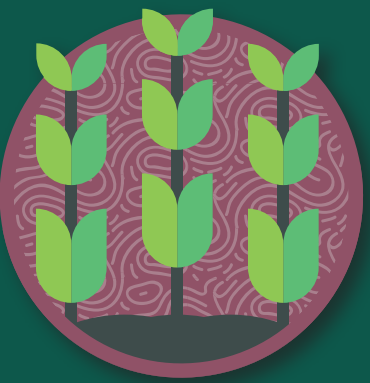

Servidores de la Nación, Campeche

EI IMTA brindó asesoría técnica a la Secretaría de Bienestar para incrementar la productividad de zonas rurales.

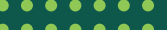
10 000

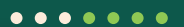
000 $\bullet \bullet \bullet \bullet \bullet \bullet$ 0 


\subsection{CENTRO DE EDUCACIÓN AMBIENTAL Y CULTURAL "MUROS DE AGUA-JOSÉ REVUELTAS"}

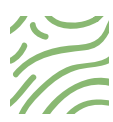
La formación de los futuros guardianes ambientales en nuestro país tiene lugar en el Centro de Educación Ambiental y Cultural (CEAC) "Muros de Agua-José Revueltas".

PARTICIPANTES: Adrián Pedrozo Acuña, Norma Ramírez Salinas, Jennifer Bañuelos Díaz, Ulises Dehesa Carrasco, Mario A. Montiel Gutiérrez, Rodrigo Ulises Santos Téllez, César Calderón Mólgora, Armando Rivas Hernández, Antonio Javier García López, Carlos Silva Luna, Emanuel Villegas Mendoza y Jorge Velázquez.

EI IMTA participó en trabajo colaborativo para la operación del CEAC "Muros de Agua-José Revueltas" en las Islas Marías. Personal del IMTA realizó acciones para hacer posible el abasto autosuficiente de agua potable conforme a la norma NOM 127 SSA1, modificación 2000, e instaló áreas demostrativas de riego agrícola por goteo con bombeo solar.

Este centro educativo se ubica en la Isla María Madre e inició operaciones el 20 de noviembre de 2020. Su objetivo es formar "guardianes del territorio" en generaciones integradas por veinte jóvenes universitarios de diferentes regiones del país.

En colaboración con la Comisión Nacional de Áreas Naturales Protegidas (Conanp), la Secretaría de Marina (Semar) y la coordinación sectorial de la Secretaría de Medio Ambiente y Recursos Naturales (Semarnat), el IMTA contribuyó con el estudio de las fuentes de abastecimiento de agua en la isla y, conforme a los resultados de la calidad del agua, determinó el sistema de potabilización para atender las necesidades presentes y futuras de las poblaciones fija y flotante.

El sistema de potabilización se compone de un filtro para remoción de partículas suspendidas; un filtro de carbón activado para remoción de color, olor y sabor, y una lámpara de rayos ultravioleta para desinfección. Se instalaron dos equipos de 1.8 litros por minuto para abastecimiento directo en el punto de uso y un equipo de 12 litros por minuto para el llenado de garrafones, con capacidad de llenar en una hora, en forma continua, 55 garrafones de 19 litros cada uno. Con este sistema de abastecimiento autosuficiente de agua potable para uso y consumo humano ya no será necesario el traslado a la isla de treinta garrafones a la semana.

También se instalaron áreas demostrativas de riego agrícola por goteo de baja presión en una parcela de 255 metros cuadrados, con un sistema de almacenamiento en olla de agua con bombeo solar, para apoyar al desarrollo de capacidades y producción sustentable. Adicionalmente, se llevaron a cabo labores para habilitar pozos y sistemas de bombeo hacia los huertos en la isla.

Asimismo, nuestros especialistas evaluaron la infraestructura de agua potable de los campamentos Balleto y Morelos, a cargo de Conanp y Semar, de tal suerte que, a través de esta actividad, se produjo una propuesta de restitución de la red de distribución del campamento Balleto, se realizaron acciones para el suministro de agua al campamento Morelos y se propuso un proyecto de conducción de agua de Balleto a Morelos.
Adicionalmente, investigadores del IMTA participaron en el diagnóstico de la infraestructura de saneamiento existente y en la revisión de las instalaciones de las plantas de tratamiento de aguas residuales. De este trabajo surgieron propuestas de alternativas más adecuadas, como son los humedales artificiales, que permiten bajar costos de operación y mantenimiento de la infraestructura, logrando así un mejor uso de los recursos económicos de este proyecto.

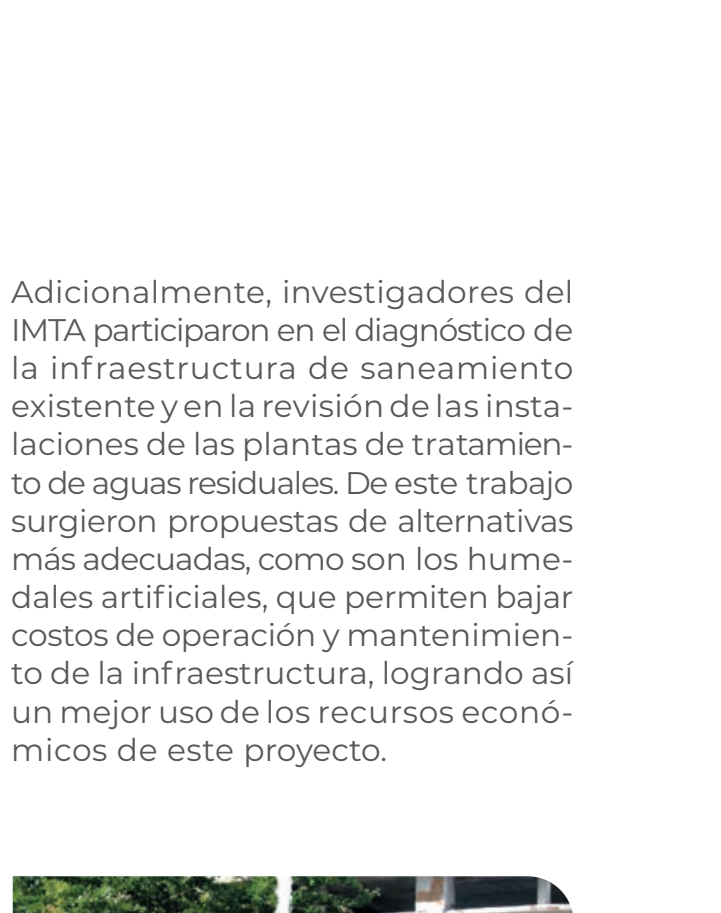

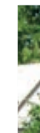

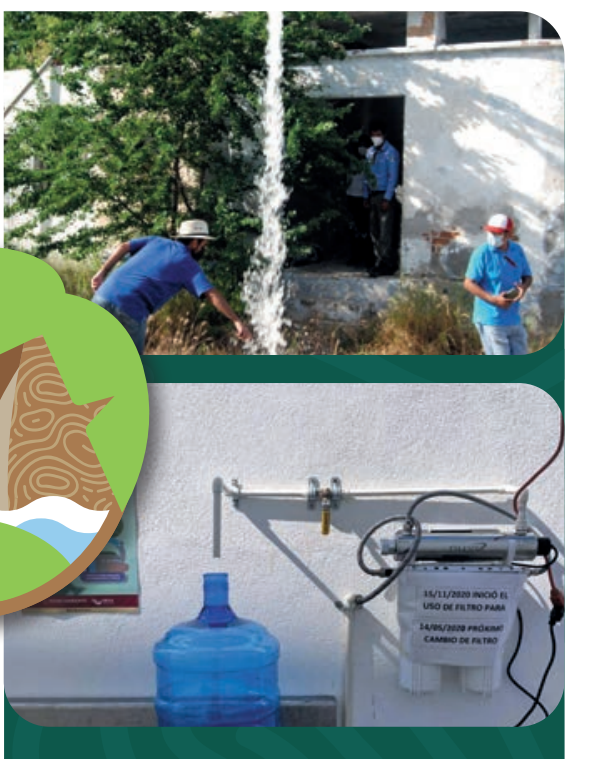

SU OBJETIVO ES FORMAR

"GUARDIANES DEL TERRITORIO"

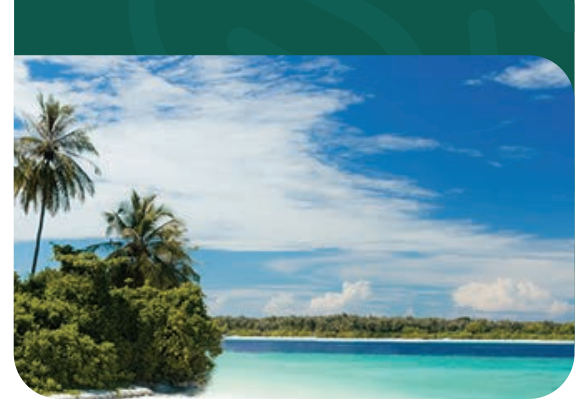




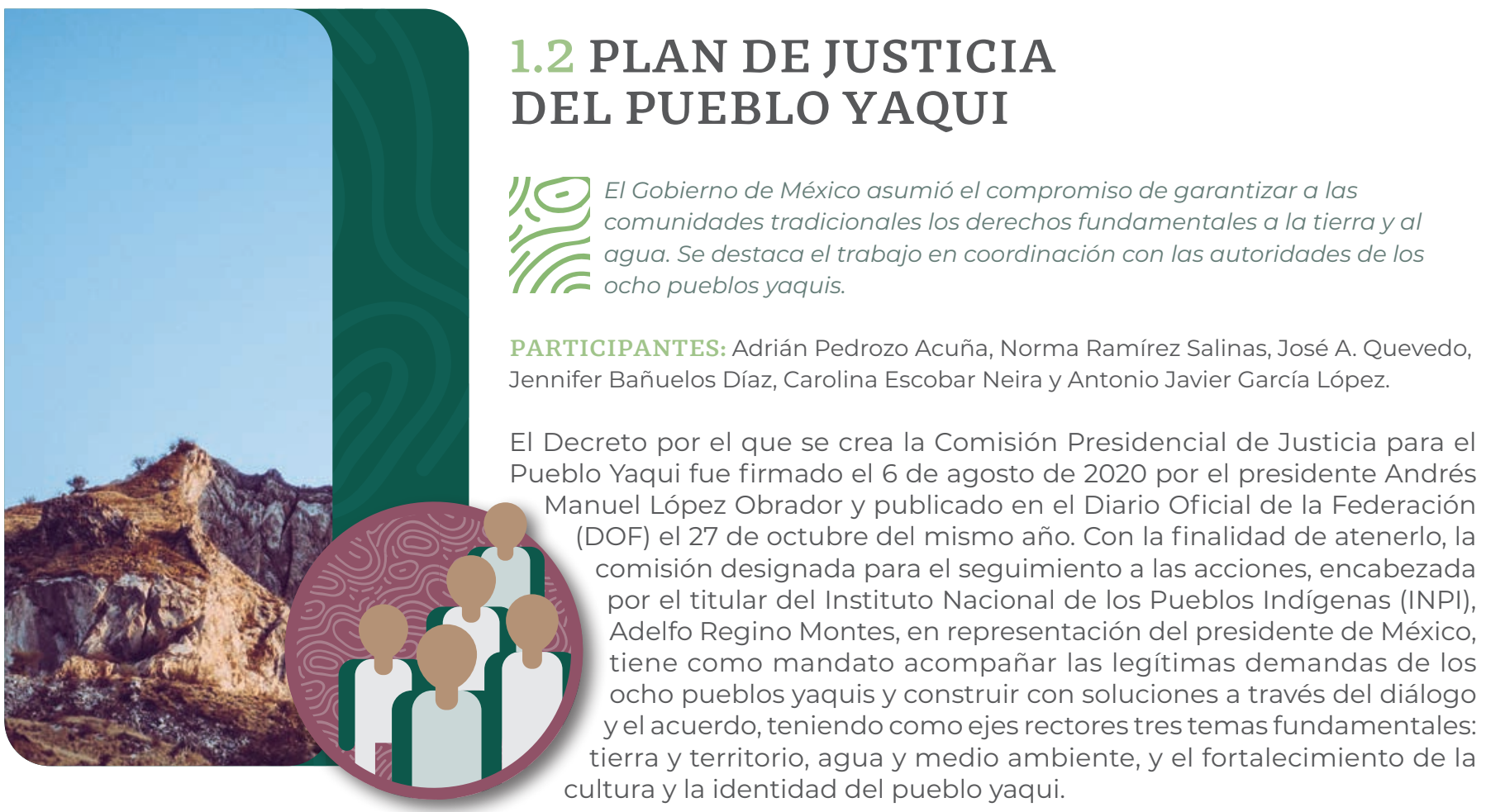

Entre los acuerdos destacan: construir el Acueducto Yaqui para proveer de agua potable suficiente y de calidad a las ocho comunidades tradicionales; atender las afectaciones medioambientales del río Yaqui mediante un caudal ecológico; llevar a cabo la transferencia del Distrito de Riego 018 al pueblo yaqui para que sea este el titular y administrador, y realizar los estudios y análisis de calidad del agua.

En conjunto con la Conagua y el INPI, el IMTA participó en reuniones de seguimiento para atenderlos acuerdos planteados en materia de agua y medio ambiente. Igualmente, para cumplir la instrucción de la secretaria de Medio Ambiente y Recursos Naturales, María Luisa Albores González, respecto a realizar el estudio de calidad del agua de las fuentes de abastecimiento y determinar las acciones necesarias para solucionar la problemática identificada, el IMTA, de forma coordinada con la Semarnat y las autoridades tradicionales, realizó un monitoreo en nueve pozos. Los parámetros medidos fueron los establecidos en la norma NOM-127-SSA1, modificación 2000, que establece los límites permisibles de calidad y tratamientos a los que debe someterse un agua para su potabilización. Con los resultados obtenidos se definieron los procesos de tratamiento requeridos para que el agua cumpla con dicha norma en cada una de las fuentes monitoreadas.

En ese sentido, el 8 de diciembre de 2020, el IMTA presentó a las autoridades de los pueblos yaquis el resultado del estudio de calidad del agua realizado, así como la propuesta de los tratamientos a considerar para la potabilización por fuente de abastecimiento que garantice la calidad del agua establecida en la norma.

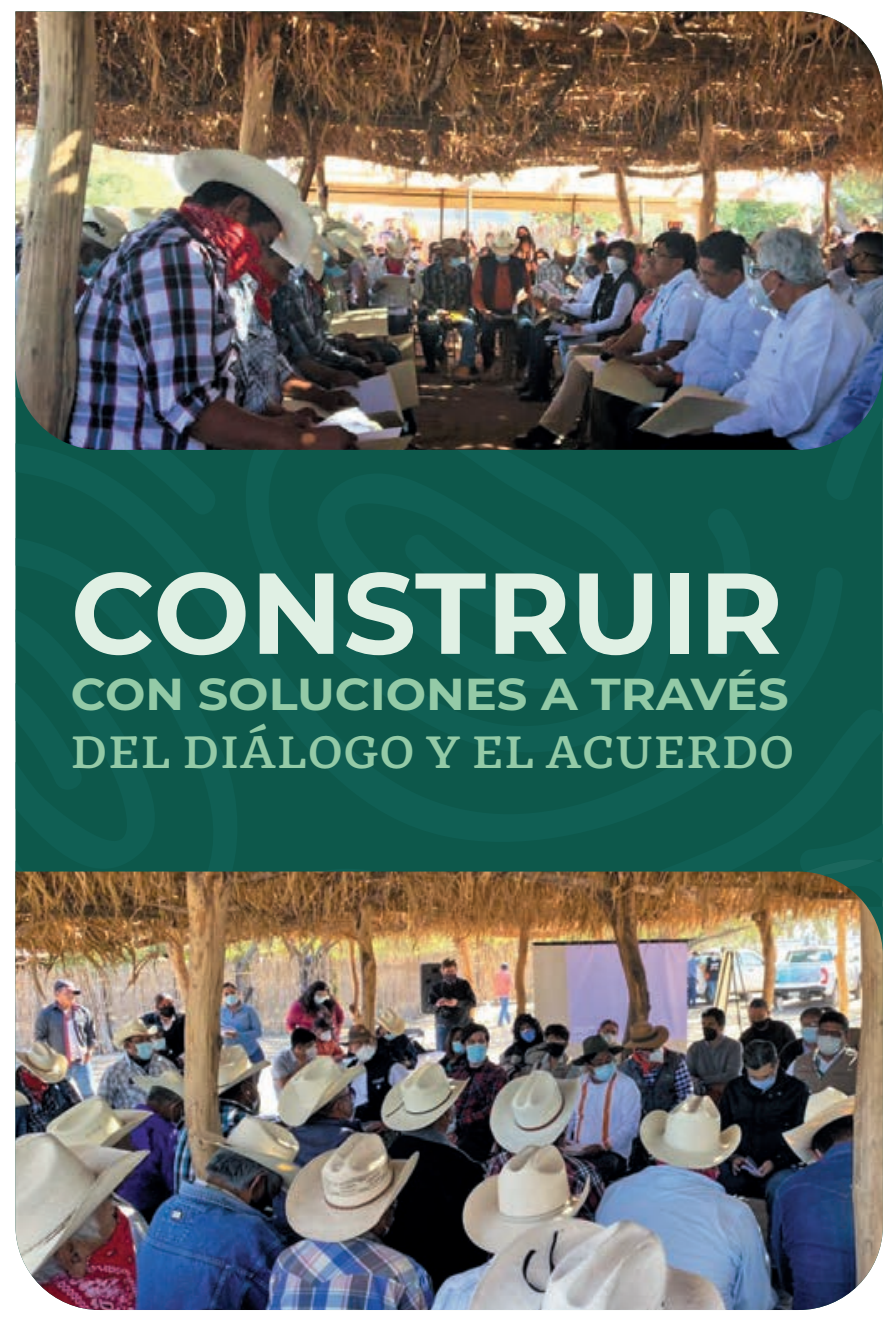




\subsection{SERVIDORES DE LA NACIÓN, CAMPECHE}

El rescate del campo, la reactivación de la economía local y la regeneración del tejido social en las comunidades son acciones puntuales que requieren de un mejor manejo del agua para impulsar un desarrollo sustentable y equitativo.

PARTICIPANTES: José Agustín Breña Naranjo, José Antonio Quevedo Tiznado, Ulises Dehesa Carrasco y Raúl Medina Mendoza.

En el marco del Programa Sembrando Vida, que trabaja para convertir los ejidos y comunidades en un sector estratégico para el desarrollo del campo mexicano, el IMTA brindó asesoría técnica a la Secretaría de Bienestar para incrementar la productividad de zonas rurales, bajo un enfoque de sustentabilidad y desarrollo regional a corto, mediano y largo plazos, y contribuir así a reducir la vulnerabilidad en la que viven los campesinos de estas regiones.

Entre otras acciones para este programa, el IMTA ha propuesto la implementación de opciones tecnológicas para la recolección de agua de lluvia y su máximo aprovechamiento en las unidades de producción, conformadas por sistemas agroforestales (SAF) como componente de repoblación forestal y milpa intercalada con árboles frutales (MIAF), con la cual se busca lograr la seguridad alimentaria de estos productores y sus familias.
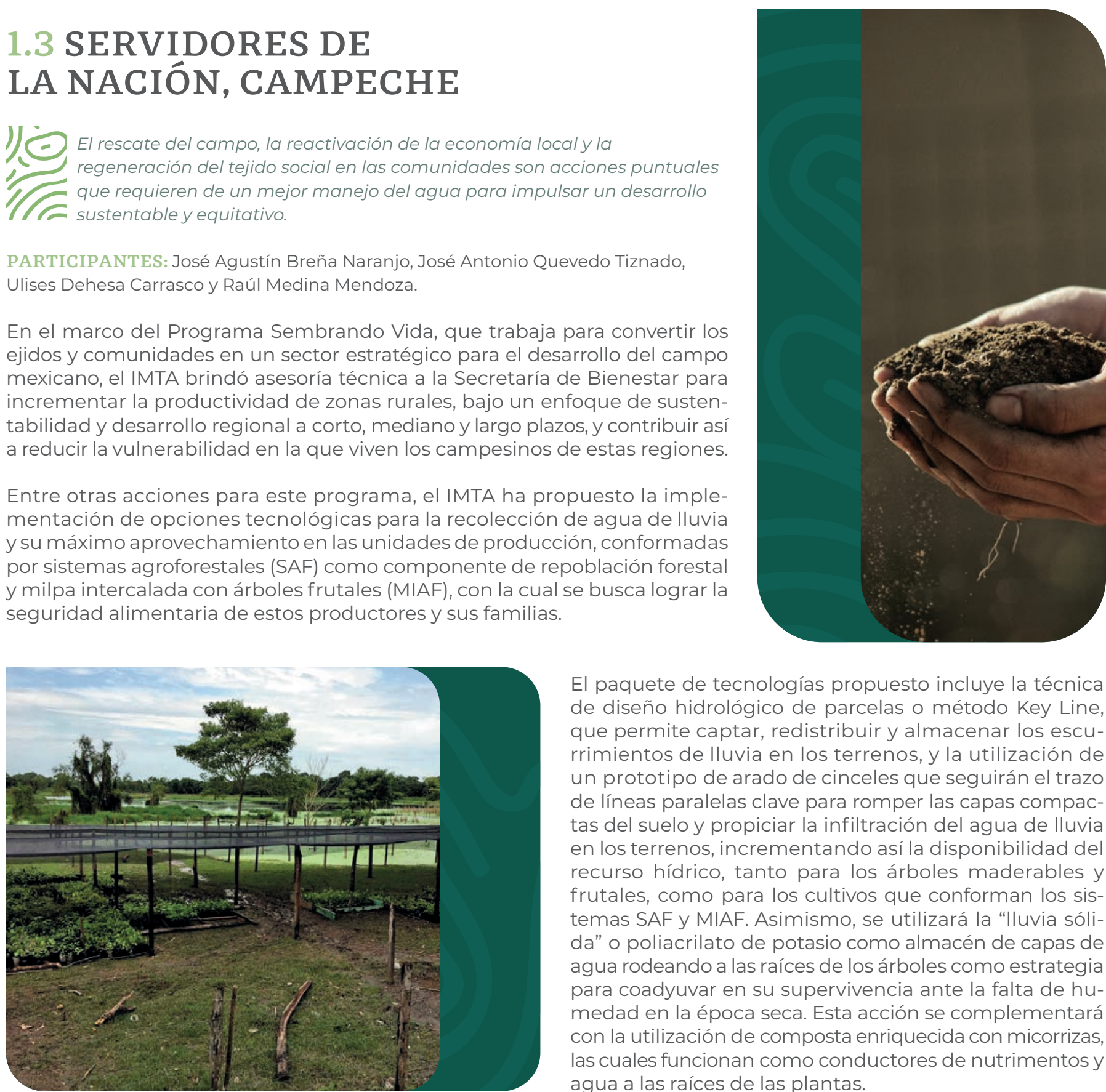

El paquete de tecnologías propuesto incluye la técnica de diseño hidrológico de parcelas o método Key Line, que permite captar, redistribuir y almacenar los escurrimientos de lluvia en los terrenos, y la utilización de un prototipo de arado de cinceles que seguirán el trazo de líneas paralelas clave para romper las capas compactas del suelo y propiciar la infiltración del agua de Iluvia en los terrenos, incrementando así la disponibilidad del recurso hídrico, tanto para los árboles maderables y frutales, como para los cultivos que conforman los sistemas SAF y MIAF. Asimismo, se utilizará la "Iluvia sólida" o poliacrilato de potasio como almacén de capas de agua rodeando a las raíces de los árboles como estrategia para coadyuvar en su supervivencia ante la falta de humedad en la época seca. Esta acción se complementará con la utilización de composta enriquecida con micorrizas, las cuales funcionan como conductores de nutrimentos y agua a las raíces de las plantas.

De igual forma, se propone la captación de agua de lluvia en los techos de las viviendas y su almacenamiento en cisternas de ferrocemento para utilizarla como riego auxiliar de un huerto familiar de traspatio, en donde se produzcan hortalizas que enriquezcan la dieta de los campesinos y sus familias, como una acción concreta hacia la seguridad alimentaria nutricional. Debido a la mala calidad del agua en la región, también se propone la utilización de un prototipo de desalinizadora solar para abastecimiento comunitario de agua potable.

El conjunto de acciones y tecnologías propuestas plantea las bases para iniciar un programa integral de desarrollo hídrico local dirigido principalmente a los pequeños productores de estas zonas de alta y muy alta marginación, quienes practican la agricultura de subsistencia, son altamente dependientes de la lluvia y están menos preparados para enfrentar la variabilidad climática y los periodos de sequía extrema.

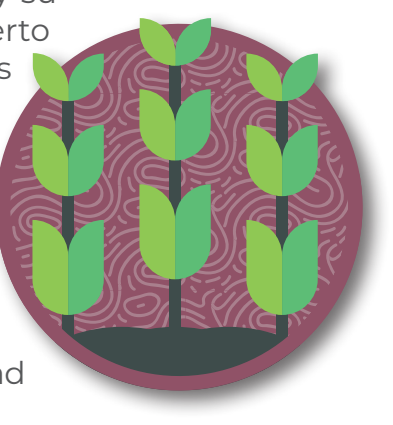




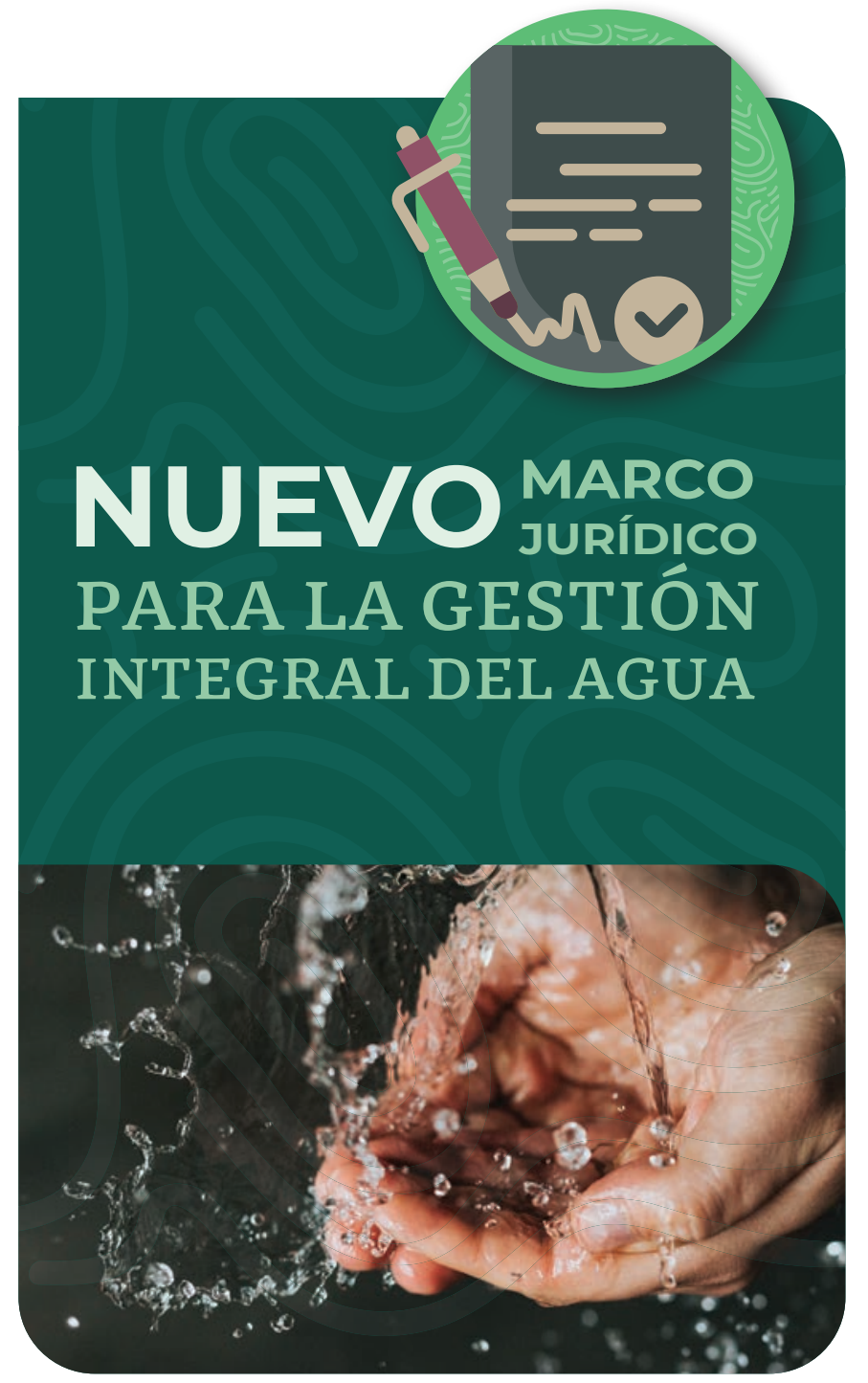

\subsection{LEY GENERAL DE AGUAS}

- La participación en la construcción de un nuevo - marco jurídico para la gestión integral del agua en México mediante el apoyo técnico y jurídico en los C distintos procesos de iniciativas de ley ha sido una 1.Clabor permanente en el IMTA.

PARTICIPANTES: Alberto Rojas Rueda, Juana Amalia Salgado López, Agustín Breña Naranjo, Norma Ramírez Salinas, José Antonio Quevedo Tiznado, Julio Soriano Monzalvo, Carolina Escobar Neira y Roberto Galván Benítez.

El IMTA ha continuado trabajando en el acompañamiento del proceso de construcción de la Ley General de Aguas mediante el análisis y asesoramiento técnico científico a las iniciativas de ley presentadas.

Entre las principales acciones desarrolladas se encuentran las siguientes:

- Acompañamiento técnico a las distintas iniciativas de la Ley General de Aguas, particularmente a la iniciativa ciudadana.

- Participación en la discusión del proceso de dictaminación de la Ley General de Aguas, a petición de las comisiones dictaminadoras de la Cámara de Diputados.

- Análisis del esquema institucional de las iniciativas presentadas de la Ley General de Aguas

- Elaboración de opiniones técnicas.

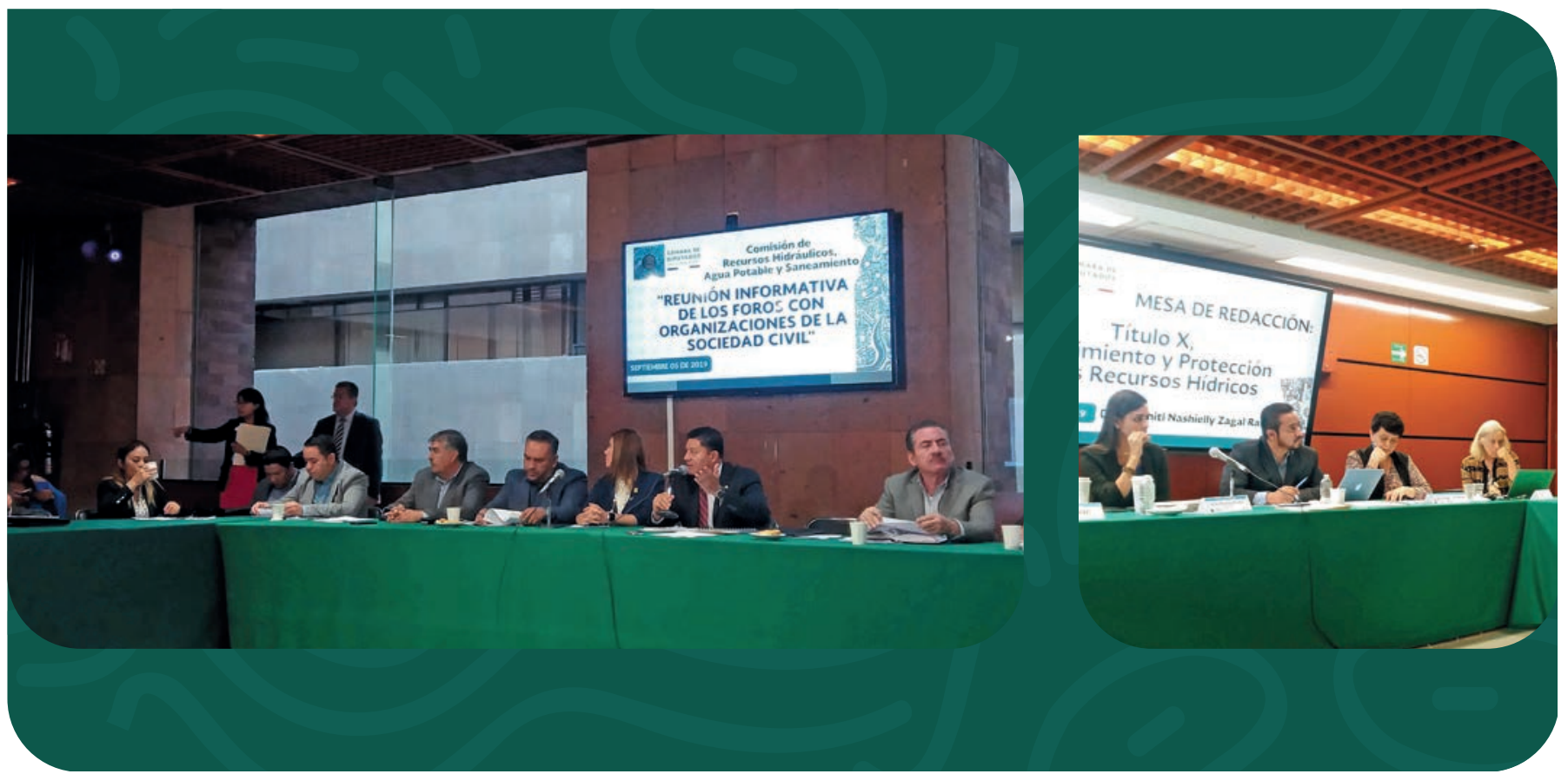




\subsection{INDICADORES DE DERECHOS HUMANOS AL AGUA Y AL SANEAMIENTO}

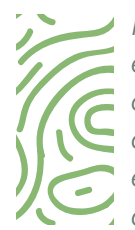

Medir el cumplimiento de los derechos humanos al agua y al saneamiento es una prioridad mundial. Por esta razón, trabajamos con la Oficina del Alto Comisionado de la ONU para los Derechos Humanos y otras dependencias del Gobierno Federal, para generar indicadores con base en evidencia que sirvan para verificar su cumplimiento y definir prioridades de política pública.

PARTICIPANTES: Carolina Escobar Neira, Alejandra Peña García y Alberto Rojas Rueda.

El IMTA impulsa el proyecto para generar los indicadores de derechos humanos al agua y al saneamiento para dar cumplimiento a las obligaciones del Estado como signatario de tratados internacionales. Se trabaja en el reporte de avances de derechos, en visibilizar la situación de cumplimiento de estos derechos en el país, contar con datos para la formulación de metas y para la toma de decisiones, identificar áreas de oportunidad, determinar prioridades en la atención e impulsar la transparencia y rendición de cuentas en materia de derechos humanos.

Asimismo, el Instituto pretende aportar para el Acuerdo de Escazú (acuerdo regional sobre acceso a información, participación pública y acceso a la justicia en asuntos ambientales en América Latina y el Caribe) y fortalecer capacidades mediante la transferencia de metodologías para el diseño de indicadores y de la experiencia nacional en su implementación.

Con este propósito, el IMTA lidera un grupo base conformado por la Secretaría de Gobernación, la Secretaría de Relaciones Exteriores, la Comisión Nacional del Agua, el Instituto Nacional de Estadística y Geografía, el Instituto Nacional de Ecología y Cambio Climático, el Programa Universitario de Derechos Humanos de la Universidad Nacional Autónoma de México (PUDH UNAM), el Espacio de Coordinación de Organizaciones Civiles sobre Derechos Económicos, Sociales y Culturales (Espacio DESCA), la Coalición de Organizaciones Mexicanas por el Derecho al Agua (COMDA), el Colegio de Geografía de la UNAM, Waterlex - HumanRight2Water y OXFAM - México.

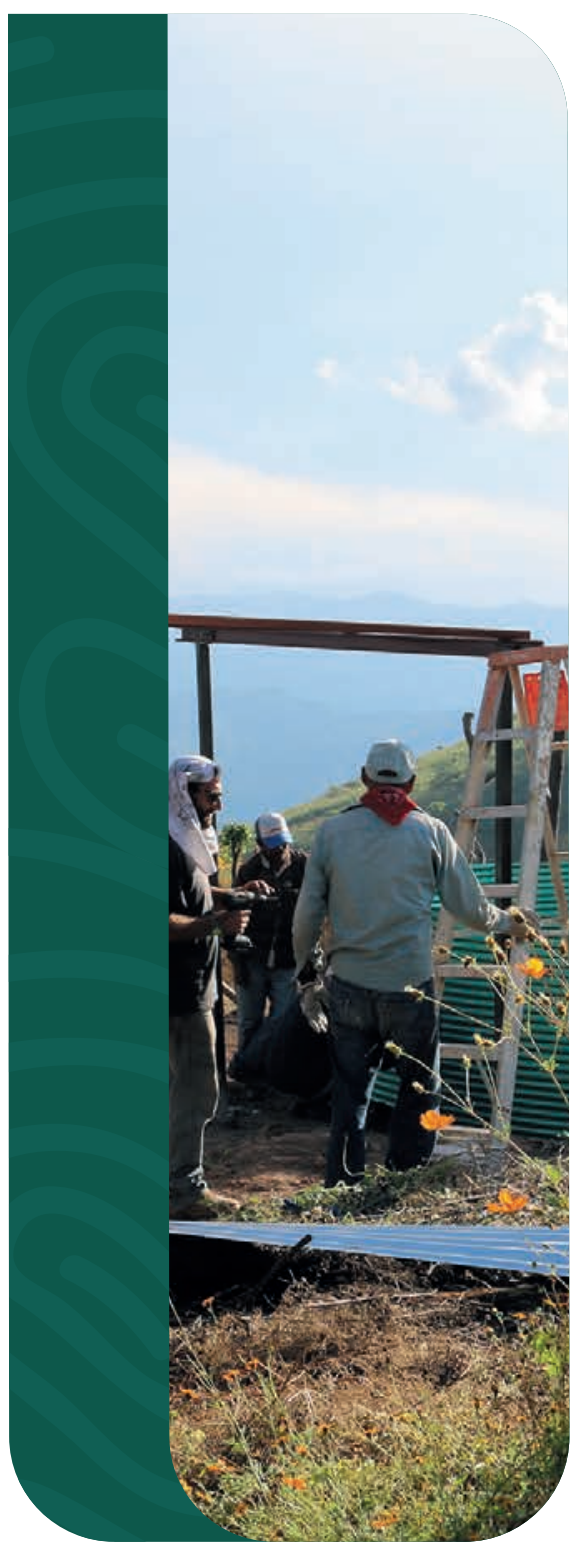

El proyecto tiene gran potencial, ya que contribuirá a dar cumplimiento a las obligaciones contraídas en el marco del Acuerdo de Escazú y otros tratados internacionales ratificados por México. Además, promueve la coopera-

ción sur-sur y sur-norte, fortaleciendo las capacidades regionales, por ser un proyecto paradigmático en la región, ya que ningún país en América Latina cuenta con indicadores de esta naturaleza.

Este proyecto responde a una de las recomendaciones del relator especial de los derechos humanos al agua y al saneamiento, quien ha puesto énfasis en ciertos componentes de acceso a la información, necesarios para el cumplimiento de las obligaciones internacionales como Estado. Los indicadores también permitirán contribuir al informe de los avances en el cumplimiento del ODS6, en el marco de la Agenda 2030 de las Naciones Unidas. 


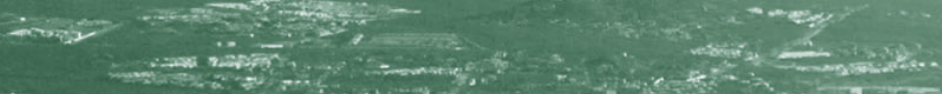

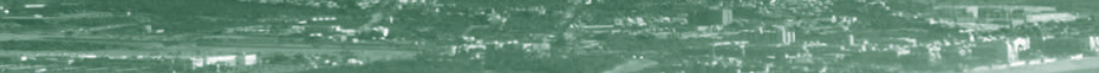

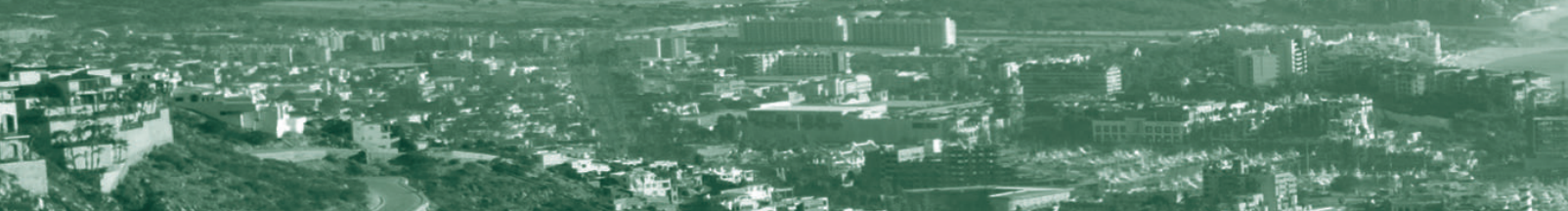

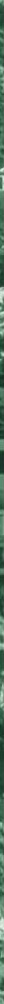
250. 24:

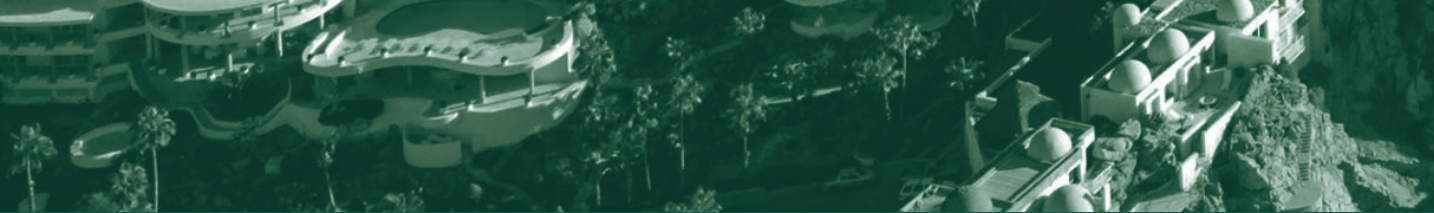

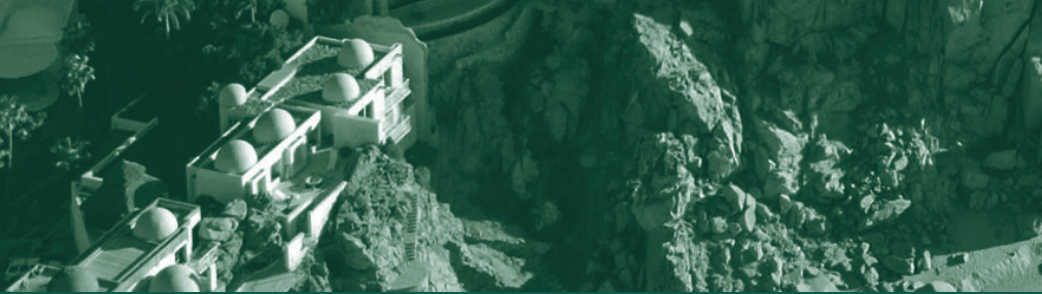




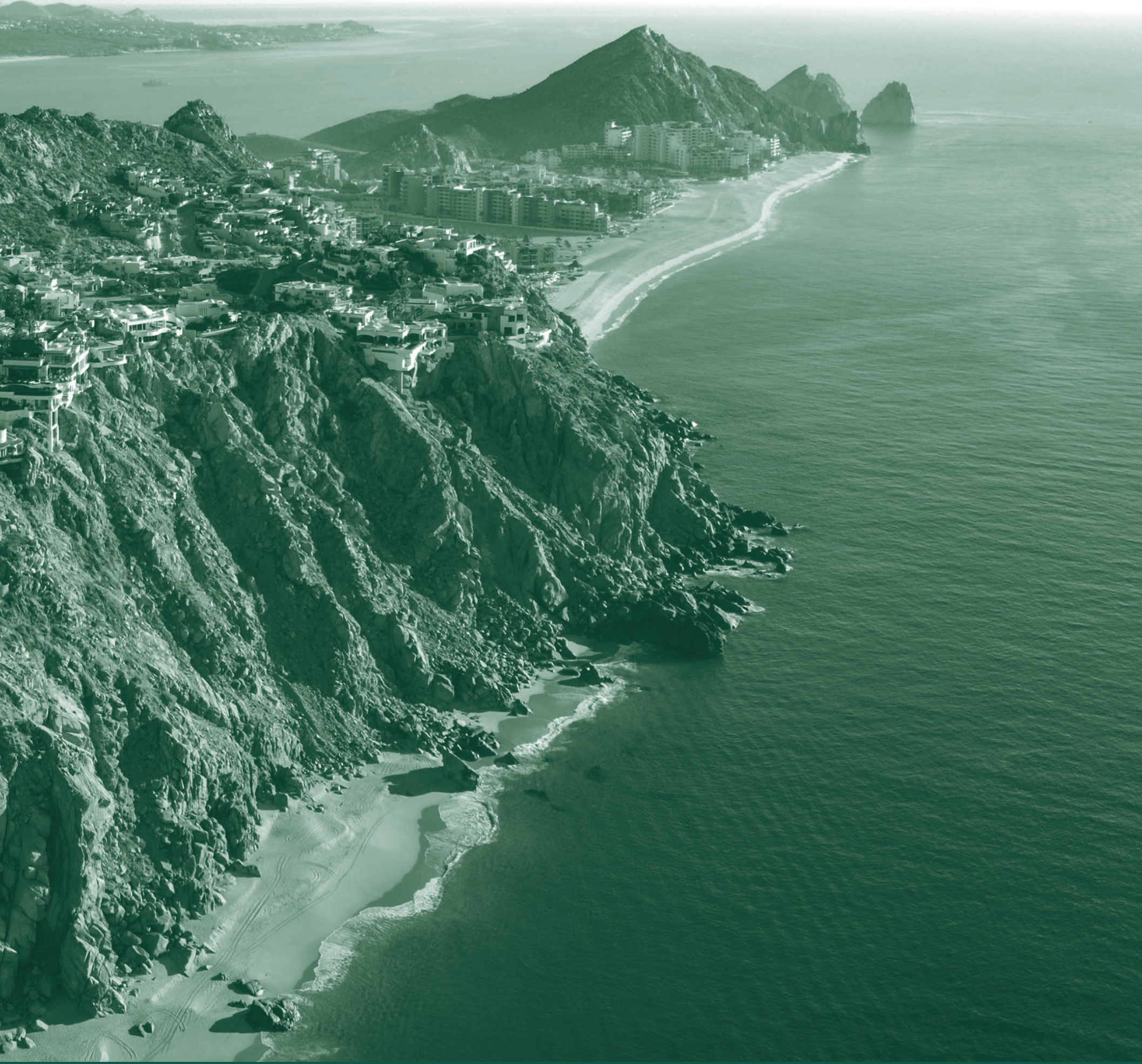




\section{AGUA Y SOCIEDAD}

BIENESTAR SOCIAL: UNA PRIORIDAD PARA EL GOBIERNO DE MÉXICO

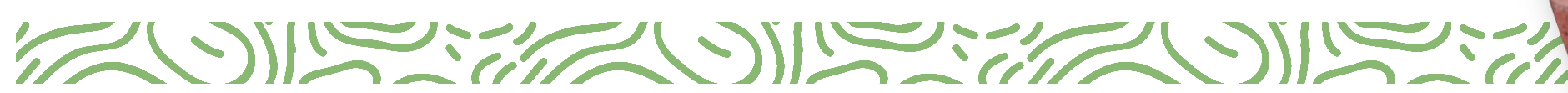

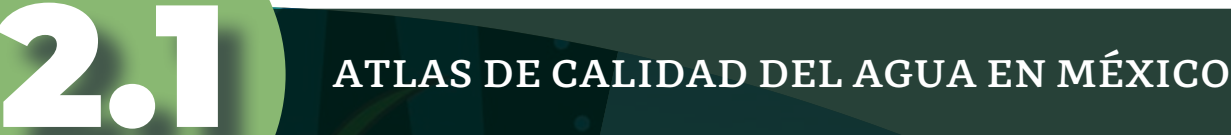

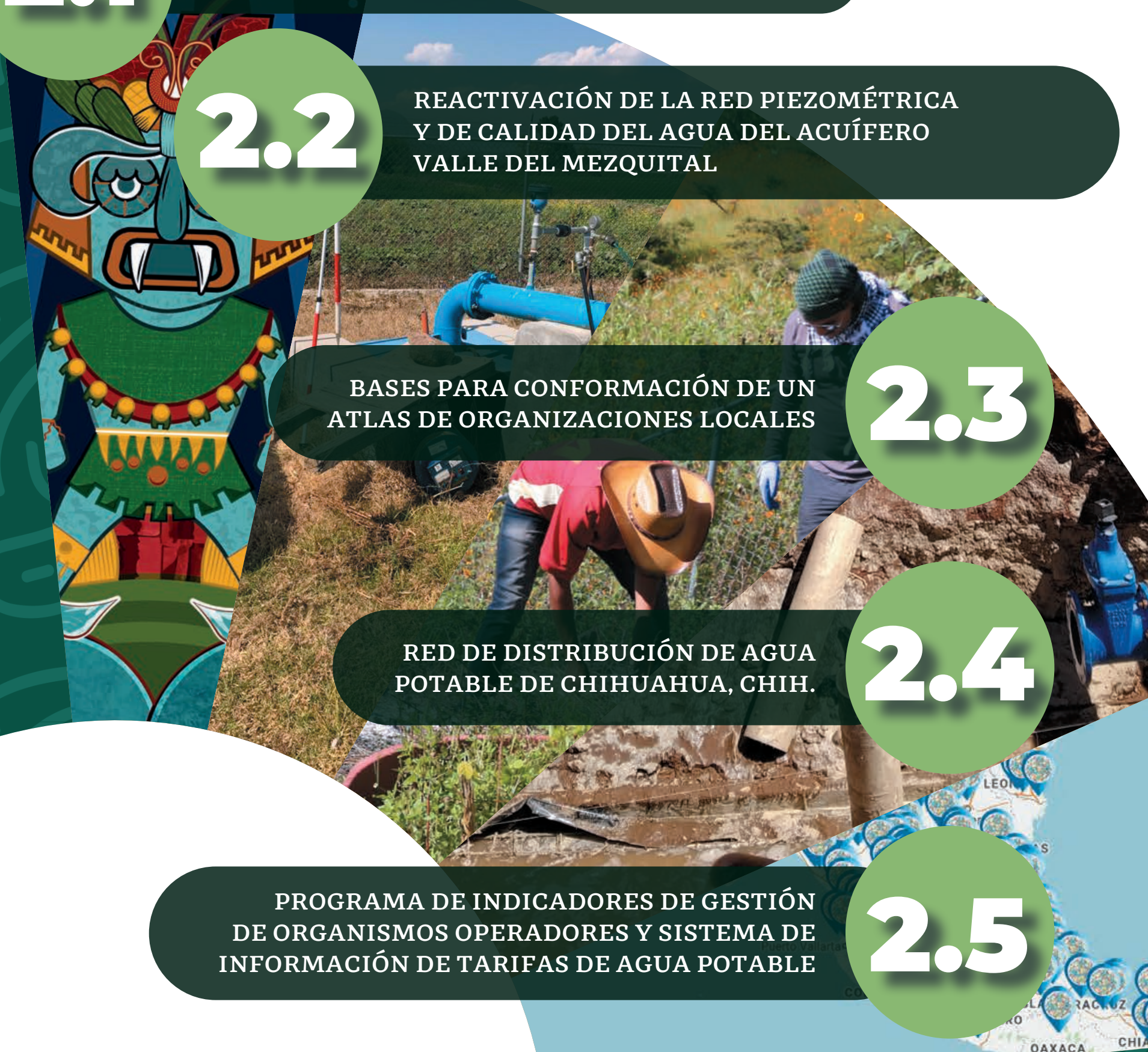




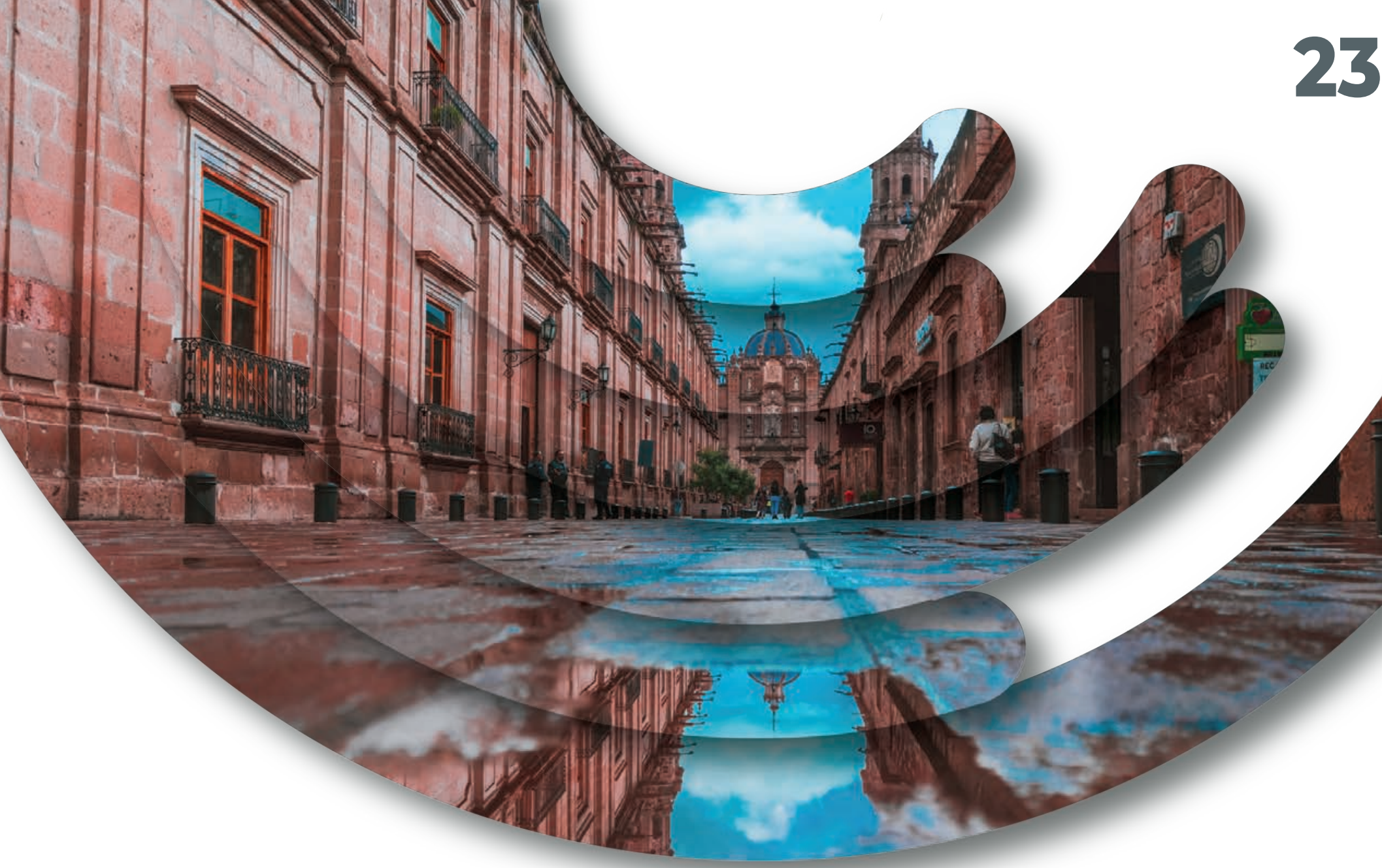

LAS DECISIONES RELACIONADAS CON LOS RECURSOS HÍDRICOS

implican procesos mediante los cuales se provee de agua se-

gura para la salud, el bienestar y la productividad econó-

mica de las sociedades. En el IMTA estamos seguros de

que es posible avanzar, de la mano del uso susten-

table del agua, hacia un México sin desigualdad,

con desarrollo económico y con calidad am-

biental. Para ello es necesario aplicar la evidencia científica moderna, el pensamiento crítico, la ética y la transparencia de la información; herramientas que nos permitirán construir soluciones junto con la sociedad.

El agua es parte de nuestro territorio e identidad local. A través de ella se vinculan los valores culturales, éticos y morales de las comunidades del país y del planeta entero. El IMTA trabaja conjuntamente con la Secretaría de Medio Ambiente y Recursos Naturales en la ciudadanización de la política ambiental, haciendo del conocimiento del agua un pilar fundamental para el desarrollo humano, sustentable y equitativo.

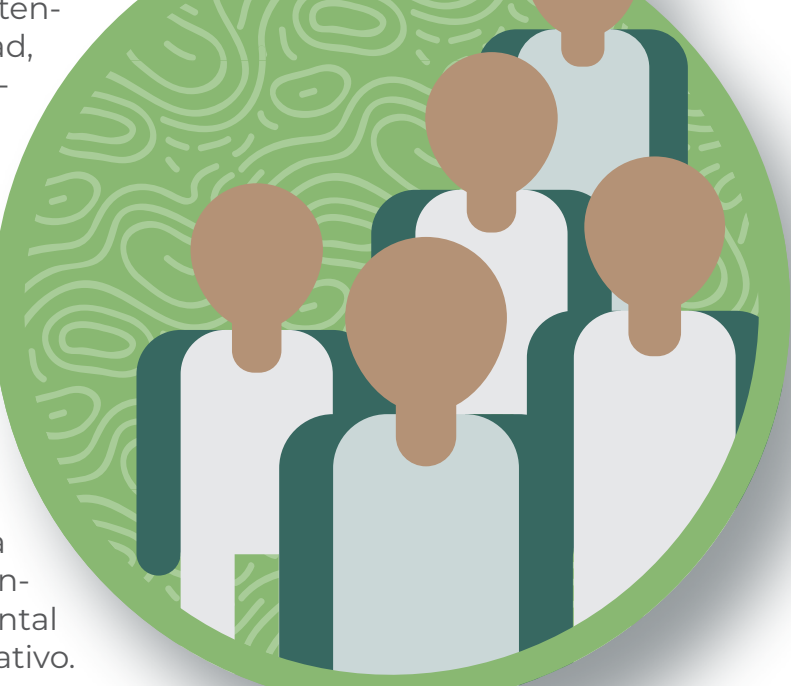




\section{) AGUA Y Y SOCIEDAD}

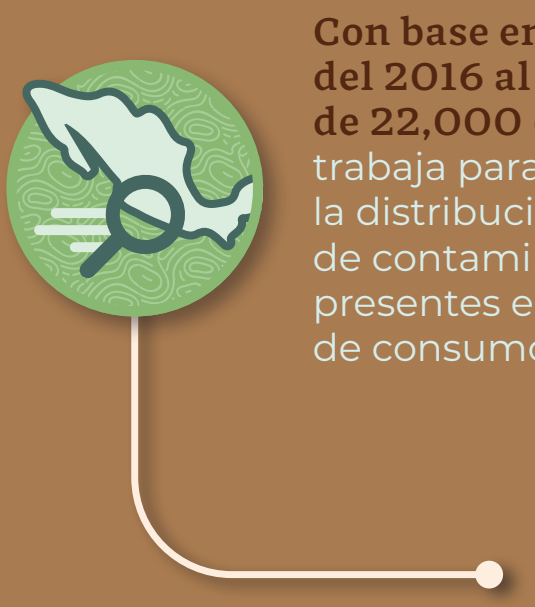

Con base en información 2016 al 2020 y más 22,000 datos, el IMTA trabaja para dar a conocer la distribución geográfica de contaminantes presentes en el agua de consumo humano.

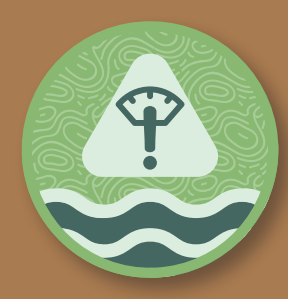

Reactivamos la red piezométrica y de calidad del agua del acuífero Valle del Mezquital. Esto permitirá conocer el estado real de este almacenamiento subterráneo en espacio y tiempo.

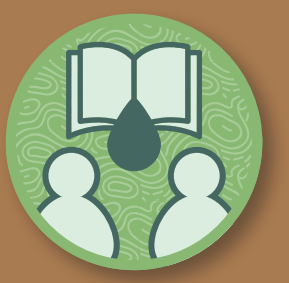

Se elaboró una metodología para tipificar diversas organizaciones locales en torno al agua en México con el fin de identificar áreas de oportunidad para su fortalecimiento.

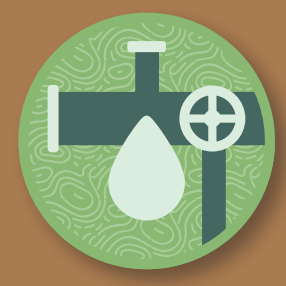

Contribuimos al

establecimiento de un modelo general para el manejo y transvase de las principales conducciones de la zona noroeste de la red de Chihuahua, Chih.

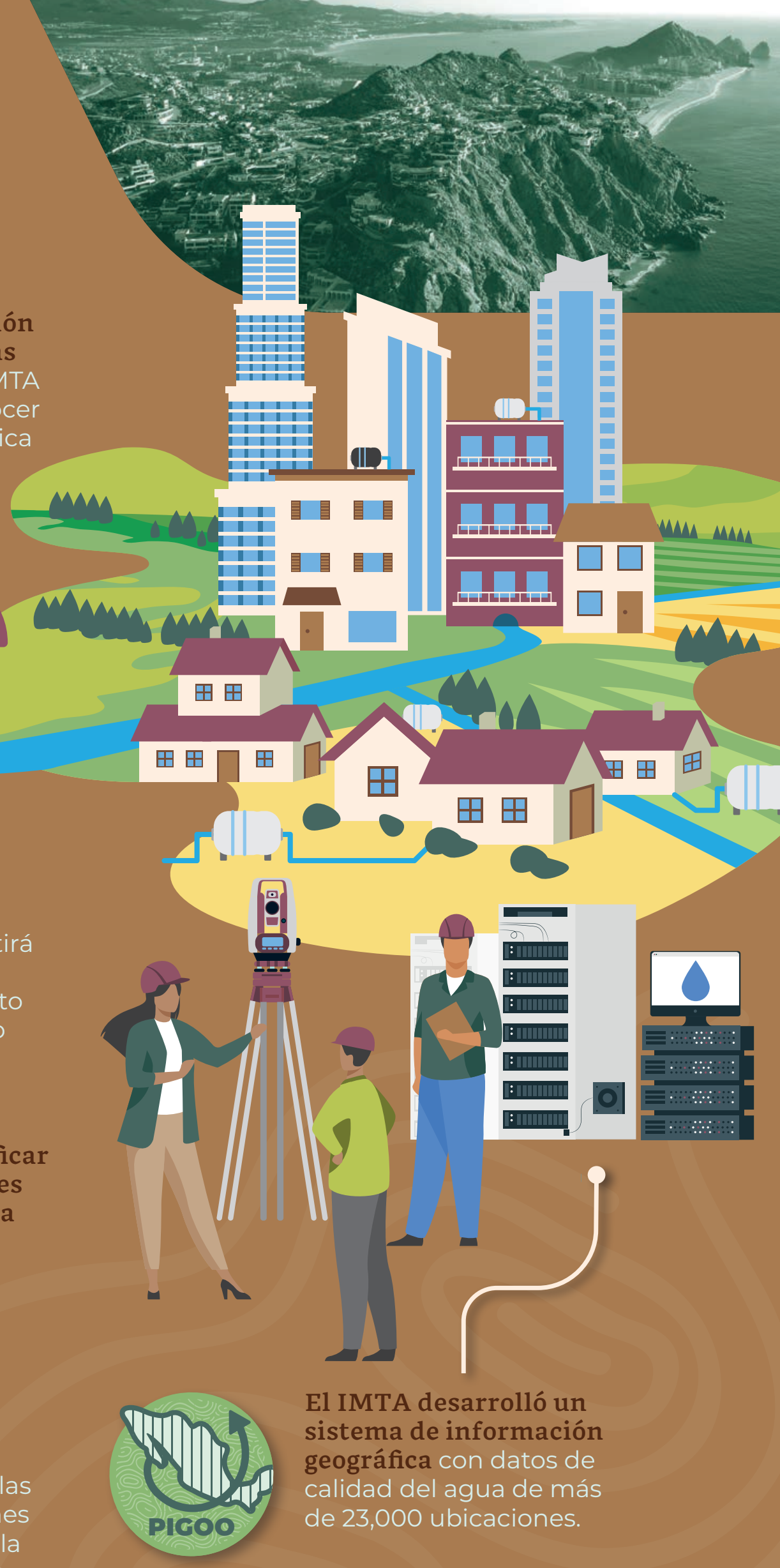




\subsection{ATLAS DE CALIDAD DEL AGUA EN MÉXICO}

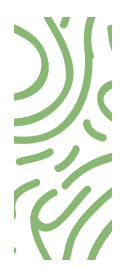

Con base en información del 2016 al 2020 y más de 22,000 datos, el IMTA trabaja para dar a conocer la

distribución geográfica de contaminantes presentes en el agua de consumo humano mediante el Atlas de Calidad del Agua en México, el cual permitirá identificar problemáticas regionales y definir acciones para incidir positivamente en este rubro.

PARTICIPANTES: Julia E. Prince Flores, Martha Avilés Flores, Jennifer Alexis Bañuelos Díaz, Juana Enriqueta Cortés Muñoz, Axel Falcón Rojas, Fernando Flores Prior, Indira Franco Salazar Humberto García Facundo, Antonio Javier García López, Juan Leodegario García Rojas, Leticia Montellano Palacios, Sara Pérez Castrejón, Ma. de Lourdes Rivera Huerta, Marco Antonio Sánchez Izquierdo, Minerva Sánchez Guzmán,

Manuel Sánchez Zarza, Carlos David Silva Luna e Iván Emmanuel Villegas Mendoza.

El Atlas de Calidad del Agua en México contribuye a la protección de la salud pública y al uso sustentable de las fuentes de abastecimiento de agua para consumo humano mediante el conocimiento de la distribución geográfica de contaminantes bacteriológicos (coliformes totales y coliformes fecales o E. coli) y de químicos regulados, tales como arsénico, plomo, hierro, manganeso, ion fluoruro, nitrógeno de nitratos, ion sulfato, así como de la dureza total, los sólidos disueltos totales, la turbiedad y el color, además de los riesgos sanitarios asociados que pudieran presentarse en la población potencialmente expuesta, a fin de identificar áreas de intervención prioritarias.

El IMTA desarrolló un sistema de información geográfica que contiene los datos de calidad del agua de redes de abastecimiento en todo el territorio nacional, con más de 23,000 ubicaciones que abarcan tanto zonas rurales como urbanas. Se realizaron estimaciones de la población circundante a los sitios de muestreo para estimar la cantidad de personas potencialmente afectadas por uno o más parámetros de calidad del agua que rebasen el límite máximo permisible establecido en la modificación del año 2000 a la norma NOM-127-SSA1-1994, que regula el agua para uso y consumo humanos.

Adicionalmente, se cuenta con una base de datos de calidad del agua por entidad federativa, que incluye datos de las localidades y sus principales características sociodemográficas. A partir de esta base de datos, se trabajó en elaborar propuestas de diferentes estrategias de potabilización, por contaminantes o grupos de contaminantes y por caudales de agua producida (sistemas intradomiciliario, intermedio y centralizado).

Alternativamente, se analizó la factibilidad de instalar sistemas de captación de agua de lluvia como una propuesta de tecnología apropiada para apoyar a las comunidades y familias a resolver la problemática de calidad del agua que pudiera presentarse en su región.

Finalmente, se realizó una evaluación del riesgo a la salud humana, considerando la ingesta de agua con las características encontradas en las distintas entidades federativas del país, para evaluar tanto el riesgo carcinogénico como el riesgo sistémico.

Este proyecto es una herramienta para facilitar la toma de decisiones y la implementación de tecnologías de potabilización del agua para consumo humano, a niveles intradomiciliario, intermedio, o centralizado, con el objetivo de solucionar problemas de calidad del agua de la red de abastecimiento en el país y contribuir de esta manera a mejorar la salud de la población.
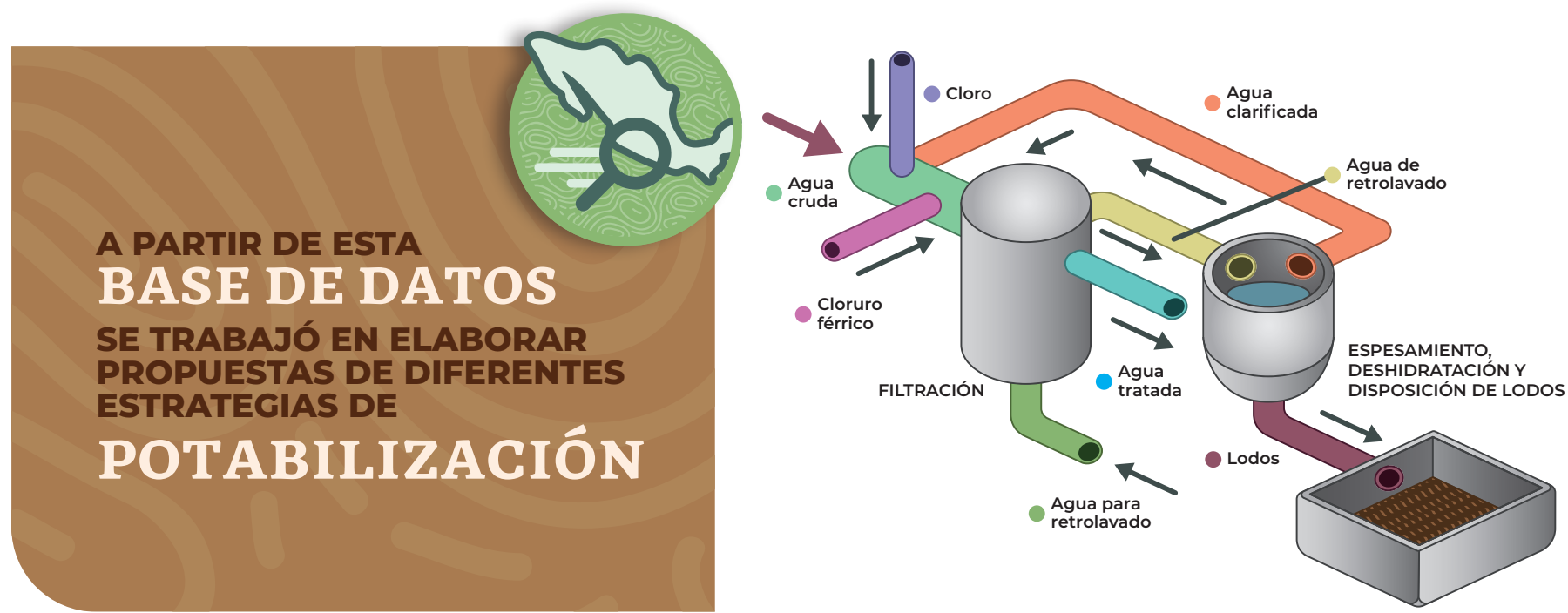


\subsection{REACTIVACIÓN DE LA RED PIEZOMÉTRICA Y DE CALIDAD DEL AGUA DEL ACUÍFERO VALLE DEL MEZQUITAL}

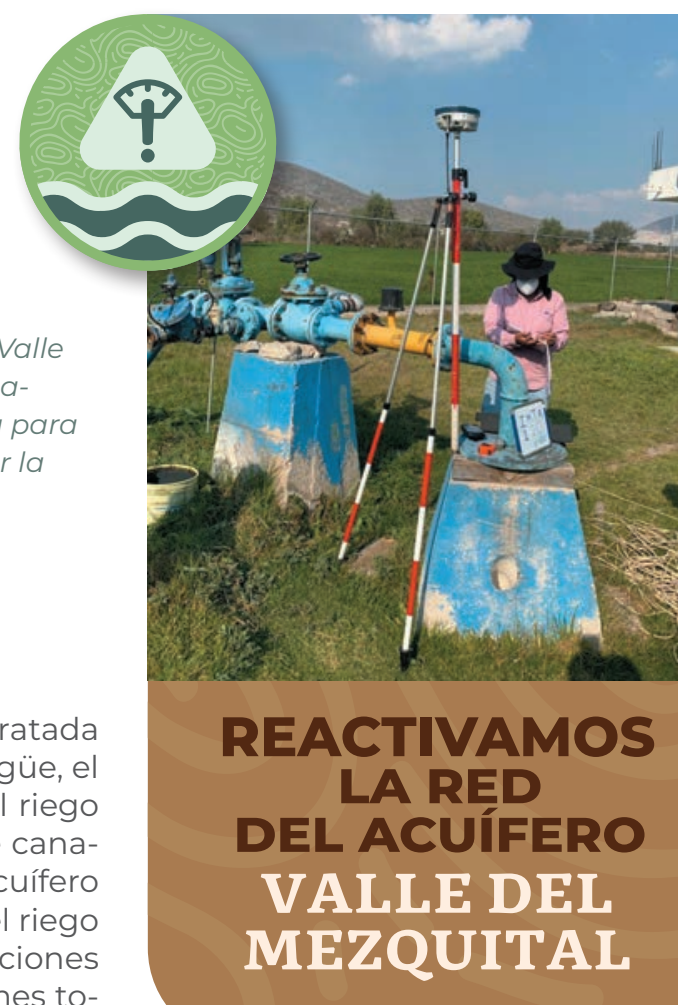

PARTiCiPAnTES: Manuel Martínez Morales, Miguel Ángel Mejía González, Vladimir Contreras González, Luis González Hita, Carlos Gutiérrez Ojeda y José Agustín Breña Naranjo.

El valle del Mezquital recibe alrededor de $50 \mathrm{~m}^{3} / \mathrm{s}$ de agua residual no tratada proveniente de la Ciudad de México a través del Gran Canal del Desagüe, el Interceptor Poniente y el Emisor Central. Esta agua se utiliza para el riego de 45,214 ha, y una gran parte se infiltra al acuífero, ya que la red de canales no se encuentra revestida. Los estudios de calidad del agua del acuífero realizados por la Conagua corroboran la contaminación de este por el riego con aguas residuales sin tratamiento, lo que se refleja en concentraciones de sodio, sólidos totales disueltos, arsénico, fluoruros, plomo, coliformes totales y coliformes fecales, entre otros parámetros, por encima de los límites máximos permisibles en zonas del acuífero.

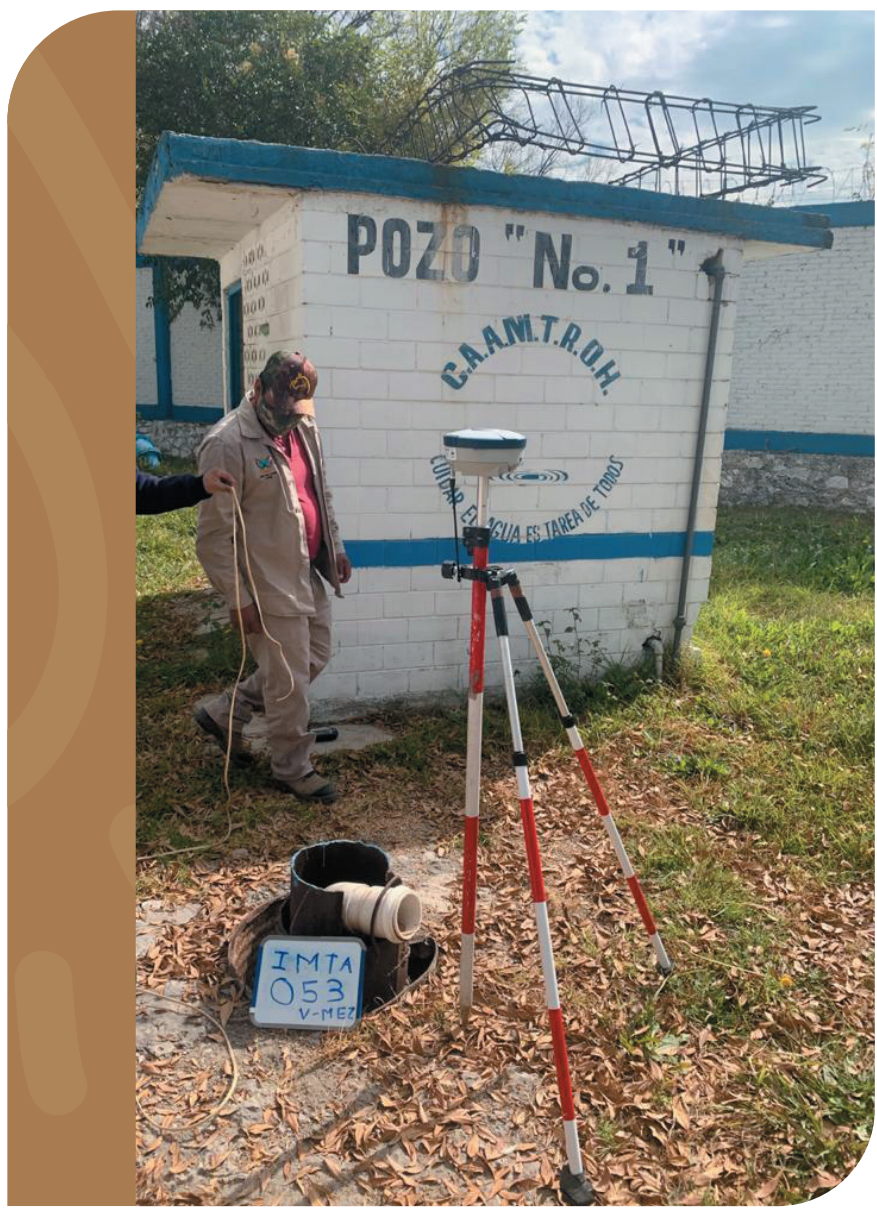

La red cubre en forma parcial las inmediaciones de la presa Endhó, y los últimos monitoreos piezométricos del acuífero fueron realizados por la Conagua en los años 2007 y 2012-2013. Por otro lado, existen pozos ubicados fuera de la zona de riego que también presentan concentraciones por arriba de la norma, lo cual puede deberse a un origen de contaminación diferente, y existen, asimismo, pozos de abastecimiento con agua de buena calidad ubicados dentro de la zona de riego.

En ese sentido, el IMTA se propuso reactivar la red de medición de niveles y calidad del agua subterránea que permita actualizar el comportamiento del acuífero en la zona de influencia de la presa en forma sistemática.

Trabajamos en analizar la información histórica de los datos de piezometría y calidad del agua, en reactivar la red de monitoreo piezométrico de la Conagua. y en monitorear la calidad del agua subterránea en sesenta aprovechamientos subterráneos en conjunto con las organizaciones sociales locales.

Para lograr el cometido se llevó a cabo la revisión de estudios previos de la zona de estudio y se identificaron los aprovechamientos del agua subterránea del valle del Mezquital. Durante los recorridos de campo se registraron las coordenadas, las características del equipamiento de los pozos y las mediciones del nivel estático de aquellos sitios donde fue posible el acceso de la sonda piezométrica. 
Una vez identificados los pozos que pudieron ser integrados a la red piezométrica se procedió a ejecutar un levantamiento topográfico del nivel del brocal de los pozos mediante el Sistema de Geoposicionamiento Global Satelital (GPS). Estos trabajos consistieron en colocar una base satelital y hacer un recorrido con otro equipo móvil para ir tomando los registros de cada aprovechamiento para su posterior procesamiento y así determinar la elevación con respecto al nivel del mar de cada punto visitado. La información generada permitirá establecer la profundidad y elevación del nivel del agua subterránea, así como la dirección del flujo.

Por otro lado, se llevó a cabo un análisis de los parámetros hidrogeoquímicos que se han medido en el espacio y tiempo en el acuífero para determinar los treinta sitios donde se tomarán muestras en las temporadas de Iluvia y estiaje. De esta manera se podrá proponer una evolución de la calidad del agua a través de la modelación hidrogeoquímica.

\subsection{BASES PARA CONFORMACIÓN DE UN ATLAS DE ORGANIZACIONES LOCALES}

\footnotetext{
'Lill Se elaboró una metodología para tipificar diversas organizaciones locales en torno al agua en México, reconociendo sus principales características y 1) 1 experiencias, con el fin de identificar áreas de oportunidad para su fortalecimiento.
}

PARTICIPANTES: Alejandra Peña García, Carolina Escobar Neira, Cipriana Hernández Arce, Ricardo López Mera y Joaquín Flores Ramírez.

El proyecto sobre la gestión local del agua permitió desarrollar una base documental amplia de la producción existente con relación a la temática de las organizaciones locales del agua en el territorio nacional y como referencia sobre la gestión comunitaria del agua en la región latinoamericana y del Caribe. Se identificaron las universidades, centros de investigación, organizaciones de la sociedad civil, grupos interdisciplinarios, investigadores y activistas que trabajan el tema de la gestión comunitaria del agua desde diferentes enfoques y motivaciones, pero con el objetivo común de fortalecerlas legal e institucionalmente, dado el papel que desempeñan al dar acceso al agua a millones de personas.

Asimismo, se creó una base de datos inicial que reúne a un conjunto amplio pero selecto de variables que permiten caracterizar la gestión comunitaria del agua en el país en los ámbitos rurales, urbanos y periurbanos. Se obtuvieron 28 variables a partir de la revisión puntual de los documentos recopilados y, para una primera etapa de la base de datos, se seleccionaron 13 casos, extrayendo información de 29 organizaciones. Estos estudios de caso pertenecen a las regiones centro, centro-norte, centro-sur y sureste. La información quedará abierta para actualizarla y seguir indagando respecto a sus posibilidades analíticas.

Se caracterizó la gestión local del agua, a partir de la experiencia documentada en diversos tipos de publicaciones, que tiene en cuenta casos de 12 entidades federativas del país y más de cincuenta localidades, en su mayoría rurales, pero también comprende zonas urbanas y periurbanas. Como resultados derivados del análisis de la información, se delinean ciertos patrones en las organizaciones, contempladas en cuanto a aspectos como su administración y funciones, pero también a diferencias significativas sobre la complejidad de sus sistemas de abastecimiento y problemáticas asociadas.

Finalmente, se creó una propuesta inicial de tipología de las organizaciones locales del agua en México a partir de una selección de estudios de caso en la que están representadas diversas regiones geográficas del país en los ámbitos rural, urbano y periurbano. Esta tipología propuesta distingue tres tipos de organizaciones y comprende variables pertenecientes a cinco categorías que se definieron a partir de la "Caracterización de las organizaciones locales de agua en México". La tipología se construyó

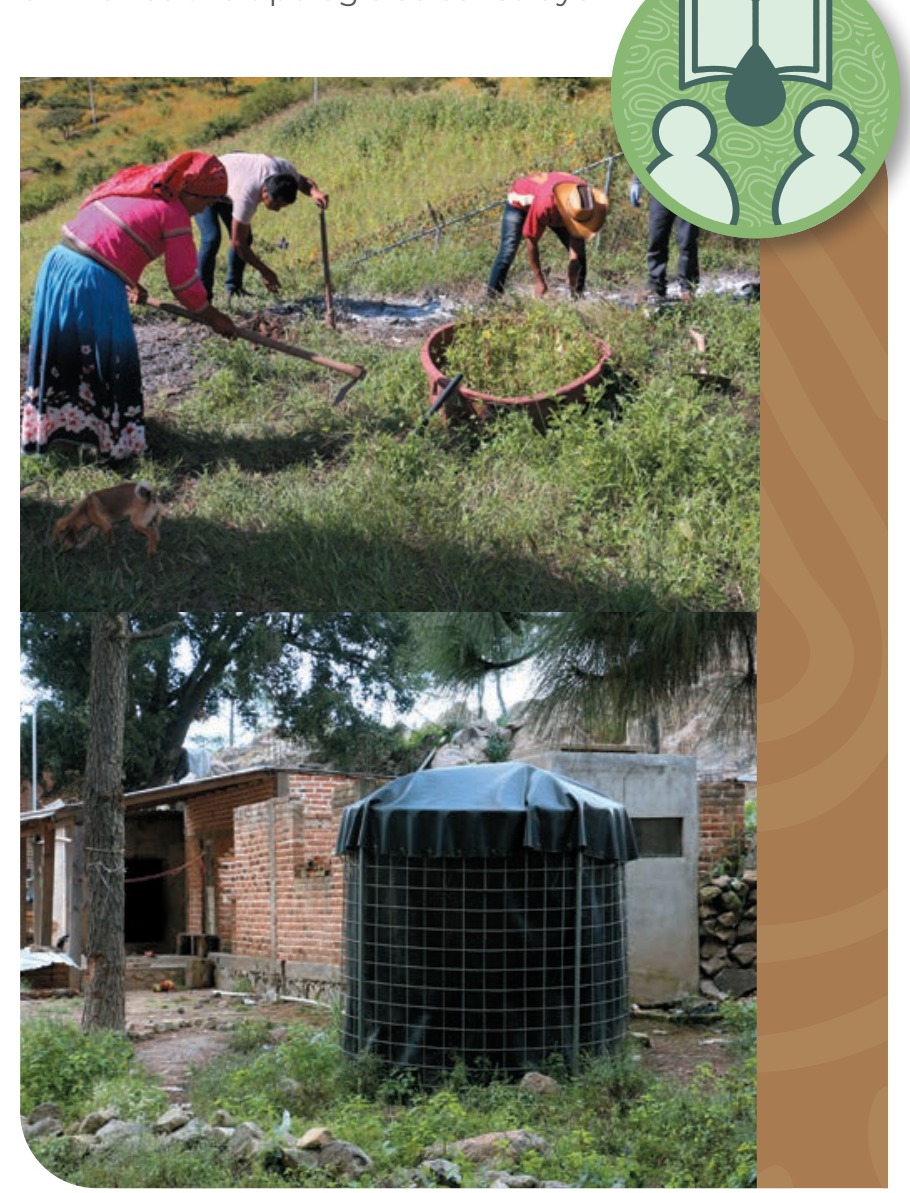




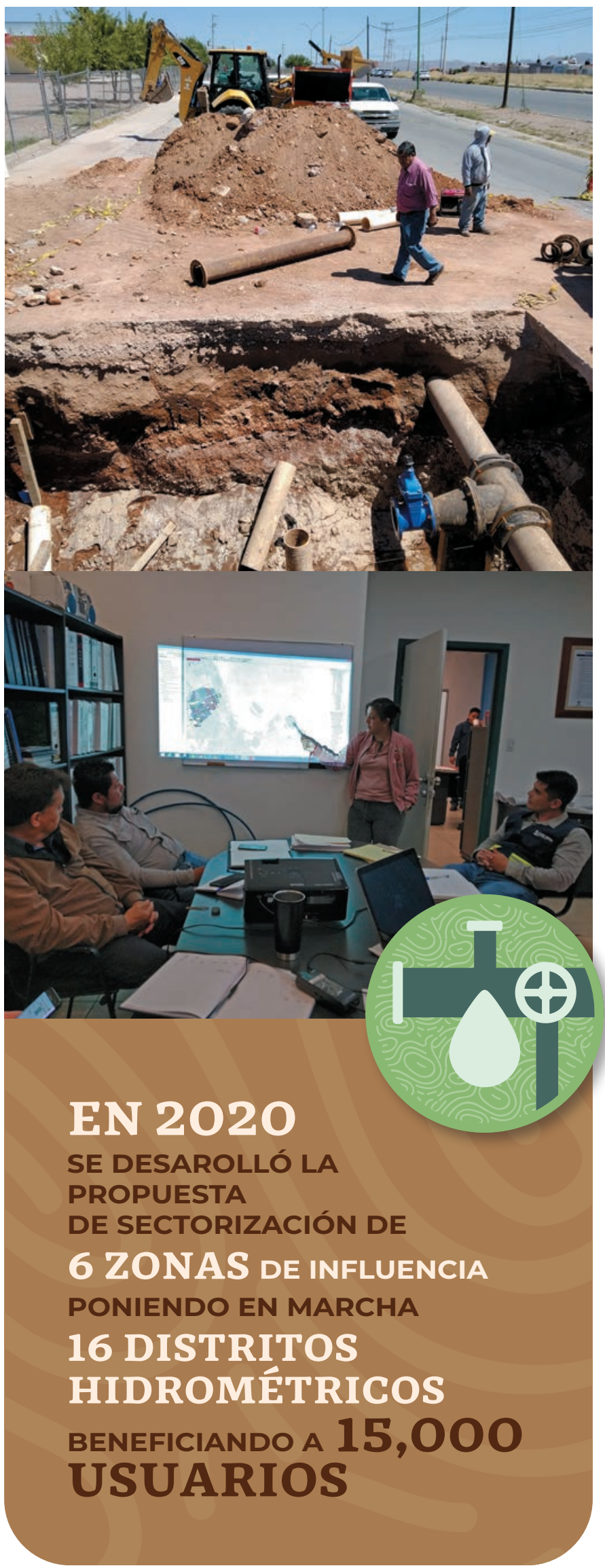

con información cualitativa, originalmente de primera mano, con el afán de generar una herramienta que permita clasificar y analizar la diversidad empírica de la gestión local del agua.

El principal beneficio potencial del proyecto es, en el largo plazo, la posibilidad de incidir en un fortalecimiento integral de las organizaciones locales del agua, lo que incluye su pleno reconocimiento legal, y en el arreglo institucional de la gestión del agua. El fortalecimiento integral de las organizaciones locales de agua potable podrá repercutir de manera positiva en el manejo sustentable de sus fuentes de agua y en la conservación ambiental y de los ecosistemas locales. Además, permite contar con estrategias de intervención con bases teórico-metodológicas sólidas para la investigación e incidencia en organizaciones locales del agua, tanto indígenas como rurales, urbanas y periurbanas, cuyo modelo pueda ser replicable en comunidades similares en todo el país.

\subsection{RED DE DISTRIBUCIÓN DE AGUA POTABLE DE CHIHUAHUA, CHIH.}

\footnotetext{
I - Contribuimos al establecimiento de un modelo

12 general para el manejo y transvase de las principa les conducciones de la zona noroeste de la red de Chihuahua, Chih. Con ello se logró incrementar el horario de servicio en sectores instrumentados, dándole así continuidad al programa de disminución de pérdidas físicas en la red asociada.
}

PARTICIPANTES: Rodrigo Ulises Santos Téllez, José Manuel Rodríguez Varela, Fidel Rafael Gómez Mendoza, Velitchko Gueorguiev Tzatchkov, Ana Laura Morales Musito, Juan Fco. Gómez Martínez, Oscar Jesús Llaguno Guilberto y Juan Maldonado Silvestre.

Desde 2017, la Junta Municipal de Agua y Saneamiento (JMAS) de Chihuahua, Chih. ha implementado, con apoyo del IMTA, un programa de recuperación de pérdidas físicas por medio de la gestión de presiones en algunos sectores de la red de distribución.

En 2020 se desarrolló la propuesta de sectorización de seis zonas de influencia: Sacramento norte, Colina, Saucito, Izalco, Chichontepec y Quetzal, que corresponden a 45 sectores hidrométricos y a 47,000 usuarios. Se trabajó en la ejecución, validación y puesta en marcha de 16 distritos hidrométricos, con lo que se mejoró el servicio para 15,000 usuarios y se migró de un suministro tandeado a uno continuo con control de presiones. También se hizo el balance y estimación de eficiencia en ocho distritos hidrométricos, se implementó un programa de sustitución de medidores domésticos para la mejora de la eficiencia comercial, y se desarrolló una metodología para la reducción de pérdidas físicas. 


\subsection{PROGRAMA DE INDICADORES \\ DE GESTIÓN DE ORGANISMOS \\ OPERADORES Y SISTEMA \\ DE INFORMACIÓN DE TARIFAS \\ DE AGUA POTABLE}

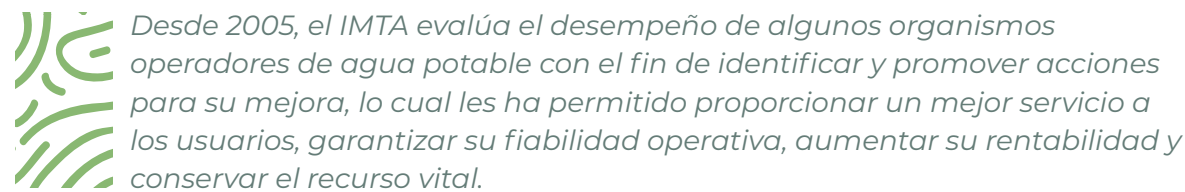

PARTICIPANTES: Martha Patricia Hansen Cruz, Flor Virginia Cruz Gutiérrez, Ana Laura Morales Musito, Gema Martínez Ocampo, Juan Fco. Gómez Martínez y Héctor Sanvicente Sánchez.

Este proyecto determina, mediante una batería de indicadores, el desarrollo y desempeño de organismos operadores de agua potable del país y da a conocer las tarifas por el servicio.

Durante 2020 se obtuvo información de 75 organismos operadores, a fin de actualizar la información en la base de datos. Además, se integró la información con la información histórica disponible.

Los beneficios para los organismos participantes es fomentar la transparencia de su información y obtener un análisis para conocer la situación de su organismo en los 32 indicadores analizados.

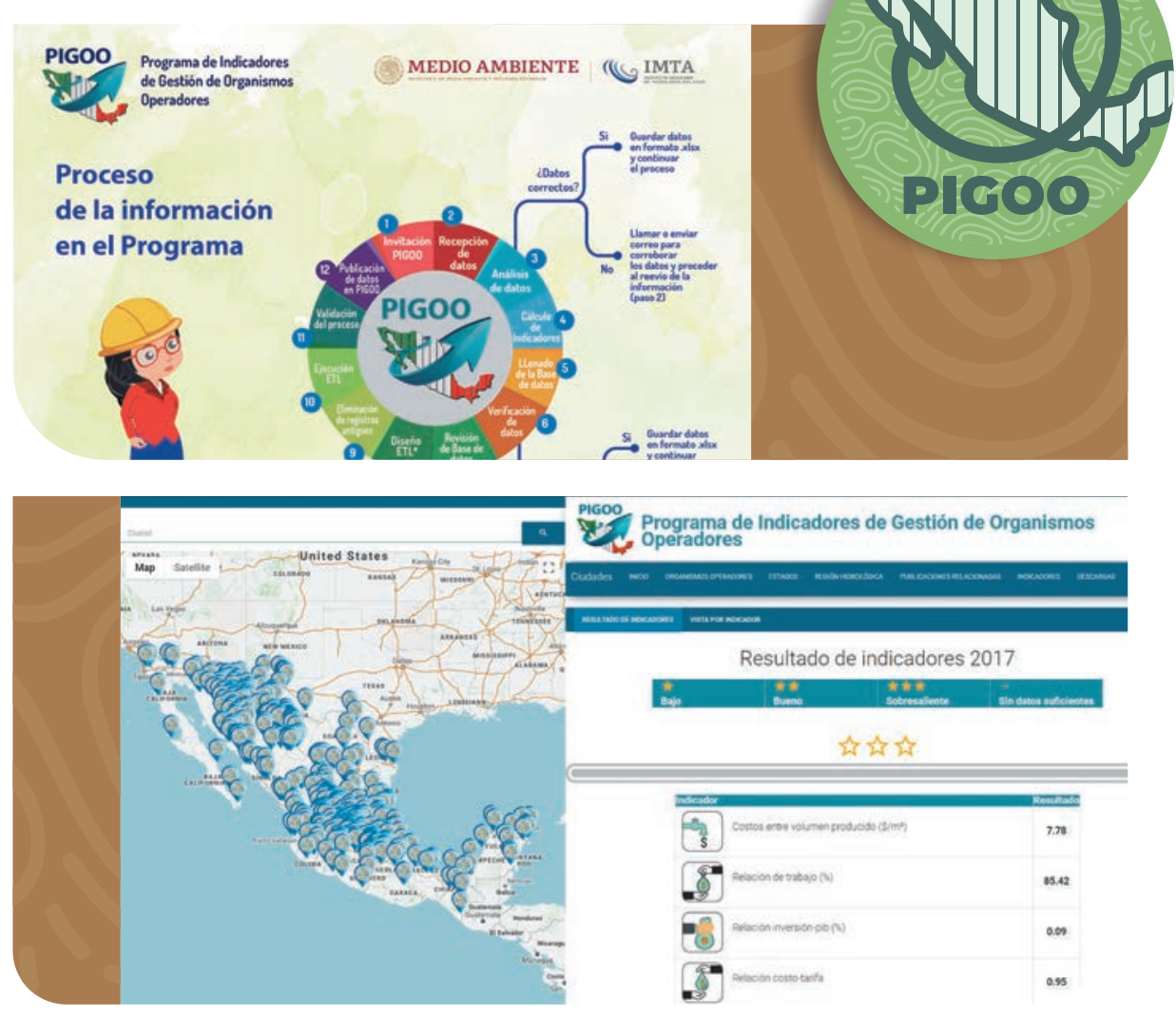




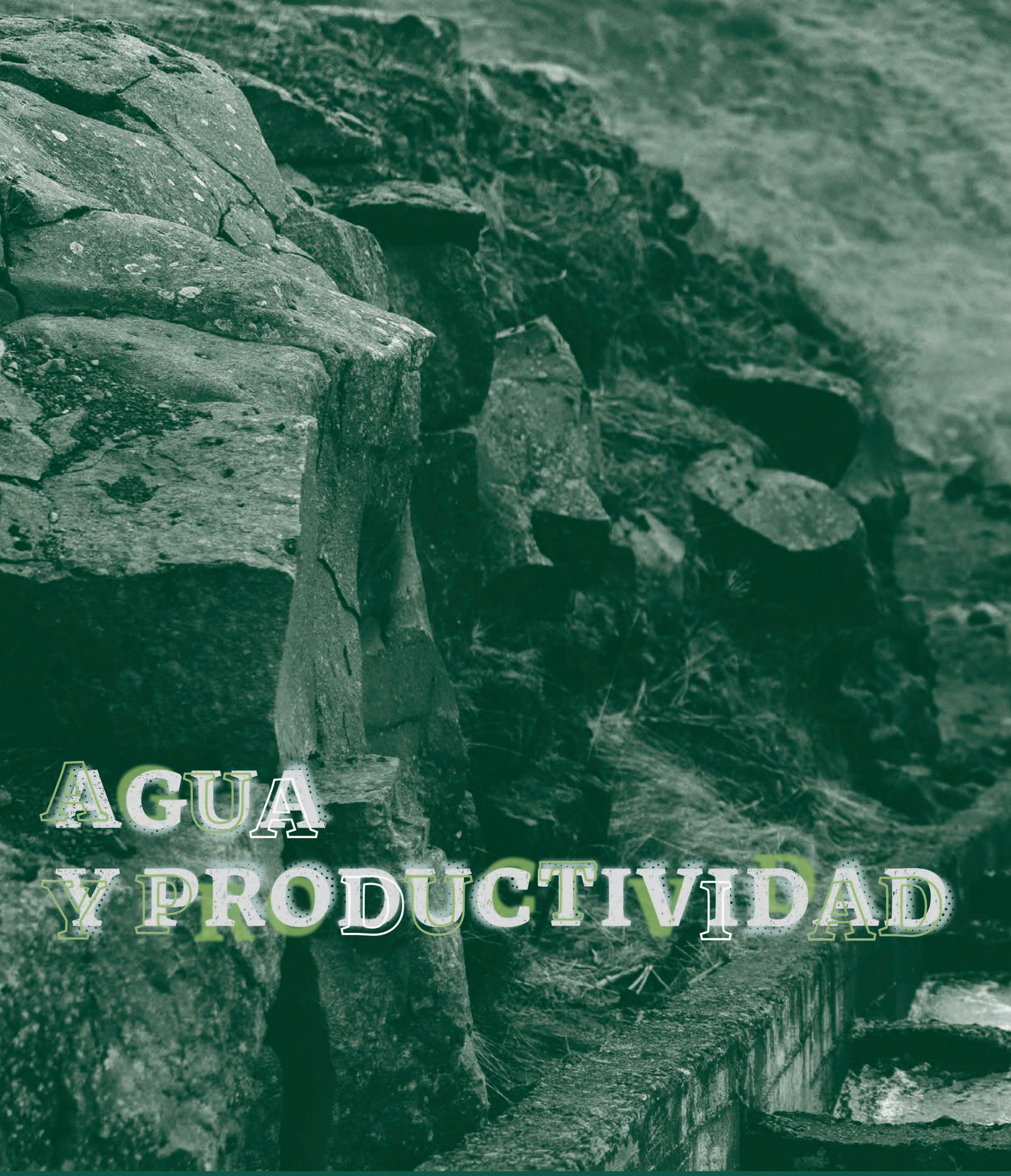




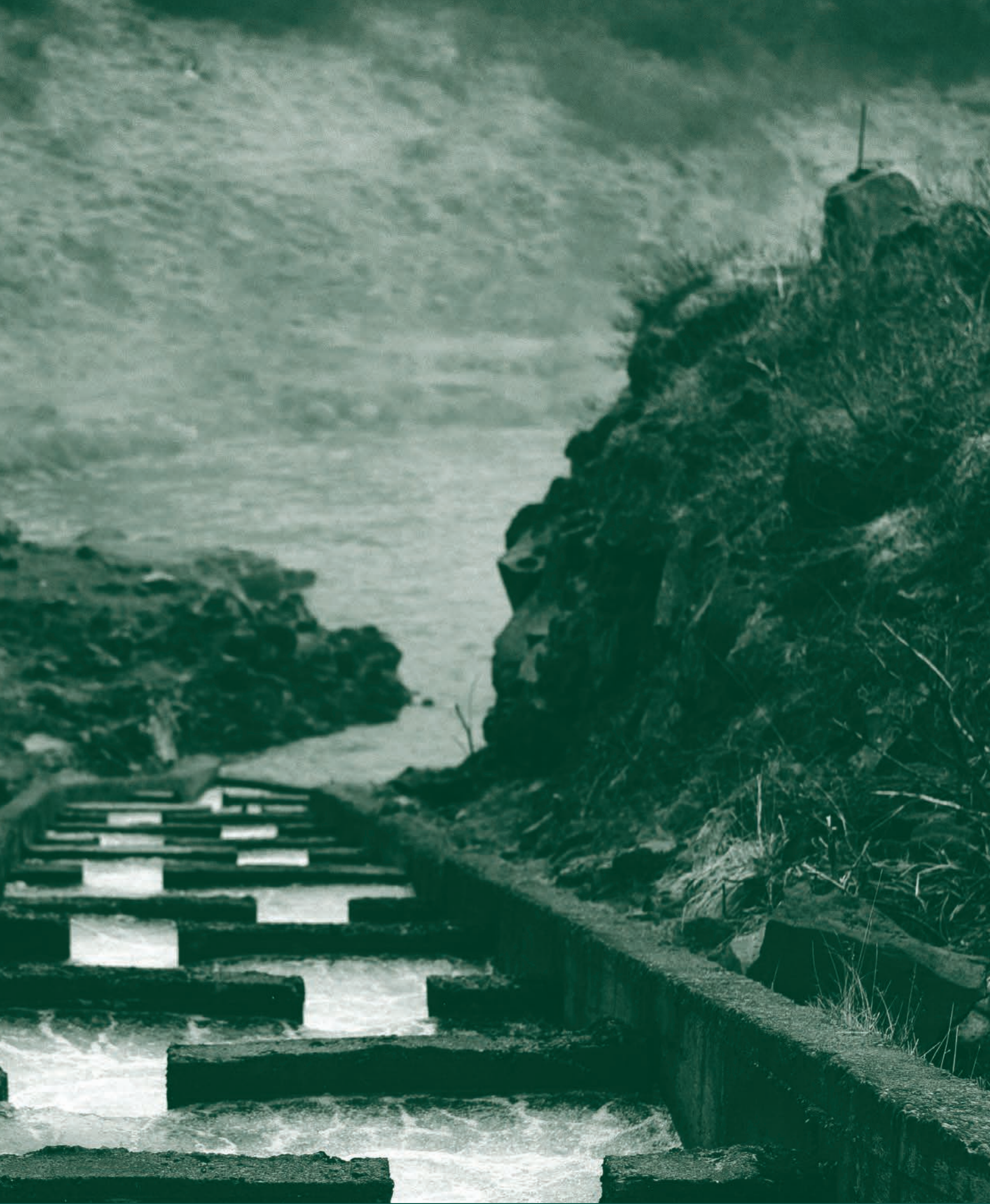




\section{AGUA Y PRODUCTIVIDAD}

CONOCIMIENTO PARA EL DESARROLLO EQUITATIVO DE MÉXICO

"r)
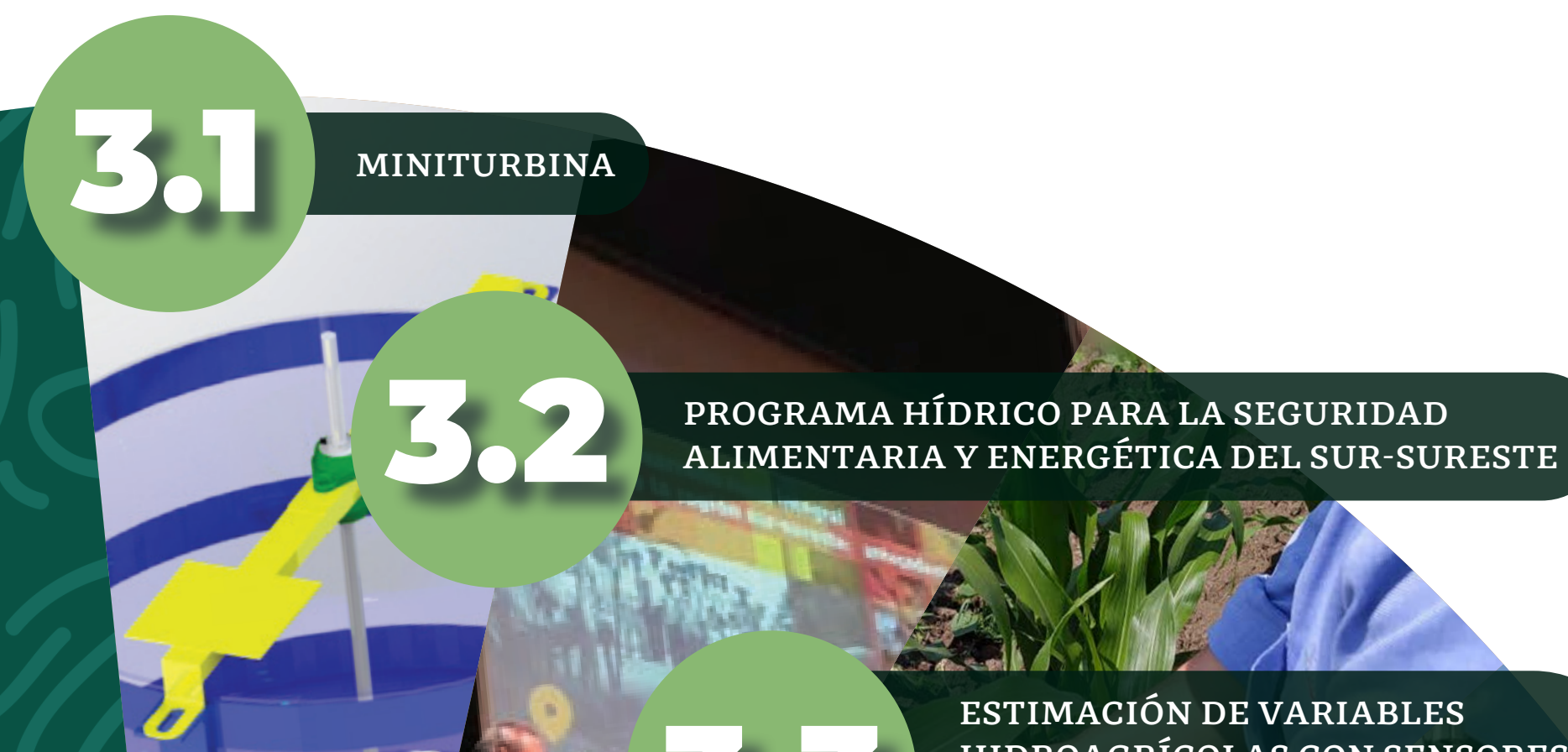

ESTIMACIÓN DE VARIABLES HIDROAGRÍCOLAS CON SENSORES REMOTOS PARA MEJORAR LA GESTIÓN DE RECURSOS HÍDRICOS

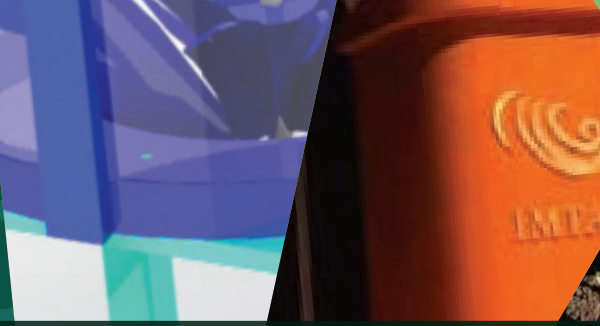

SISTEMAS DE DESALINIZACIÓN MEDIANTE TECNOLOGÍA FOTOVOLTAICA Y NANOFILTRACIÓN
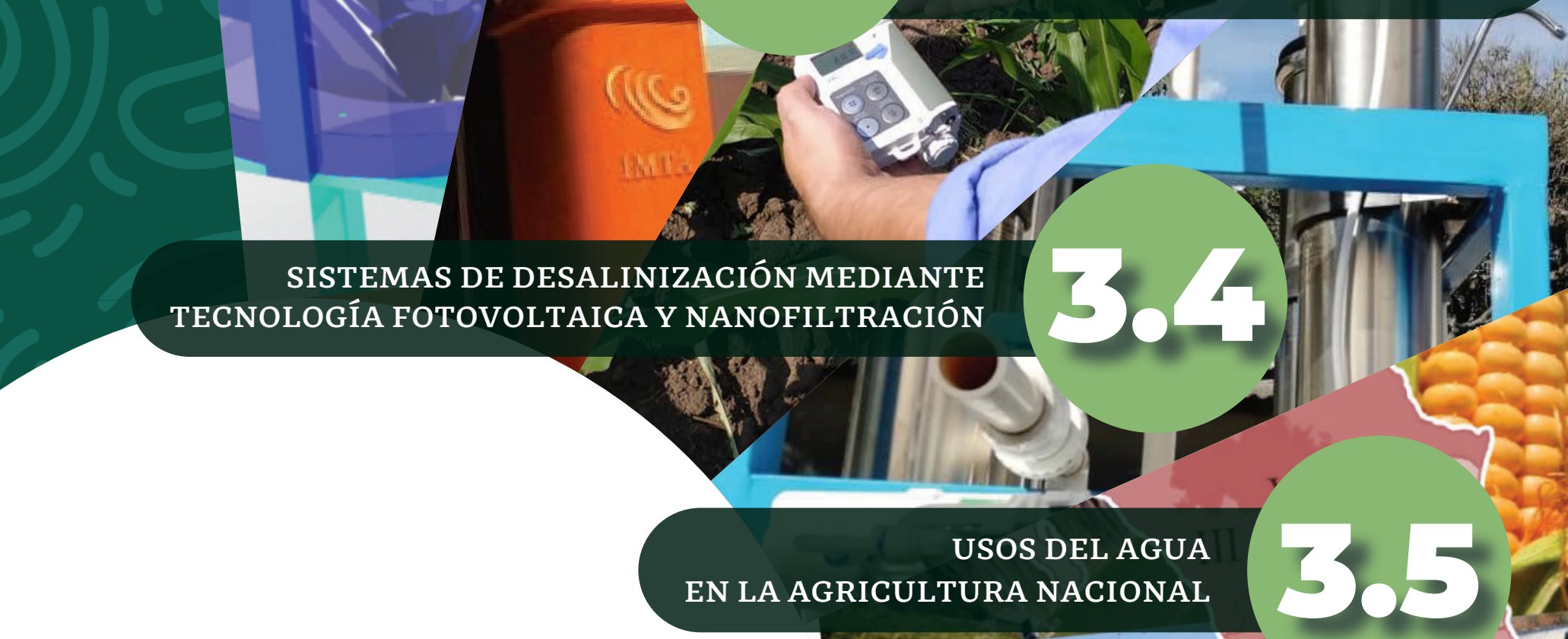


\section{Y) AGUA Y PRODUCTIVIDAE}

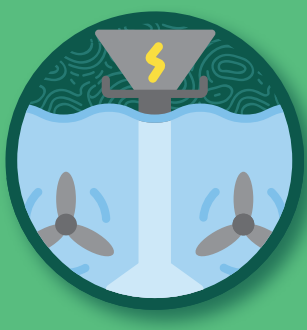

El IMTA

realizá investigaciones para

crear alternativas de generación

eléctrica a través de vórtices

hidráulicos.

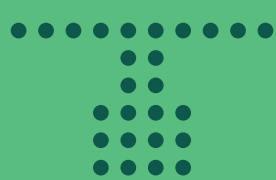

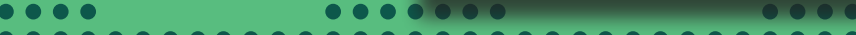

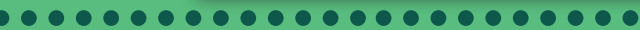

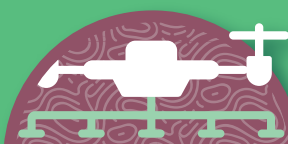

iा) 1 in

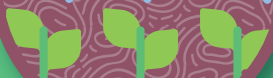

Sensores remotos

(

El agua que se extraiga

debe ser regresada al ambiente con la misma calidad con la que fue extraída necesitamos reconocer que la tarea es una

○

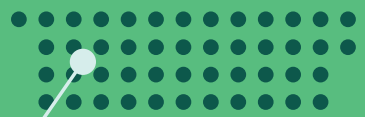
adecuado al agua.

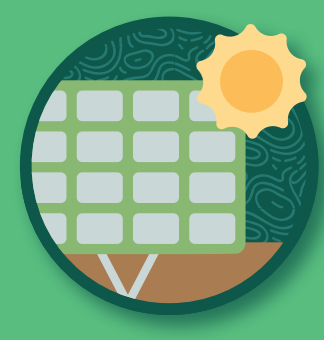

El IMTA

promueve la calidad de vida a través de la desalinización de agua, mediante tecnología fotovoltaica.

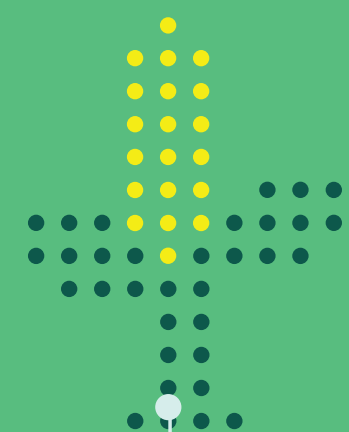

0

-

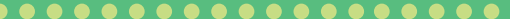
$0000000000000000000 \mathrm{c}$

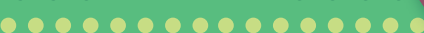
$0000000000000000000 \mathrm{c}$

Agricultura nacional Generación de datos actualizados para el uso de agua en la agricultura de riego nacional a través de imágenes satelitales.

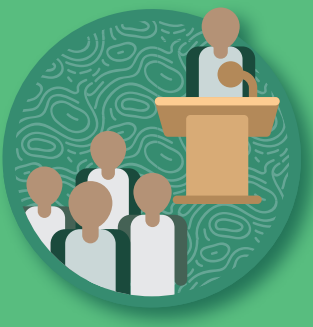

Programa Hídrico para la Seguridad Alimentaria y Energética del Sur-Sureste Con el fin de atender las urgentes necesidades de la región Sur-Sureste de México se implementaron foros para una intervención gubernamental que contribuya a reducir la pobreza. 


\subsection{MINITURBINA}

览

Investigamos para crear alternativas de generación

de electricidad a través de vórtices hidráulicos en

zonas de riego, y reducir así los costos del suministro

eléctrico.

PARTICIPANTES: Ulises Dehesa Carrasco, Irving Juvenal Álvarez Celso y José Agustín Breña Naranjo.

El sector energético está enfrentando importantes cambios en todo el mundo. Por ejemplo, mayor demanda de energía por el crecimiento poblacional, reducción de fuentes de combustibles fósiles, el compromiso con el cuidado del medio ambiente y la mitigación del cambio climático.

En este contexto, surge la necesidad de investigar y desarrollar un nuevo sistema de microcentrales hidroeléctricas, aprovechamientos en pequeña escala que resulten ser económicamente más accesibles y provoquen un menor impacto ambiental.

Una microcentral hidroeléctrica es una fuente de energía renovable eficiente y fiable, que aprovecha el potencial energético de pequeños ríos y arroyos. No requiere grandes embalses reguladores y su impacto ambiental es limitado. La potencia generada por este tipo de centrales se encuentra en el rango de 1 a $100 \mathrm{~kW}$. Es un suministro descentralizado de energía. En la mayoría de los casos puede ser bastante rentable en términos financieros. De igual manera, puede presentar impactos positivos de gran repercusión social y ambiental, lo que justifica las subvenciones.
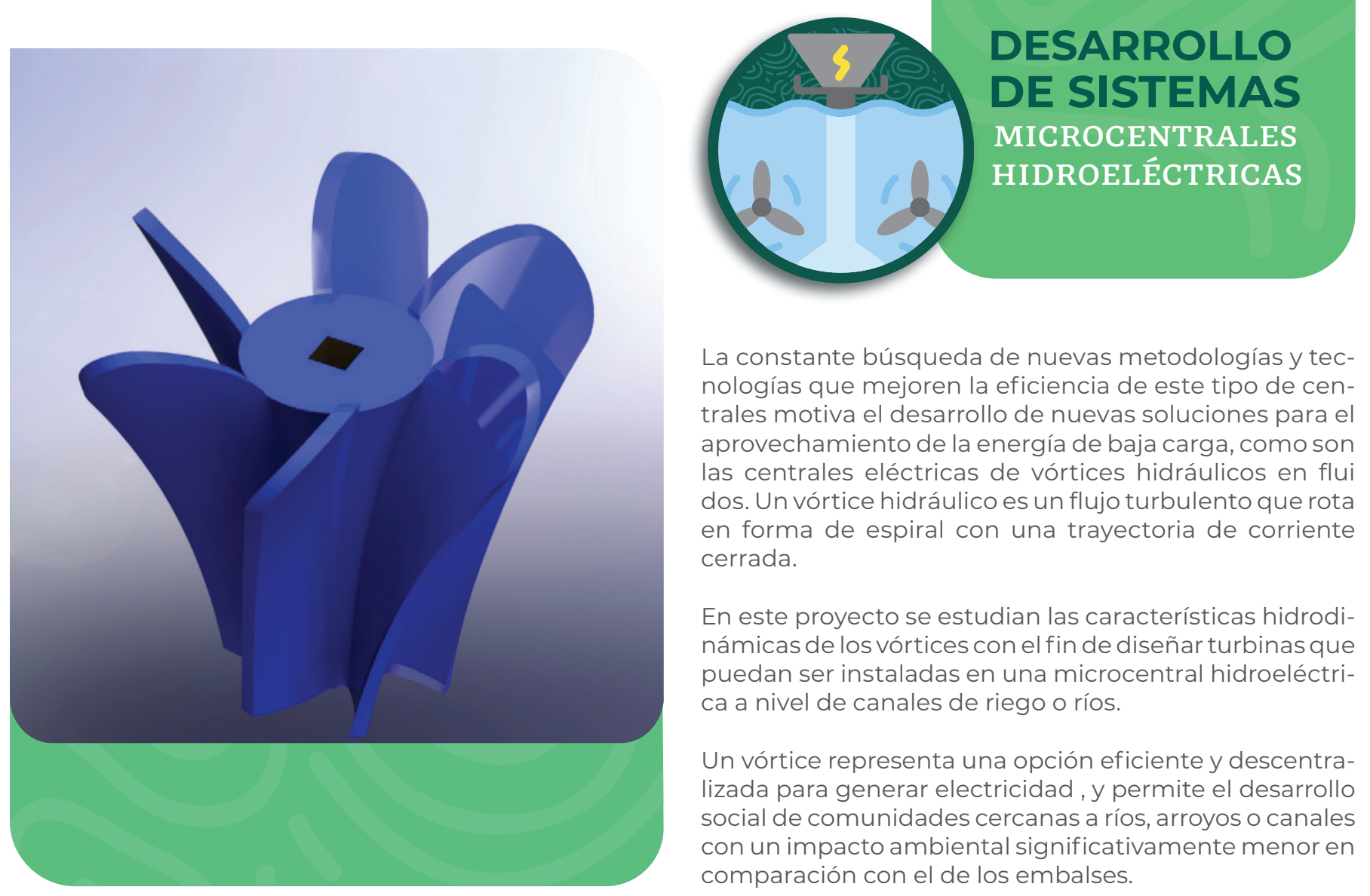

La constante búsqueda de nuevas metodologías y tecnologías que mejoren la eficiencia de este tipo de centrales motiva el desarrollo de nuevas soluciones para el aprovechamiento de la energía de baja carga, como son las centrales eléctricas de vórtices hidráulicos en flui dos. Un vórtice hidráulico es un flujo turbulento que rota en forma de espiral con una trayectoria de corriente cerrada.

En este proyecto se estudian las características hidrodinámicas de los vórtices con el fin de diseñar turbinas que puedan ser instaladas en una microcentral hidroeléctrica a nivel de canales de riego o ríos.

Un vórtice representa una opción eficiente y descentralizada para generar electricidad, y permite el desarrollo social de comunidades cercanas a ríos, arroyos o canales con un impacto ambiental significativamente menor en comparación con el de los embalses. 


\subsection{PROGRAMA HÍDRICO PARA LA SEGURIDAD ALIMENTARIA Y ENERGÉTICA DEL SUR-SURESTE}

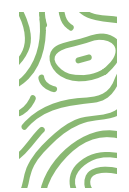

Con el fin de atender las urgentes necesidades del Sur-Sureste de México hemos dedicado esfuerzos para diseñar una intervención gubernamental que contribuya a reducir la pobreza y dar seguridad alimentaria y energética a los habitantes de la región.

PARTICIPANTES: José Antonio Quevedo Tiznado, Raúl Medina Mendoza, Olga Xóchitl Cisneros Estrada, Leonardo Pulido Madrigal, Leticia Becerra Soriano y José Agustín Breña Naranjo.

El 25 de febrero de 2020 se celebró el foro El Desarrollo Rural Integral de la Región Sur-Sureste de México: Antecedentes y Perspectivas, con el objetivo de analizar la situación actual e identificar las alianzas tecnológicas e institucionales que mejor contribuyan al desarrollo rural integral y al manejo sustentable del agua y sus recursos asociados en el Sur-Sureste de México.

Durante el desarrollo del foro se abordaron los antecedentes de los programas gubernamentales realizados en el área de interés, durante los últimos cuarenta años, haciendo énfasis en los logros alcanzados por el Programa de Desarrollo Rural Integrado del Trópico Húmedo (Proderith), desarrollado con participación del IMTA, que podría ser replicado por las políticas de la Cuarta Transformación, para apoyar la eficacia de sus programas en ejecución y planeados para dicha región de México.

En este contexto, se analizó la política agroalimentaria de la Cuarta Transformación en el Sur-Sureste y la prioridad de autosuficiencia alimentaria y de los programas actualmente en ejecución, como el Programa Nacional de Transición hacia la Agroecología, y otros dentro del área de influencia en la región, como el Programa Mesoamérica sin Hambre.

En el IMTA seguimos desarrollando esta propuesta, en la que el recurso hídrico es el elemento vinculante y motor de la gestión del territorio. Con ello se propone cerrar las brechas de desigualdad, avanzar en la justicia social y garantizar la seguridad hídrica.

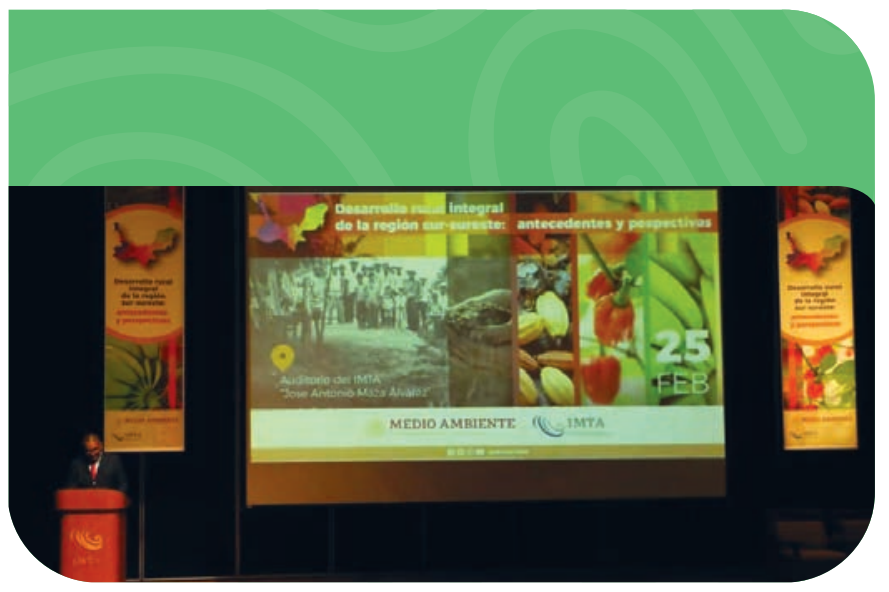

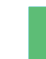

\section{DE FEBRERO DE 2020}

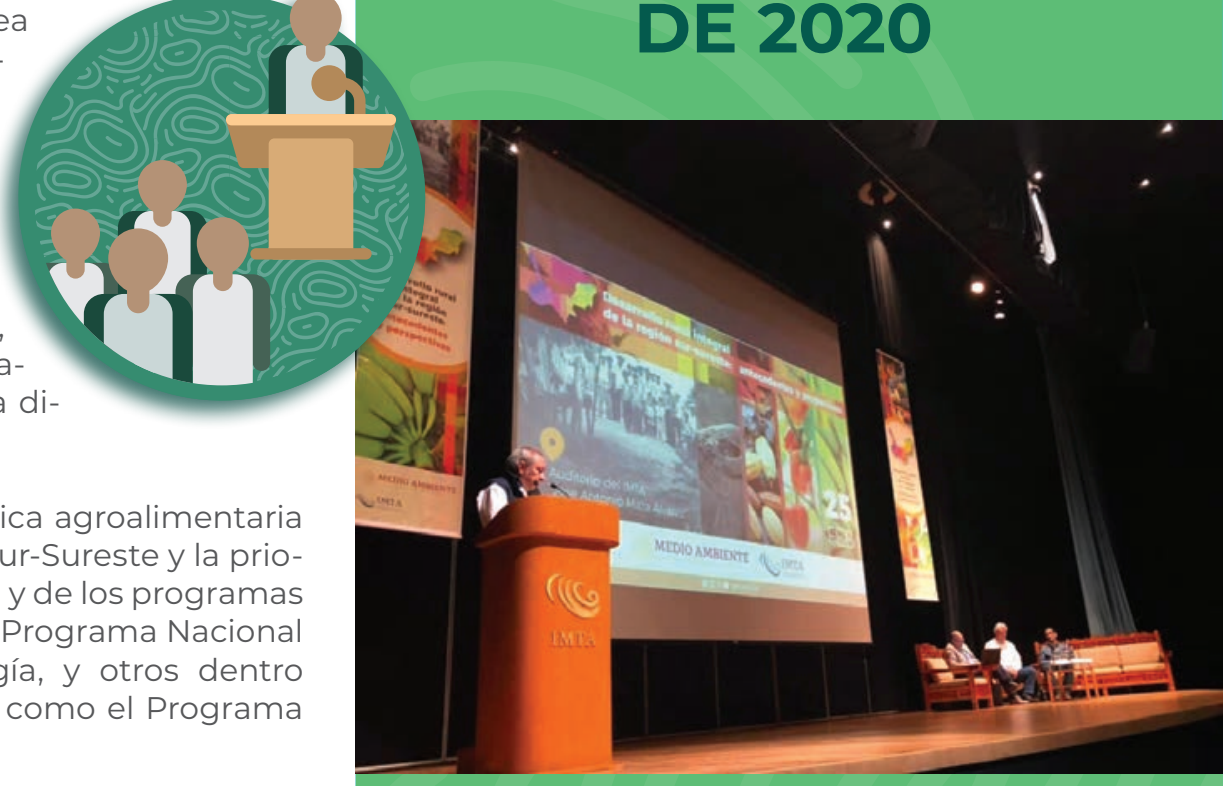

SE CELEBRA EL PRIMER FORO

I DESARROLLO RURAL INTEGRAL DE LA REGIÓN SUR-SURESTE DE MÉXICO 


\subsection{ESTIMACIÓN DE VARIABLES HIDROAGRÍCOLAS CON SENSORES REMOTOS PARA MEJORAR LA GESTIÓN DE RECURSOS HÍDRICOS}

) Utilizamos la tecnología para mejorar procesos

PARTICIPANTES: Ronald Ernesto Ontiveros Capurata, Alberto González Sánchez, René Lobato Sánchez y Juan Manuel Ángeles Hernández.

Este proyecto se llevó a cabo con la finalidad de desarrollar y validar una metodología para la estimación de variables hidroagrícolas de importancia en la gestión de recursos hídricos, basada en información observada y simulada, usando sensores remotos y análisis espectral.

El proyecto se desarrolló en parcelas de maíz de la Facultad de Estudios Superiores de la Universidad Autónoma de México en Cuautitlán (FES-UNAM), ubicada en la localidad de San Sebastián Xhala, Edo. Méx., y en el campus experimental del Instituto Nacional de Investigaciones Forestales Agrícolas y Pecuarias (Inifap) en Zacatepec, Mor.. En estos lugares se midieron variables agrícolas y se tomaron imágenes aéreas con drones y firmas espectrales.

Con las firmas espectrales recopiladas en Zacatepec, Mor., y en Cuautitlán, Edo. Méx., se construyó un banco de firmas espectrales del cultivo de maíz en sus diferentes etapas fenológicas. Como resultado del procesamiento de imágenes se obtuvieron dos tipos de productos: ortomosaicos y modelos digitales de elevación (MDE) para cada una de las zonas estudiadas (campus de Inifap en Zacatepec, Mor. y la FES-UNAM).

Este proyecto demostró que el uso de imágenes de alta resolución espacial, obtenidas con el uso de drones, constituyen una herramienta factible y eficiente para la estimación de fenología y el monitoreo de cultivos, comparado con imágenes satelitales, ya que presentan la ventaja de mostrar con más detalle la cobertura vegetal.
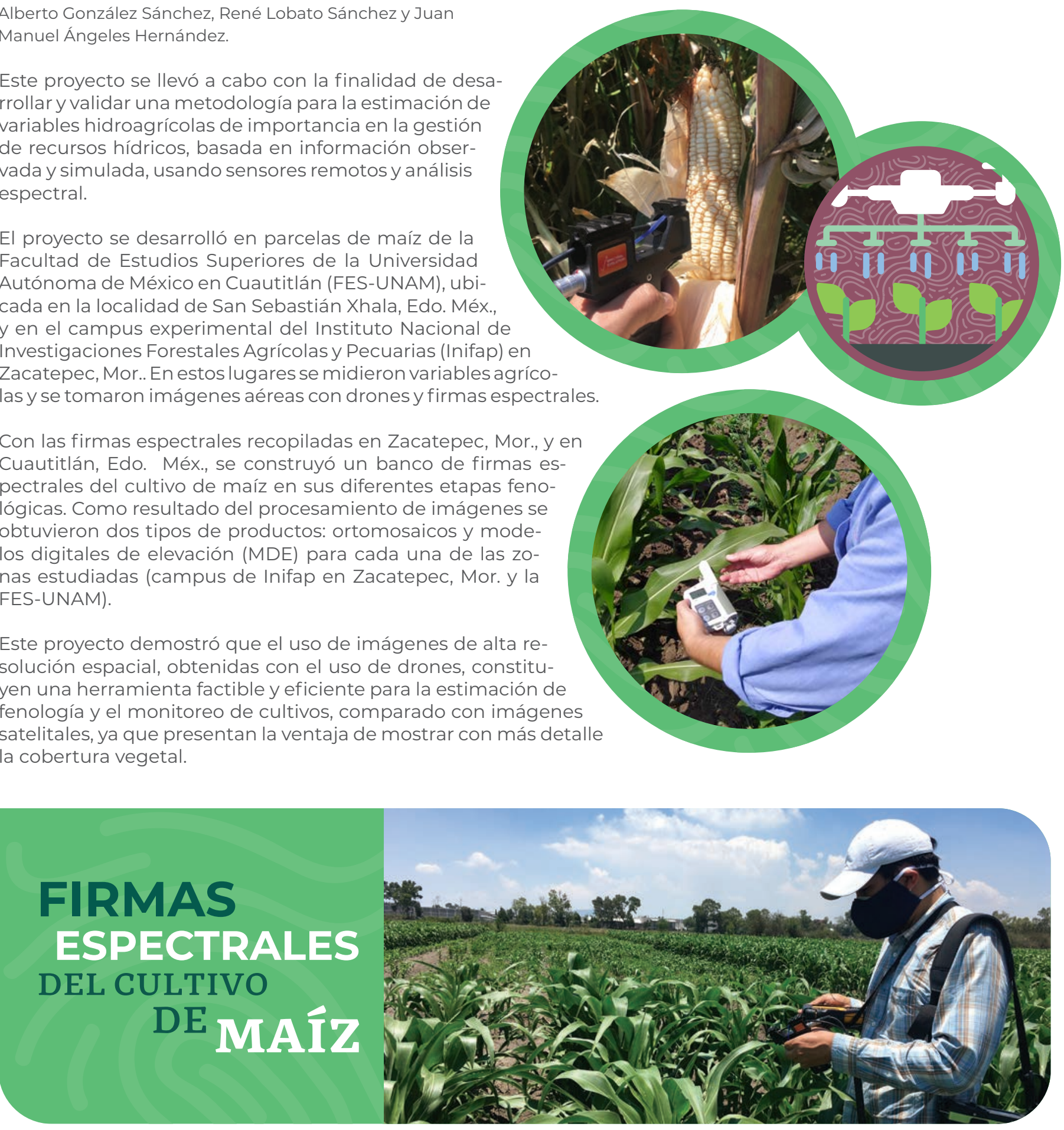


\subsection{SISTEMAS DE DESALINIZACIÓN MEDIANTE TECNOLOGÍA FOTOVOLTAICA Y NANOFILTRACIÓN}

㟶

- El IMTA promueve el desarrollo social y económico a través de la desalinización de agua salobre basada en nanofiltración y alimentada con tecnología fotovoltaica y destilación por membrana para la producción de agua de uso agrícola, ganadero y para consumo humano.

PARTICIPANTES:ULISES Ulises Dehesa Carrasco, Eduardo Venegas Reyes, José Alfredo Díaz Magaña, Marcia Yáñez Kernke y Jonathan Ibarra Bahena.

Este proyecto promueve mejorar la calidad de vida de los usuarios, ya que el agua desalinizada se puede utilizar para consumo humano y para incrementar la productividad de los cultivos, lo que genera la posibilidad de aumentar los ingresos económicos de las familias.

Asimismo, potencializa del desarrollo económico local al manejar cultivos rentables para los mercados nacional e internacional, e incluso favorece la creación de clusters de agricultura de alta tecnología para exportación.

Estas tecnologías, incrementan la disponibilidad de agua dulce, lo que permite diversificar los cultivos e incrementar su productividad, y pueden ser replicables e impactar en el desarrollo social y económico de diversas regiones.

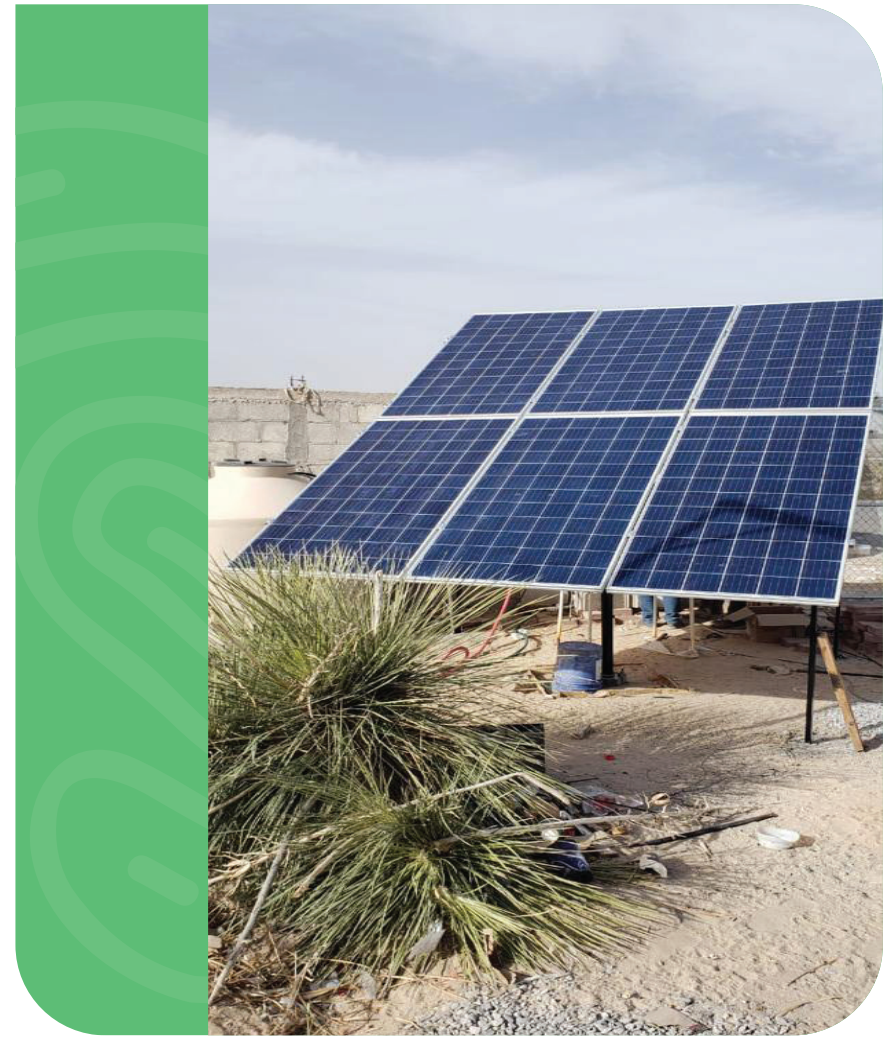

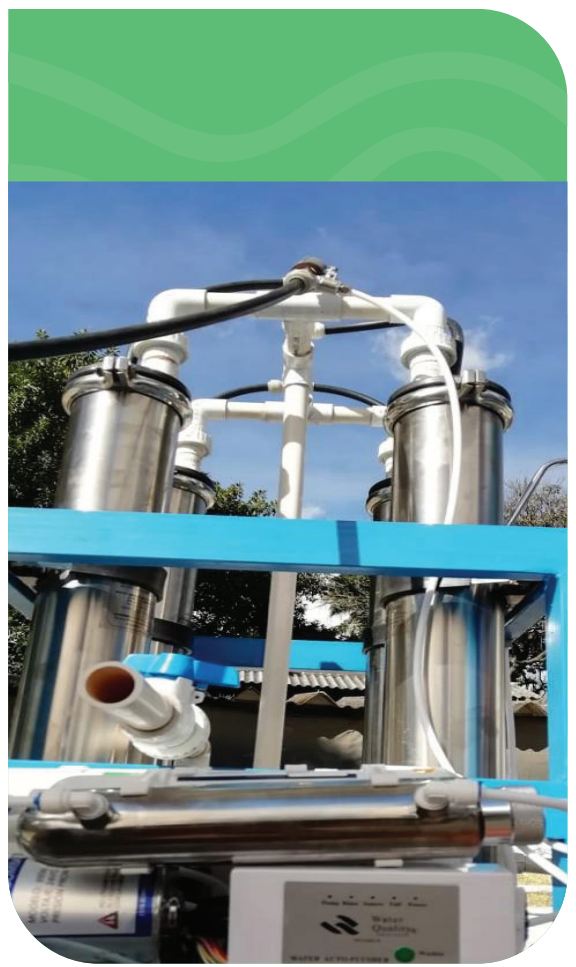

Entre las actividades realizadas en el marco de este proyecto se llevó a cabo la recopilación de información de calidad del agua disponible en los estados de Querétaro, San Luis Potosí y Zacatecas para identificar los sitios que tienen fuentes de agua salobre, así como datos de algunos productores de la región. Se integró así un sistema de información geográfica que incluye los tres estados donde se implementarán las plantas demostrativas comprometidas en el proyecto. Adicionalmente, en algunos sitios de interés se tomaron muestras para determinar la calidad del agua e identificar su factibilidad. En forma paralela se llevó a cabo la difusión del proyecto entre productores de los sitios donde se identificaron fuentes de agua salobre, para considerarlos como posibles sitios de implementación de las plantas demostrativas.

También se realizó el diseño conceptual de las plantas de desalinización, así como la selección de membranas y dimensionamiento de los sistemas fotovoltaicos que alimentarán a las plantas desalinizadoras. Se diseñaron asimismo las estructuras de soporte de los paneles fotovoltaicos y de las membranas, se efectuó el dimensionamiento del sistema solar térmico que alimentará a un prototipo de desalinización de destilación por membrana, y se diseñó un invernadero tipo que será implementado en las plantas demostrativas para uso agrícola.

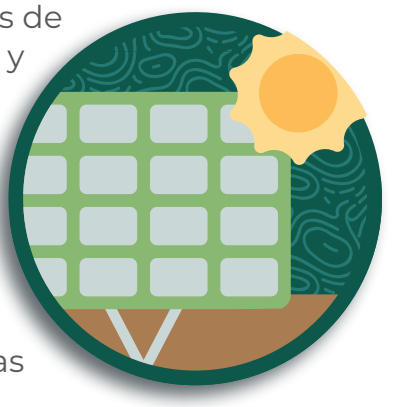




\subsection{USOS DEL AGUA EN LA AGRICULTURA NACIONAL}

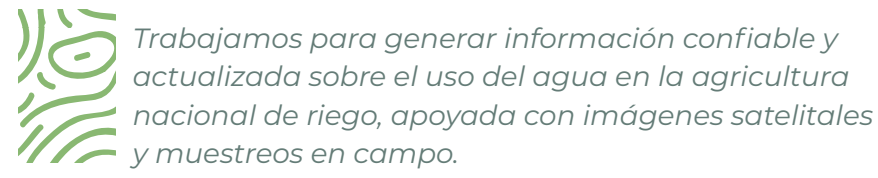

PARTICIPANTES: Alberto González Sánchez, Ronald Ernesto Ontiveros Capurata, Alberto González Sánchez, Víctor Manuel Gordillo Salinas, Juan Manuel Ángeles y René Lobato Sánchez.

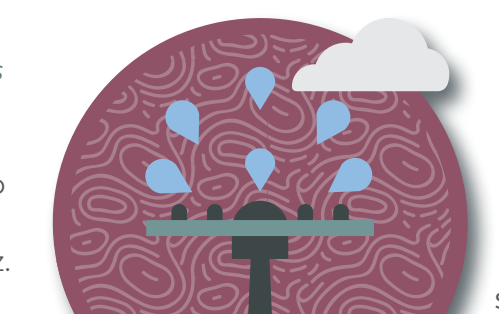

2020 se trabajó en la tercera etapa de este proyecto, en la que se logró desarrollar una versión prototipo de la plataforma, con el nombre clave de Sisuar (Sistea de Información sobre Usos del Agua en la Agricultura de Riego). Esta versión integra fuentes de información sobre acuíferos, presas de almacenamiento y derivación, estadísticas agrícolas de distritos y unidades de riego, calidad del agua en México, estaciones hidrométricas, índices de marginación e infraestructura de distritos de riego, e incorpora también información tabular y geográfica. La versión prototipo puede ser consultada en sisuar. imta.mx. Queda pendiente la incorporación de información de superficies bajo riego, fuentes de abastecimiento, principales cultivos regados y volúmenes utilizados para riego.

La construcción de esta plataforma requirió de metodologías para la estimación de variables de alta variabilidad espacial y temporal en el país, como la evapotranspiración de referencia y la precipitación. La estimación de los requerimientos hídricos de los cultivos a nivel municipal es un reto actual, pero factible, ya que existe un incremento en la densidad de estaciones agroclimatológicas automatizadas, y en la resolución espacial y temporal de las imágenes satelitales de última generación, y las series estadísticas agrícolas son de más años y las bases de datos climatológicas son más robustas.

Este proyecto también suministra información para un acoplamiento armonioso entre la demanda y la oferta de agua y permitirá un uso agrícola más eficiente para disminuir las externalidades negativas, tales como la sobreexplotación o destrucción de los recursos asociados al suelo, el agua y la energía.

La incorporación de una plataforma web con elementos dinámicos e interactivos para proveer información sobre los recursos hídricos de una región, municipio o localidad, significa un adelanto cuantitativo, al llenar un vacío con el manejo de información robusta, oportuna y accesible del uso del agua por las zonas agrícolas. 


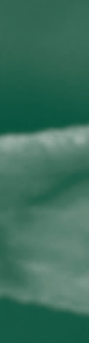

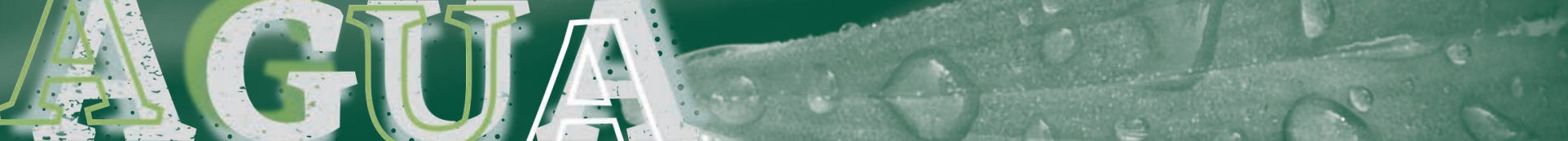

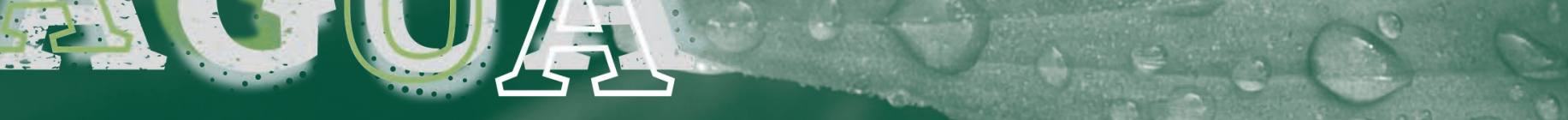

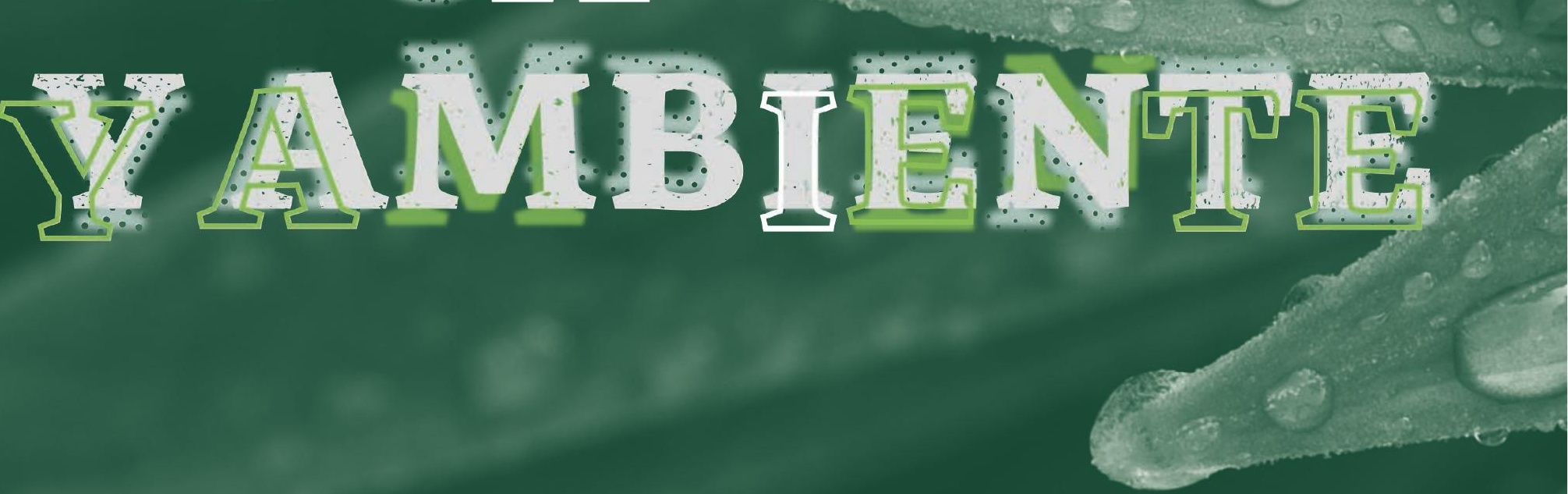




\section{AGUA Y AMBIENTE}

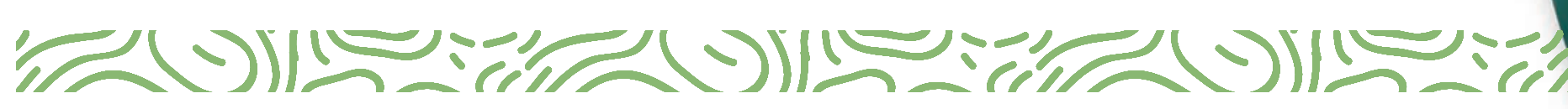

\section{B.}

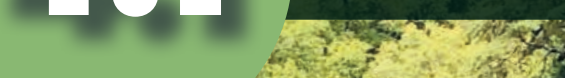

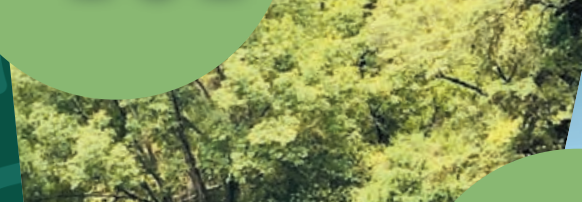

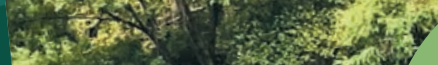
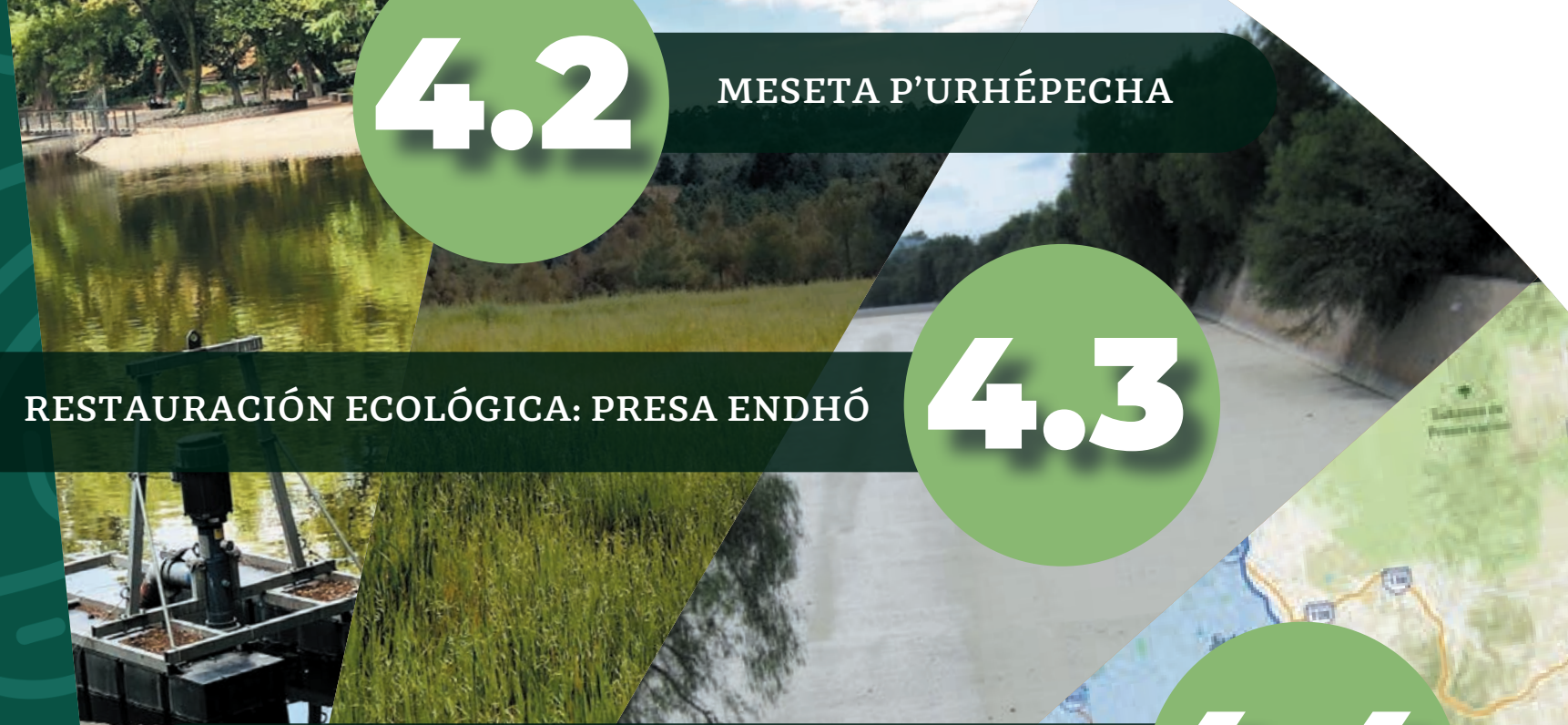

at she

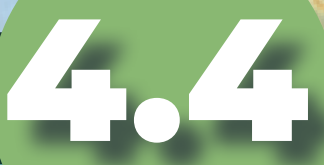

리

Yautepece

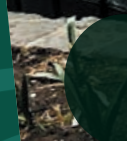

\section{MONITOREO DE PARÁMETROS AMBIENTALES}
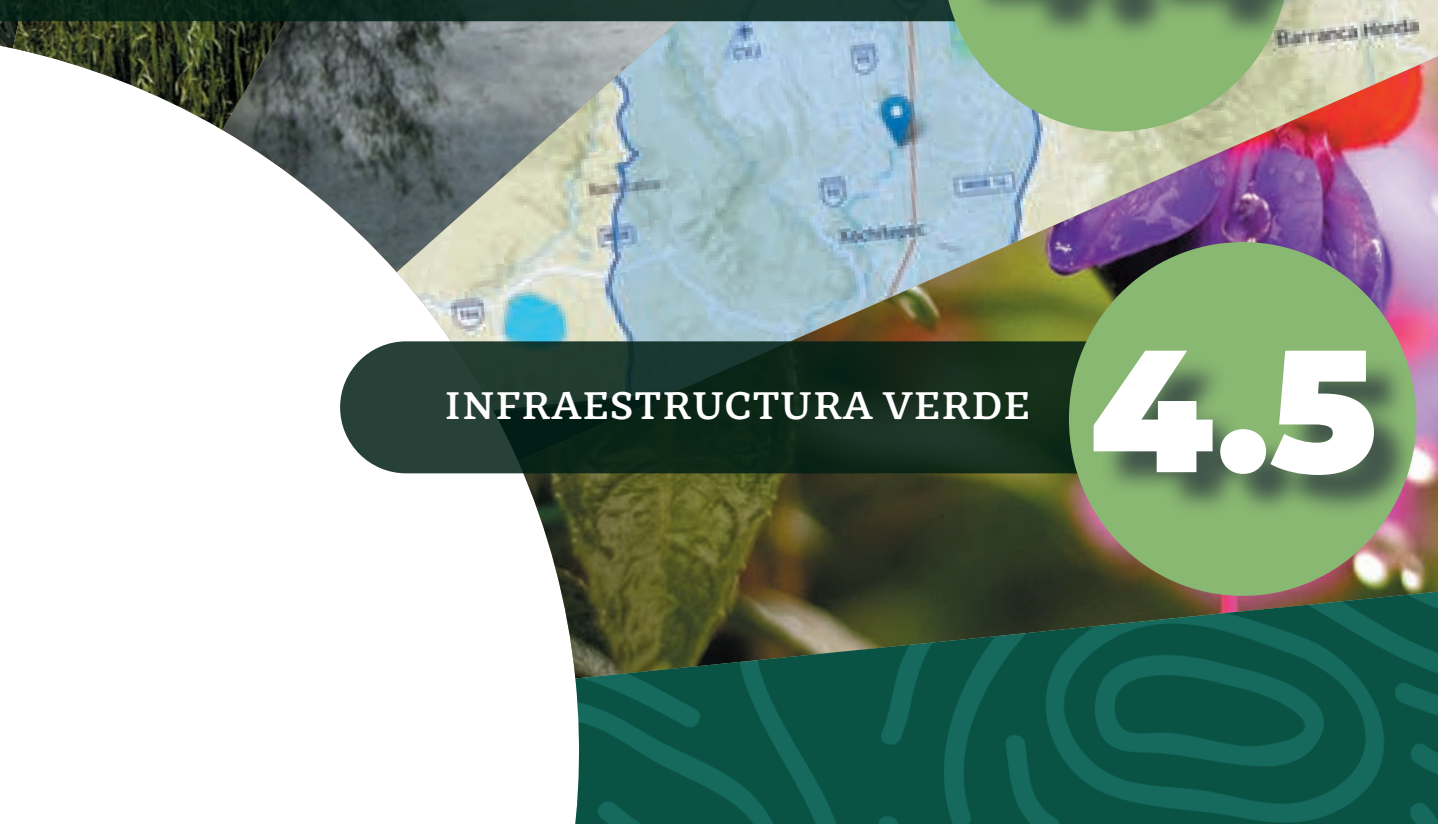

(1) 
1 ,

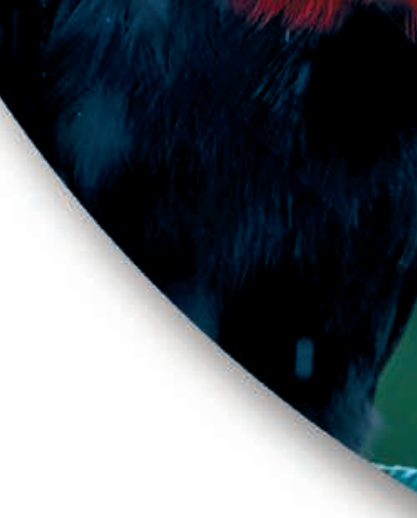

EL RÁPIDO DESARROLLO ECONÓMICO GLOBAL ha puesto una fuerte presión sobre nuestro planeta; a tal grado, que este ha desencadenado cambios repentinos y de no retorno en el ambiente, y que hoy se manifiestan a través de incendios en sus grandes pulmones, en sequías extremas, inundaciones y en la propagación espacial de un virus que pone en riesgo el aseguramiento de la salud y prosperidad de todas las naciones.

La pandemia de COVID-19 Ilegó como una llamada de atención planetaria para señalarnos que cuando parecía estar todo bien por el desarrollo económico del mundo, en realidad no lo estaba. El planeta nos dice, a través de un virus con propagación global, que nuestra salud personal sí se relaciona y afecta con la salud del planeta, y que con la degradación ecológica se entrelazan la salud humana y el crecimiento económico global.

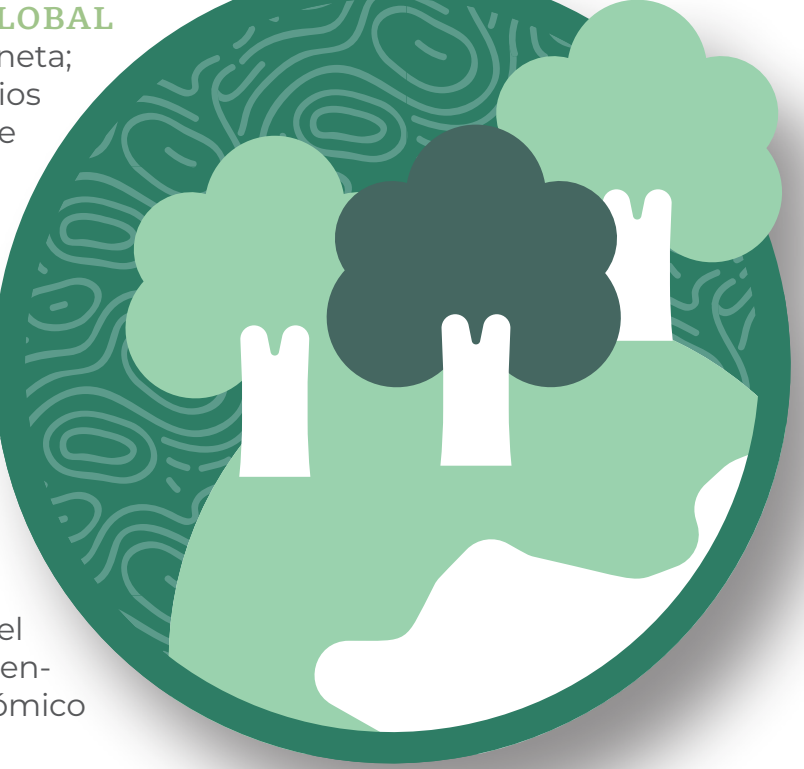

La conservación y recuperación del ambiente son tareas impostergables para la humanidad entera. En el IMTA trabajamos para tener los conocimientos que nos permitan rehabilitar y preservar los recursos hídricos de México, soporte de vida y base para el desarrollo humano equitativo y respetuoso de la naturaleza. 


\subsection{Bosque de Chapultepec}

Este proyecto representa un cambio en el paradigma en la gestión integrada de los recursos hídricos, ya que se prevé la detonación de un proceso de planeación participativa interinstitucional.

\subsection{Meseta P'urhépecha}

Durante el 2020 se trabajo en la definición de problemas como una ventana de oportunidad para revertir los procesos de degradación en la región, basados en soluciones enfocadas en territorio, sociedad y participación institucional.

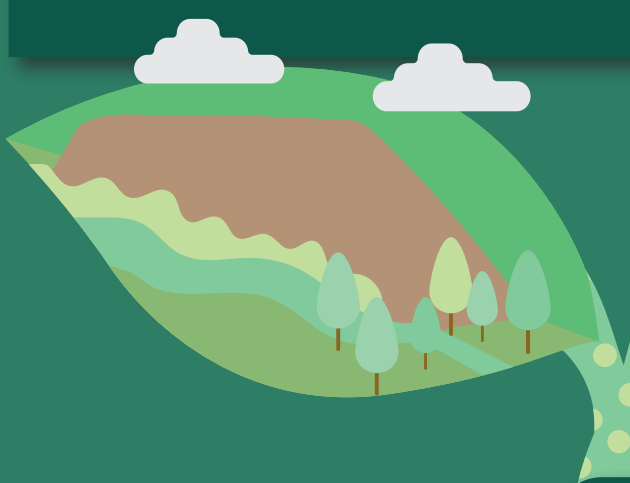

\subsection{Restauración ecológica: presa} Endhó

Es indispensable tratar toda el agua residual que llega a la presa Endhó de manera que se remueva al menos $95 \%$ de las cargas contaminantes.

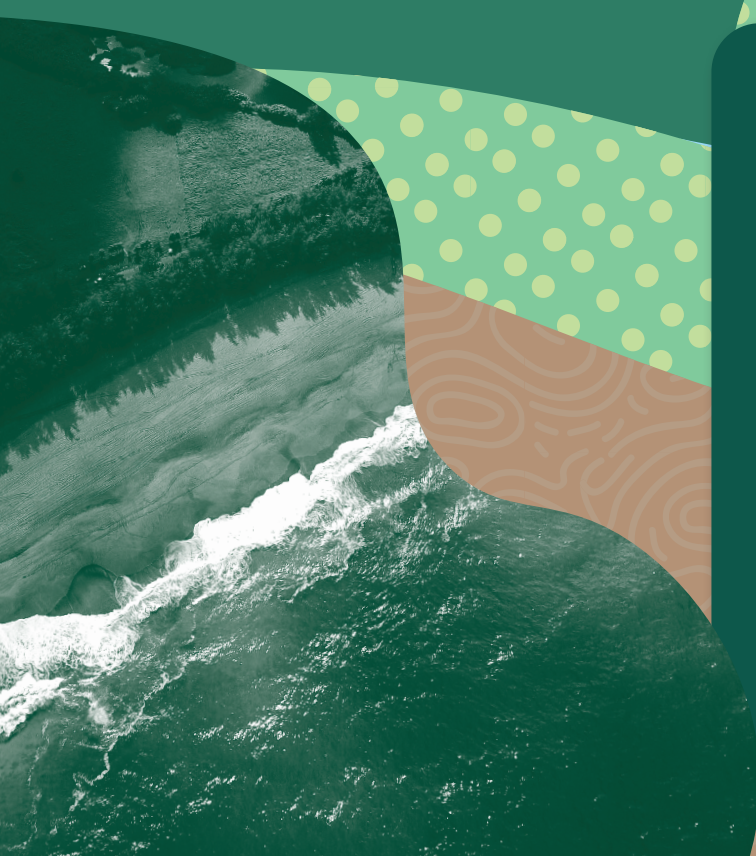

\subsection{Monitoreo de parámetros ambientales}

El IMTA trabajó para implementar un sistema de monitoreo continuo de parámetros de campo y nivel, que permita conocer en el tiempo los rangos de variación de los parámetros ambientales en el sitio.

\subsection{Infraestructura verde}

Se presentó un caso de estudio dentro de las instalaciones del IMTA, donde se realizó el análisis geohidrológico, hidrológico e hidráulico para la implementación de una infraestructura verde en el que se estudió la construcción de un jardín de lluvia.

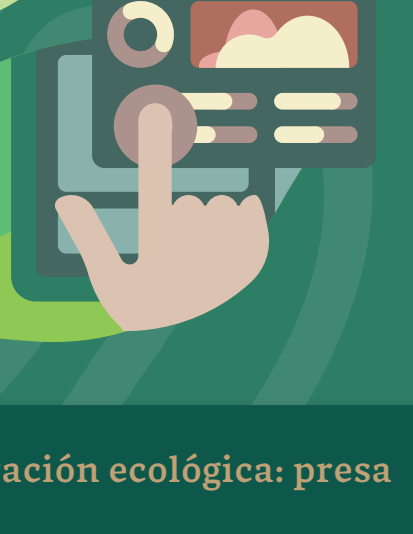




\subsection{BOSQUE DE CHAPULTEPEC}

10

El IMTA aporta conocimiento y experiencia para alcanzar la gestión sostenible de los recursos hídricos en el bosque de Chapultepec.

PARTICIPANTES: José Avidán Bravo Jácome, Julio César Soriano Monzalvo, José Agustín Breña Naranjo, Rosario Yadira Peña Montiel, Rodrigo Roblero Hidalgo, Héctor A. Ballinas González, Margarita E. Preciado Jiménez, Yolanda Solís Alvarado, Edgar Yuri Mendoza Cazares, Carlos Gutiérrez Ojeda, Citlalli Astudillo Enríquez, Luis Alberto Bravo Inclán, José Javier Sánchez Chávez, Juan Leodegario García Rojas, Roel Simuta Champo, Luis González Hita, Blanca de Jesús Carteño Martínez, Julia E. Prince Flores, Antonio Javier García López, Minerva Sánchez Guzmán, Manuel Sánchez Zarza, Martha Avilés Flores, Armando Rivas Hernández,

Norma Hernández Cruz, Gabriela Mantilla Morales, César Guillemo Calderón Molgora, Maricarmen Espinosa Bouchot, Norma Ramírez Salinas, Lorena Castillo Rodríguez y Leticia Montellano Palacios.

El proyecto Bosque de Chapultepec: naturaleza y cultura es dirigido por la Secretaría de Cultura, y el IMTA contribuye a través del Consejo Nacional de Ciencia y Tecnología (Conacyt), con el objetivo de obtener un diagnóstico y elaborar las propuestas de las estrategias que permitan la adecuada gestión de los recursos hídricos en las cuencas de este importante bosque.

La información generada en este proyecto permite evaluar la factibilidad de las acciones que deberán emprenderse en el marco de la restauración del parque ecológico, a efecto de mejorar los servicios ecosistémicos que ofrece a sus visitantes y a la Ciudad de México (CDMX).

Para lograrlo, se hizo una visita prospectiva a la zona de estudio los días 7, 8, 9 y 26 de octubre de 2020 para el reconocimiento del terreno y de la infraestructura hidráulica, así como para la ubicación de fuentes de abastecimiento y del personal encargado en cada zona. También se descargaron y analizaron los volúmenes concesionados de aguas superficiales y subterráneas del Registro Público de Derechos del Agua (Repda) para la determinación de la oferta de agua y se construyó un modelo hidrológico de simulación continuo (diario) y se cuantificaron las demandas de agua en la zona.

Asimismo, se ubicaron los cruces vehiculares, la infraestructura hidráulica y el personal encargado en cada zona. Se realizó también la caracterización fisiográfica y climática de la zona de estudio. Se construyeron cuatro modelos hidrodinámicos bidimensionales que incluyen las cuencas de aportación al polígono del bosque de
Chapultepec, los cuales cuentan con un nivel de detalle topográfico de alta resolución en el que actualmente se encuentran simulándose las avenidas de diseño en análisis.

Además, se identificaron los sitios para muestreo geofísico y de infiltración y se ha recopilado y analizado la información disponible y de estudios previos. Se gestionaron los permisos ante la Secretaría del Medio Ambiente de la CDMX y el Instituto Nacional de Antropología e Historia para realizar las pruebas de infiltración y geofísica en la zona.

En materia de calidad del agua, se seleccionaron los sitios para muestreo, y se ubicaron las descargas, plantas de tratamiento de aguas residuales y accesos a los sitios. el plan de muestreo se ejecutará en 2021.

Este proyecto representa un cambio en el paradigma en la gestión integrada de los recursos hídricos, ya que se prevé la detonación de un proceso de planeación participativa interinstitucional que parta de la generación de bases de datos y del mapeo necesario para realizar el diagnóstico actual de los recursos hídricos en el bosque de Chapultepec, con el fin de proponer las medidas que permitan la gestión sustentable de los recursos hídricos de forma integral a nivel de cuenca y su preservación, a efecto de que se contribuya al desarrollo ambiental, cultural, económico y social del parque ecológico. 


\subsection{MESETA P'URHÉPECHA}

\footnotetext{
览

En colaboración con la Comisión Nacional Forestal, el IMTA participa en el diseño e implementación de una estrategia para mejorar las condiciones ambientales, sociales y económicas de los pobladores de la meseta P'urhépecha, en Michoacán.
}

PARTICIPANTES: José Agustín Breña Naranjo, Mayrén Alavez Vargas y Raúl Medina Mendoza.

La meseta P'urépecha se ubica al centro-oeste del esta-do de Michoacán, con una alta presencia de población indígena (P'urhépecha) y un régimen de propiedad comunal que presenta un legado de organización agraria.

Esta región registra una importante pérdida de cobertura forestal que ha provocado una fuerte modificación del flujo hidrológico, debido a la menor infiltración y a la mayor demanda de agua originada por el crecimiento poblacional y el incremento significativo de las huertas de aguacate y las alteraciones que de ello derivan.

Durante 2020 se trabajó en la definición del problema, que desde la perspectiva ambiental y social considera las siguientes dimensiones:

- La disponibilidad de agua para consumo humano en las poblaciones ha disminuido considerablemente y ha aumentado la contaminación de los mantos freáticos por el uso intensivo de agroquímicos, en especial por el incremento de las plantaciones de aguacate.

- La cobertura forestal ha sido afectada considerablemente por el cambio de uso de suelo, provocando degradación forestal, pérdida de servicios ecosistémicos y afectación de la biodiversidad.

- El desempleo y la migración en los núcleos agrarios (comunidades indígenas) fomentan el deterioro de la cohesión interna y las estructuras organizativas de la propiedad comunal sobre los recursos naturales.

La implementación de esta estrategia interinstitucional iniciará en los siguientes años, y se considera una oportunidad para revertir los procesos de degradación en la región, con la premisa del manejo integrado del territorio y con la participación y empoderamiento de las comunidades, gobiernos locales e instituciones del sector ambiental (Conafor, IMTA, Dirección General de Agroecología y Patrimonio Biocultural-Semarnat) y la Secretaría de Agricultura y Desarrollo Rural (Sader).

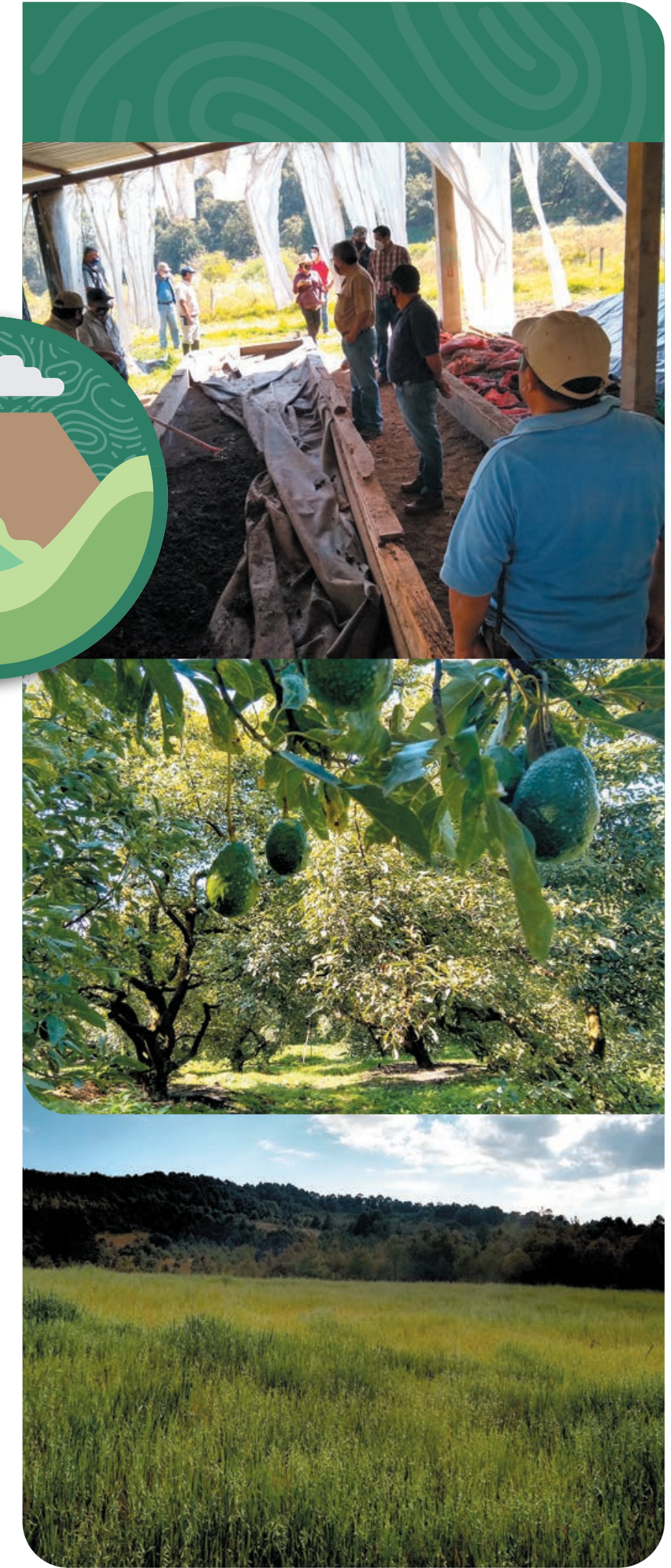




\subsection{RESTAURACIÓN ECOLÓGICA: PRESA ENDHÓ}

览

Contribuimos a la restauración ecológica de la presa Endhó a través de una estrategia para mejorar la calidad del agua en este cuerpo de agua, que incluye la aplicación de un adsorbente selectivo de fósforo para su saneamiento gradual.

PARTICIPANTES: Anne M. Hansen, José Agustín Breña Naranjo, Carlos Gutiérrez Ojeda, Rubén Antelmo Morales Pérez, Juan Gabriel García Maldonado, Luis Alberto Bravo Inclán, Marco Antonio Mijangos Carro, Denise Freitas Soares de Moraes y Roberto Romero Pérez.

A través del proyecto Dimensión del mejoramiento de la calidad del agua de la presa Endhó, Hidalgo, el IMTA contribuye en dimensionar el mejoramiento de la calidad del agua en esta presa.

La cuenca hidrológica de la presa Endhó pertenece a la Región Hidrológica Núm. 26 Pánuco, que se extiende desde el valle de México hasta su desembocadura en el golfo de México. Se localiza dentro de los límites de la Región Hidrológica Administrativa Núm. XIII, Subregión Tula, administrada por el Organismo de Cuenca Aguas del Valle de México (OCAVM). La extensión territorial de esta cuenca es de aproximadamente 1,266 km² y abarca parte de Hidalgo y el Estado de México.

La mala calidad del agua en la presa Endhó es causada por las entradas de agua residual provenientes del valle de México, de la subcuenca del río Tepeji y de la cuenca propia, así como de la producción de biomasa dentro de la presa, que juntos resultan en la acumulación de sólidos, nutrientes y sustancias que demandan oxígeno. El resultado de estas cargas contaminantes es agua altamente contaminada, con mal olor, crecimiento excesivo de algas y presencia de insectos nocivos.
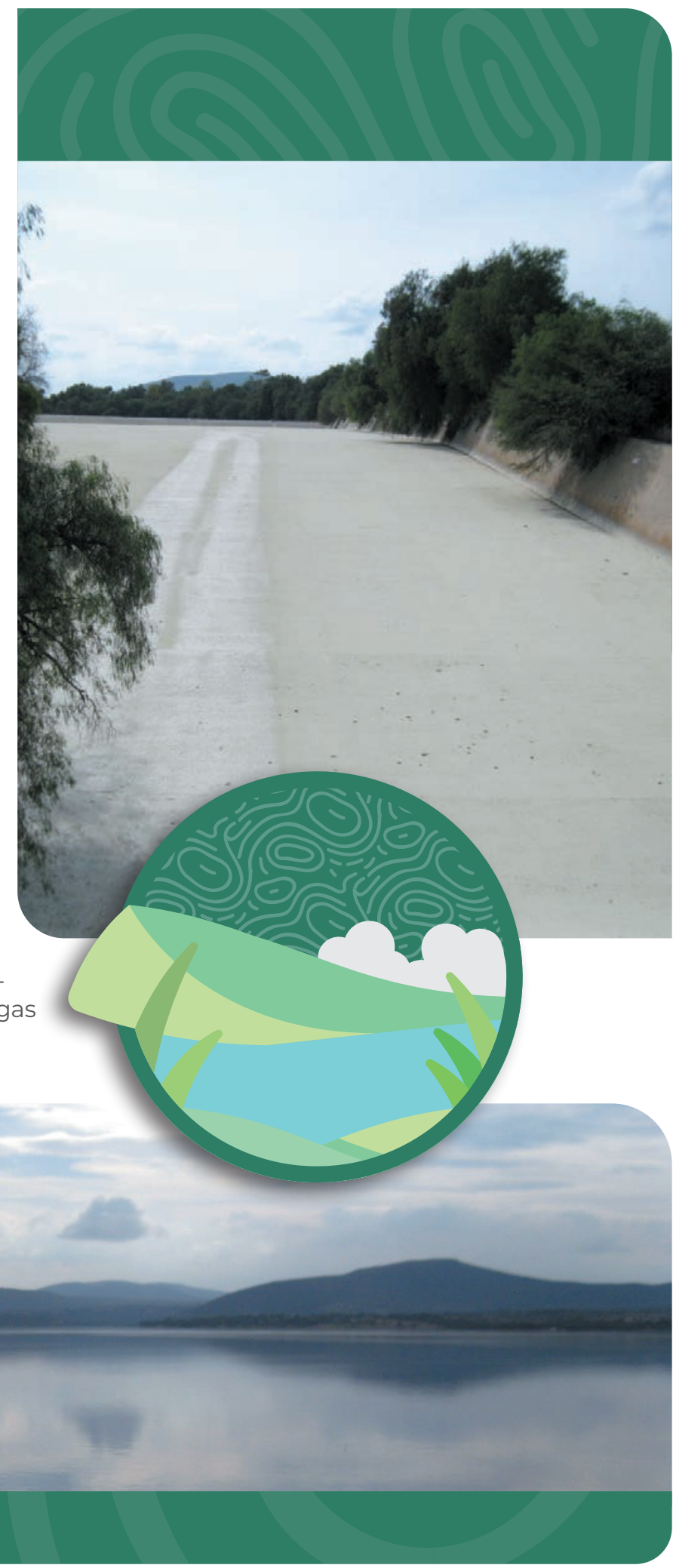
En 2020 se determinaron las velocidades de entrada, salida y acumulación de contaminantes en la presa Endhó y se desarrollaron los modelos de balance de fósforo y oxígeno y su demanda, así como la combinación de ambos. Se evaluaron diferentes escenarios de saneamiento. Asimismo, mediante análisis de la norma NOM-001-SEMARNAT-1996, se muestra que los límites para descarga de agua residual en nuestro país son mayores a los establecidos en otros países, y permiten descargas con concentraciones más elevadas que las que pueden asimilar los cuerpos de agua. También se debe considerar el caudal de agua residual sin tratamiento que se recibe del valle de México que, aun si se tratara antes de llegar a la presa Endhó, no sería suficiente para controlar la contaminación en el cuerpo de agua, por lo que es indispensable tratar toda el agua residual que llega a la presa Endhó de manera que remueva al menos 95 \% de las cargas contaminantes y, al mismo tiempo, deben aplicarse tecnologías de oxigenación y de control de fósforo dentro del cuerpo de agua.

Se identificaron los informantes clave entre actores sociales e institucionales de los tres niveles de gobierno. Se desarrollaron y se aplicaron los instrumentos de recopilación de información a los actores identificados vía electrónica y telefónica. Se cuestionó a los actores si estarían interesados en participar en algunas actividades del proyecto, a lo que el $94 \%$ respondió afirmativamente, y solo el 6 \% señaló que no podía colaborar.

El diagnóstico de la percepción del saneamiento de la presa Endhó por parte de actores sociales contempla la obtención de datos desde dos fuentes de información: a) entrevistas a actores institucionales y encuestas a pobladores ribereños afectados por la contaminación y b) talleres grupales con pobladores, líderes y organizaciones sociales de la presa Endhó. Continúa pendiente la impartición de los talleres participativos con pobladores, líderes y organizaciones locales, hasta no contar con las condiciones sanitarias que permitan reuniones grupales (de manera presencial) en la zona de estudio u otra estrategia que permita su ejecución sin poner en riesgo a los participantes.

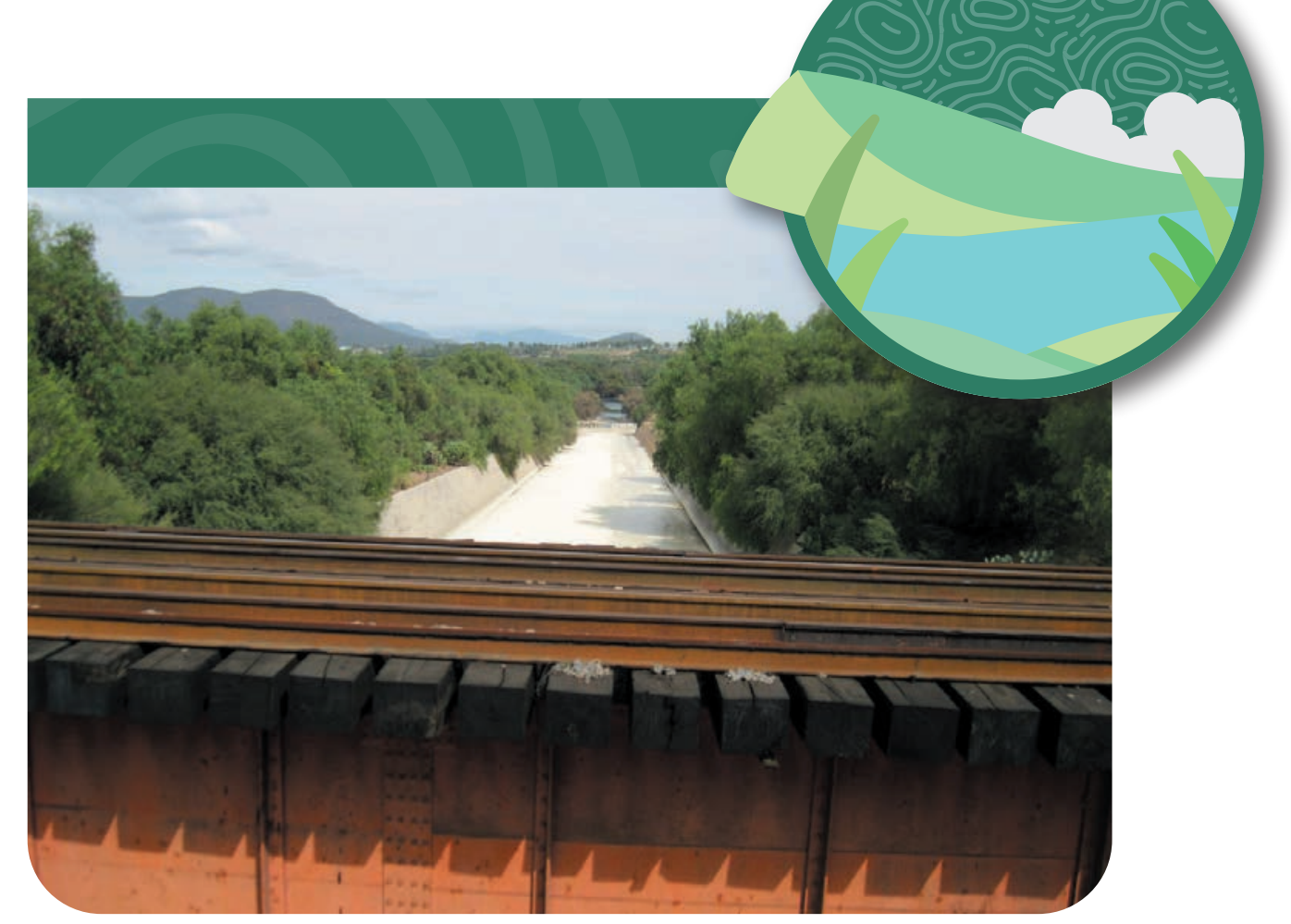




\subsection{MONITOREO DE PARÁMETROS AMBIENTALES}

) En el IMTA nos hemos propuesto generar tecnología propia que permita abatir costos y generar independencia. En 2020 se logró desarrollar un sistema de bajo costo para el monitoreo permanente de parámetros ambientales y de calidad del agua para probarlo en el río Cuautla, y con ello brindar una línea base del entorno ambiental asociado a la operación de la termoeléctrica.

PARTICIPANTES: Rodrigo Ulises Santos Téllez, José Javier Sánchez Chávez, Fernando Flores Prior y Jorge Luis Izurieta Dávila.

El trabajo de monitoreo de parámetros de calidad del agua en ríos y embalses se lleva a cabo de manera puntual. Con la disponibilidad actual de diferentes opciones de sensores, con los avances en materia de sistemas de adquisición de datos y su trasmisión, es posible ofrecer alternativas económicas para llevar a cabo el monitoreo continuo de estas variables ambientales, utilizando desarrollos propios que permitan hacer eficientes los recursos y ampliar la cobertura de sitios, que con opciones comerciales resultaría oneroso.

El IMTA trabajó para implementar un sistema de monitoreo continuo de parámetros de campo y nivel, y su ubicación en un sitio a seleccionar, que permita conocer en el tiempo los rangos de variación de los parámetros ambientales en el sitio, así como el desarrollo de una aplicación para la consulta de la información en tiempo real.

El equipo logró construir un prototipo del dispositivo para medición de parámetros en tiempo real, integrado con una tarjeta programable Electrón, y seis sensores para la medición de variables físicas y de calidad del agua. La tarjeta Electrón recopila la información de los sensores, la transmite a la base de datos en internet y la guarda en una tarjeta micro SD.

El dispositivo de medición de calidad de agua está compuesto por una cápsula que da soporte y protección a los sensores y a una tarjeta PCB diseñada para interconectar los componentes electrónicos.

También se desarrolló una aplicación web para la consulta de la información generada por los sensores en tiempo real. De esta manera se cuenta con un desarrollo institucional que permite el monitoreo de parámetros ambientales y la trasmisión de información a una plataforma web, evaluando diferentes marcas de sensores para proponer las mejores soluciones de bajo costo y extender así el monitoreo en diferentes cuerpos de agua del país.

\section{APLICACIÓN WEB}

\section{PARA LA CONSULTA DE LA INFORMACIÓN GENERADA POR LOS SENSORES}

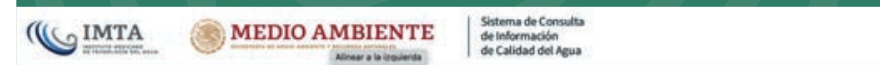

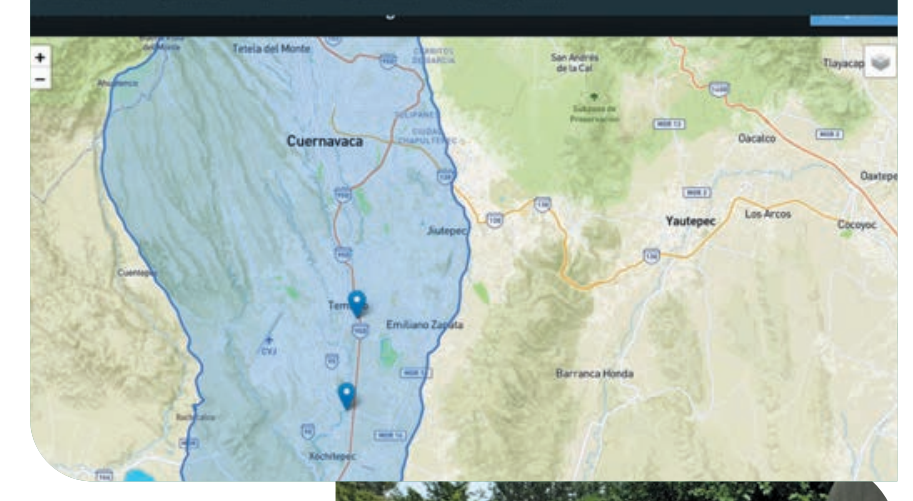

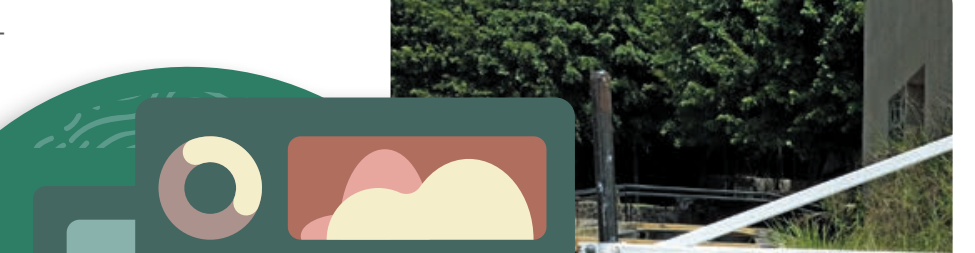




\subsection{INFRAESTRUCTURA VERDE}

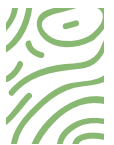
La naturaleza ofrece soluciones a los problemas de degradación ambiental y se reconocen como medidas sostenibles, de fácil implantación, bajo costo y que pueden ayudar en el control de escorrentías e inundaciones y en el saneamiento.

PARTICIPANTES: Oscar Jesús Llaguno Guilberto, José Manuel Rodríguez Varela, Juan Maldonado Silvestre, Rodrigo Ulises Santos Téllez, Raúl Medina Mendoza, Gerardo Ortiz Flores, Alberto González Sánchez y Ronald Ontiveros Capurata.

Con la finalidad de aportar a la elaboración de una propuesta de diseño de infraestructura verde que se pueda construir dentro del IMTA, en 2020 se realizó el estado del arte sobre la infraestructura verde, dando una perspectiva general y proveyendo de ideas para comprender el término.

En ese sentido, se realizó una consulta bibliografía del estado del arte para conocer las diferentes estructuras de bajo impacto que se han desarrollado e implementado como infraestructura verde.

\section{DENTRO DEL IMTA, EN 2020}

SE REALIZÓ EL ESTADO DEL ARTE SOBRE LA INFRAESTRUCTURA VERDE, DANDO UNA PERSPECTIVA GENERAL Y PROVEYENDO DE IDEAS PARA COMPRENDER EL TÉRMINO.

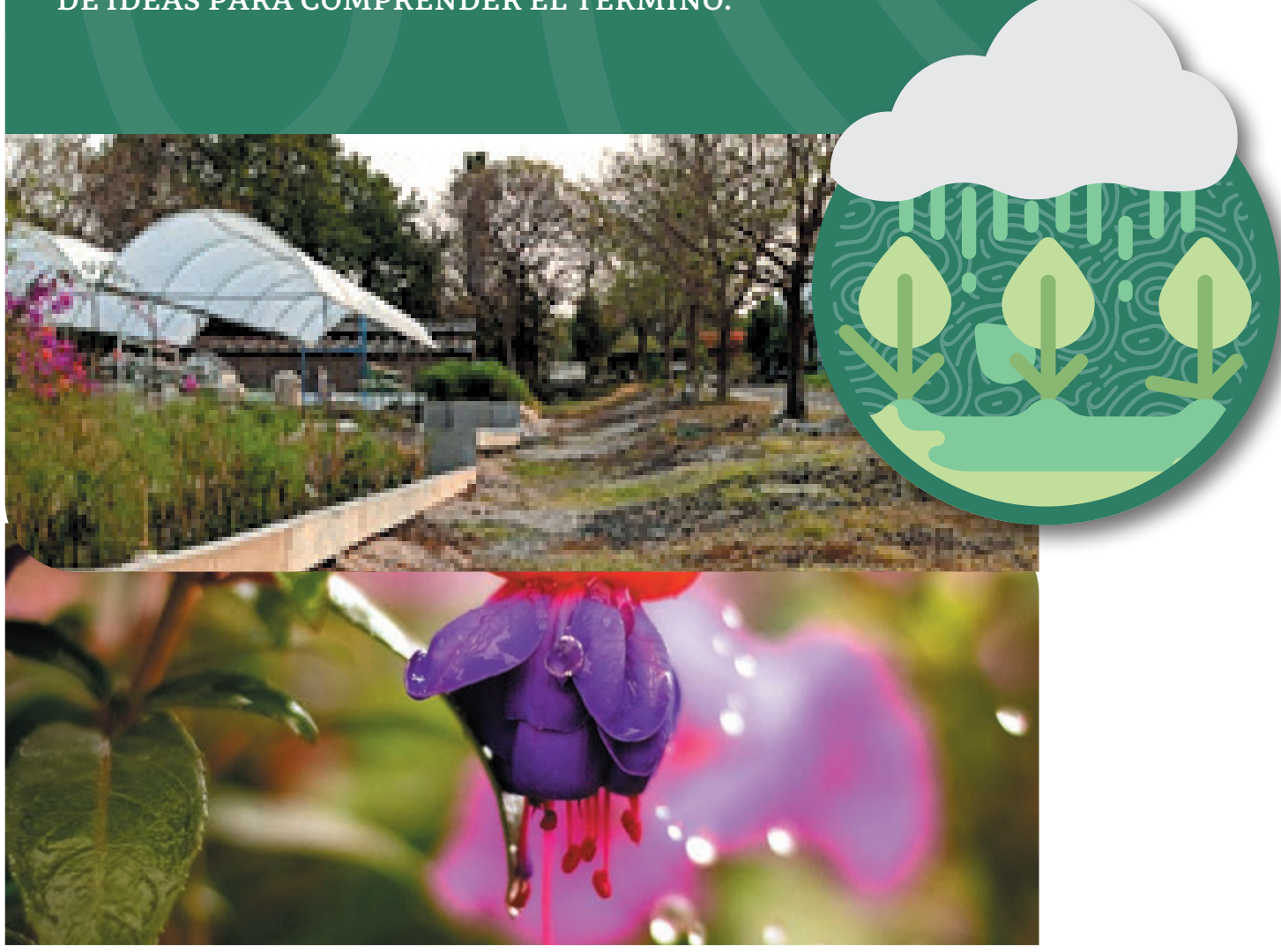


Se presentó un caso de estudio dentro de las instalaciones del IMTA, donde se realizó el análisis geohidrológico, hidrológico e hidráulico para la implementación de una infraestructura verde en el que se estudió la construcción de un jardín de lluvia. También se estableció que la dirección de los flujos de agua subterránea es en dirección norte a sur, con base en el análisis de aguas subterráneas. En la parte hidrológica se estimaron avenidas y lluvias de diseño para diferentes escenarios y el impacto que tendría en el IMTA, y se elaboraron fichas de árboles nativos del estado de Morelos que pueden utilizarse en algún tipo de infraestructura verde.

La implementación de infraestructura verde permite lograr un control de contaminación de fuentes no puntuales mediante la restauración del ambiente natural, ahorros energéticos, mejora de la calidad del aire, enriquecimiento de la biodiversidad, reducción de emisiones de gases efecto invernadero, reducción del efecto de la isla de calor urbana y mejora de la calidad de vida en la comunidad, así como mitigación de los riesgos de inundación y elevación de su adaptabilidad a los nuevos estresores que surjan en el futuro.
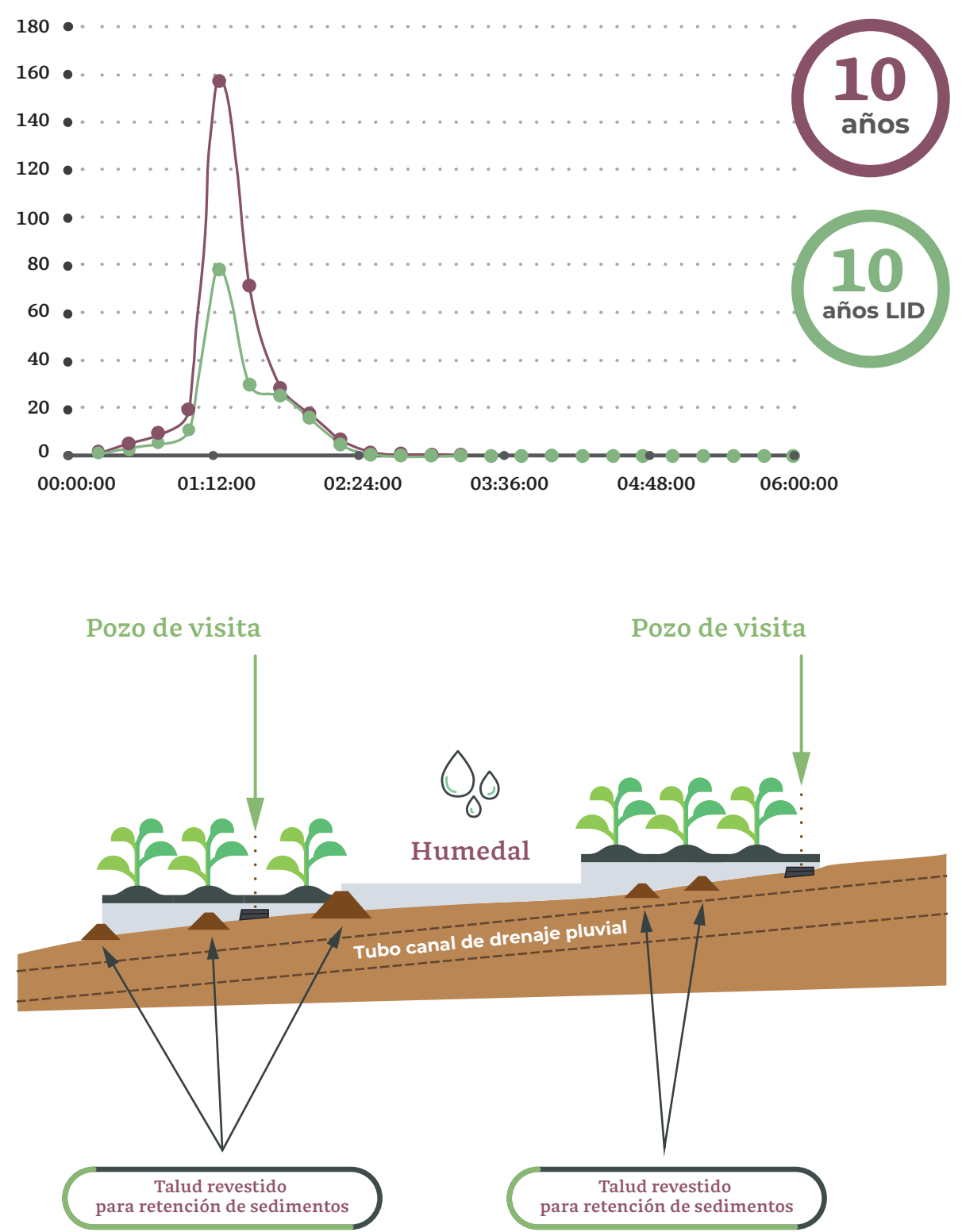



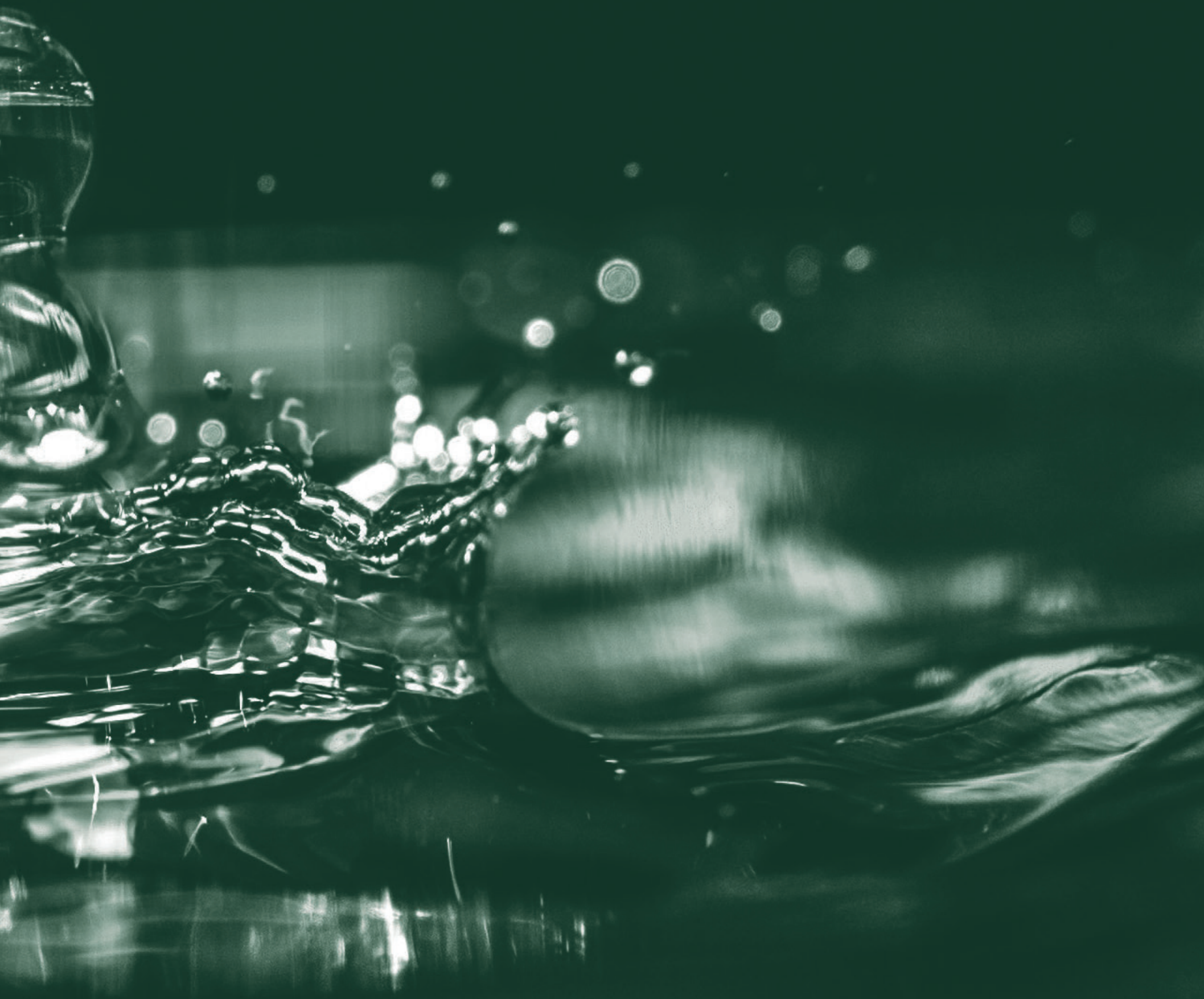




\section{IMTA TRANSVERSAL}

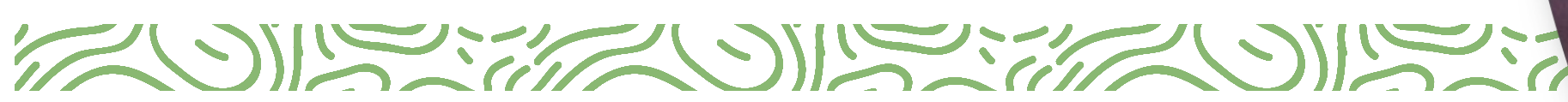
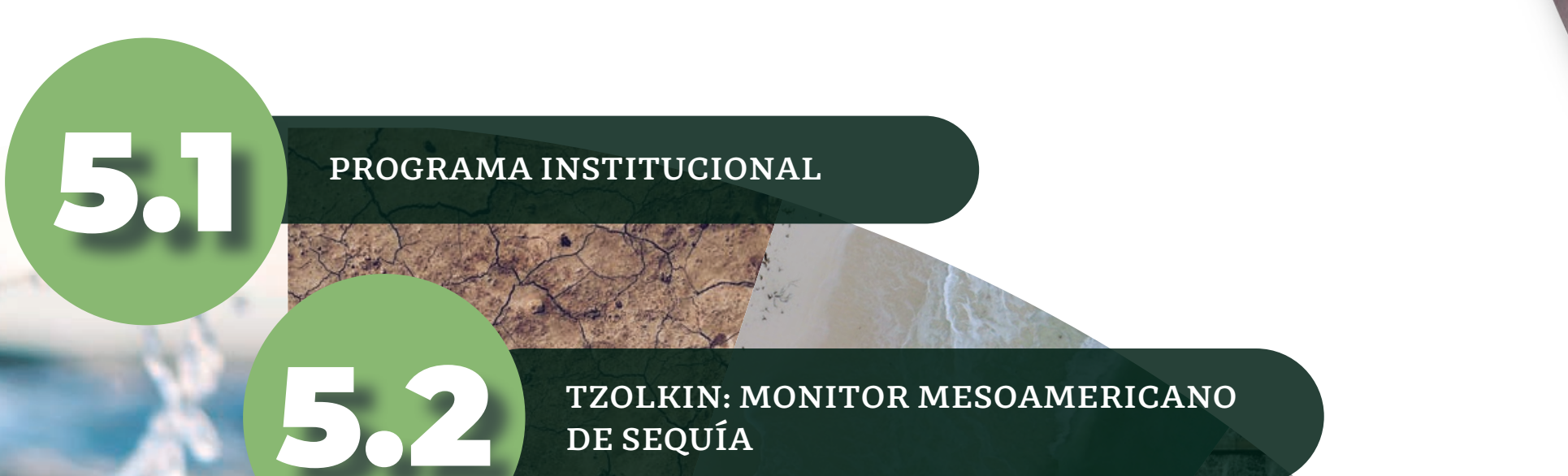
DE SEQUÍA

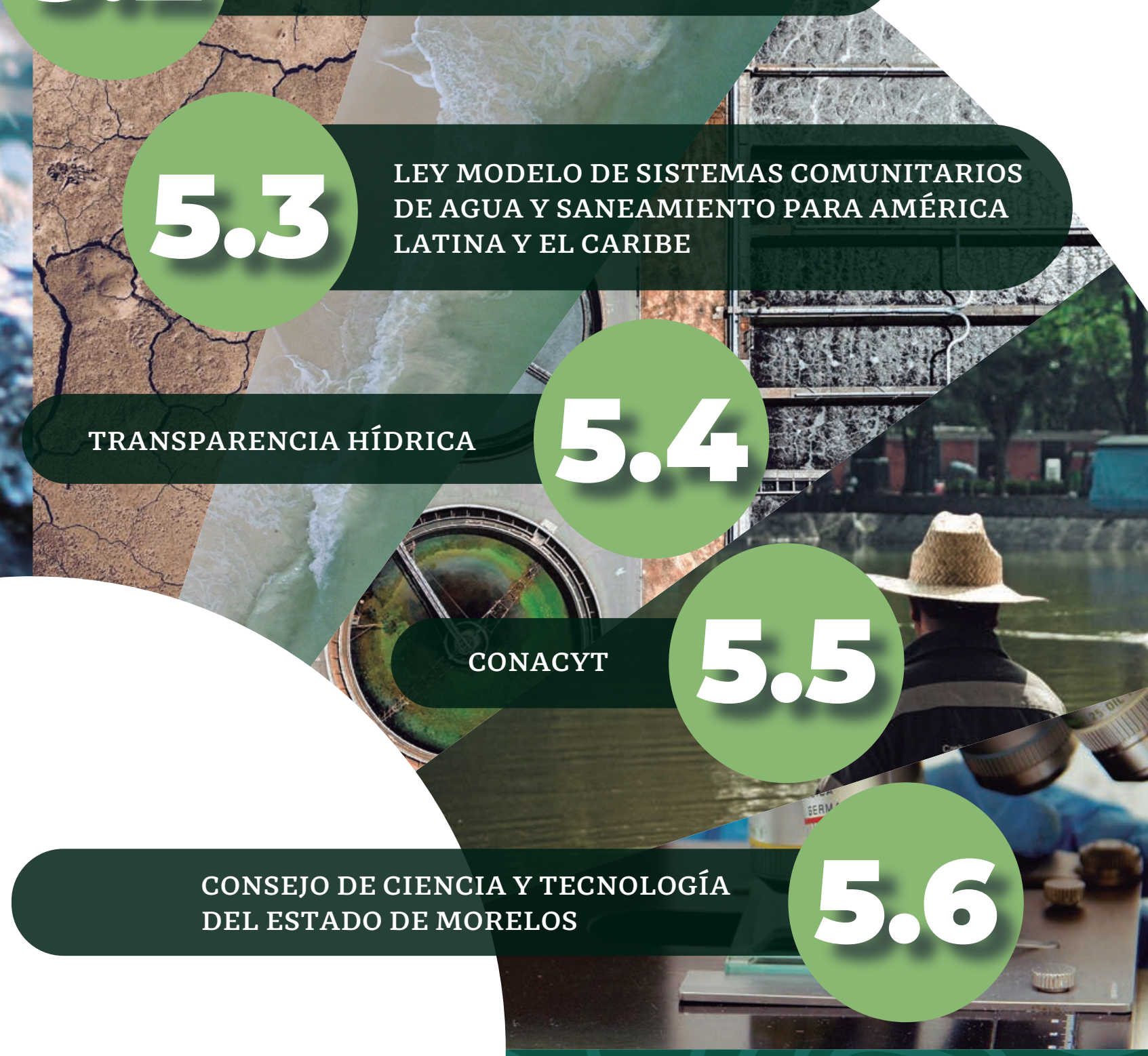




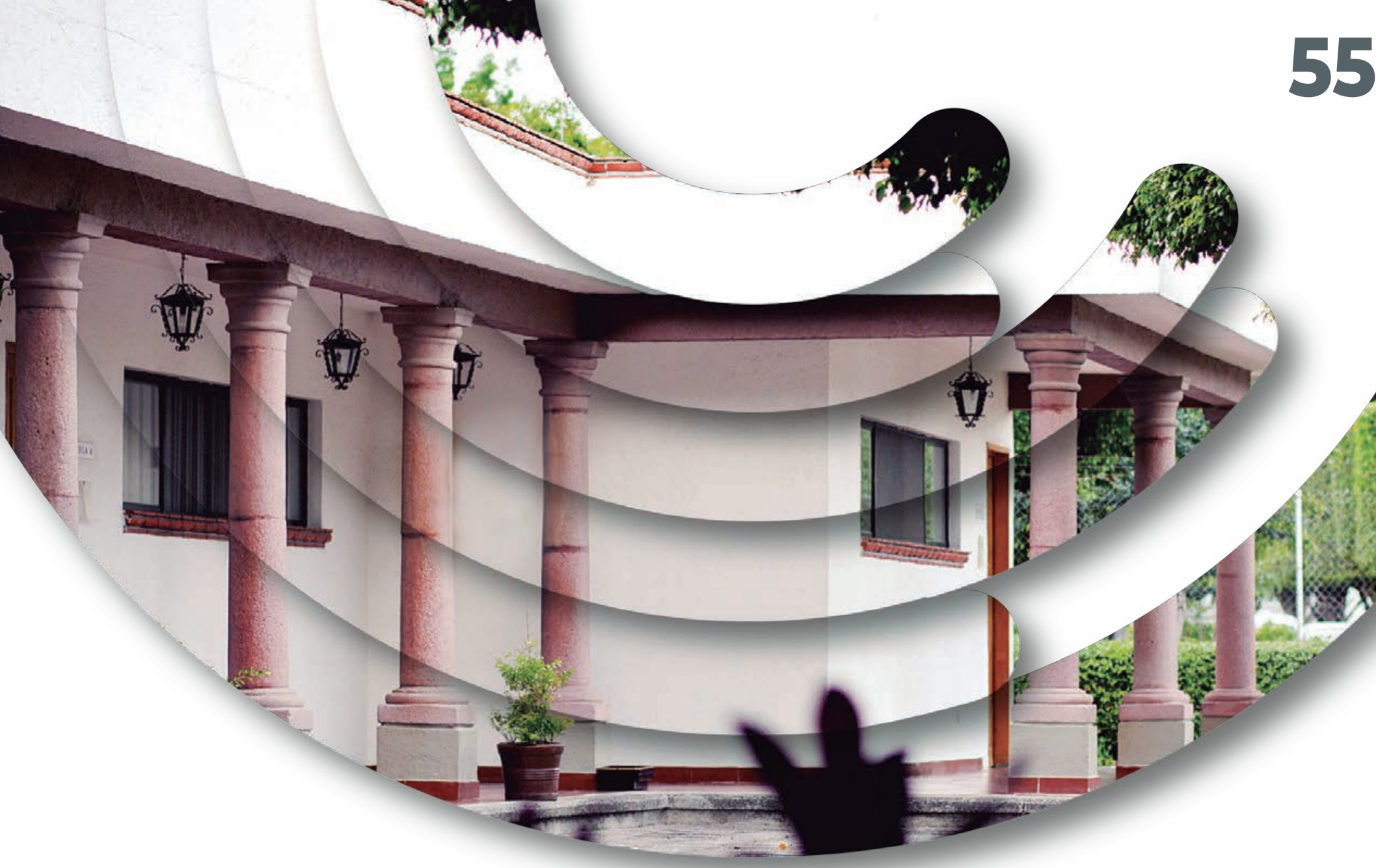

EN EL INSTITUTO SABEMOS QUE SUMANDO esfuerzos alcanzaremos mejores resultados en el manejo, la conservación y la rehabilitación del agua en México, gracias al trabajo sostenido que hemos realizado para fortalecer nuestra colaboración con las instancias que comparten este mismo objetivo: el sector ambiental, el gobierno federal, las instituciones académicas, las organizaciones de la sociedad civil y sector privado.

EI IMTA está comprometido con la construcción colectiva de soluciones, fundamentadas en principios éticos, que fortalezcan la vida y el bienestar de todos (sociedad, empresas y gobierno) y apoyen la toma de decisiones con base en evidencia científica, información transparente y rendición de cuentas.

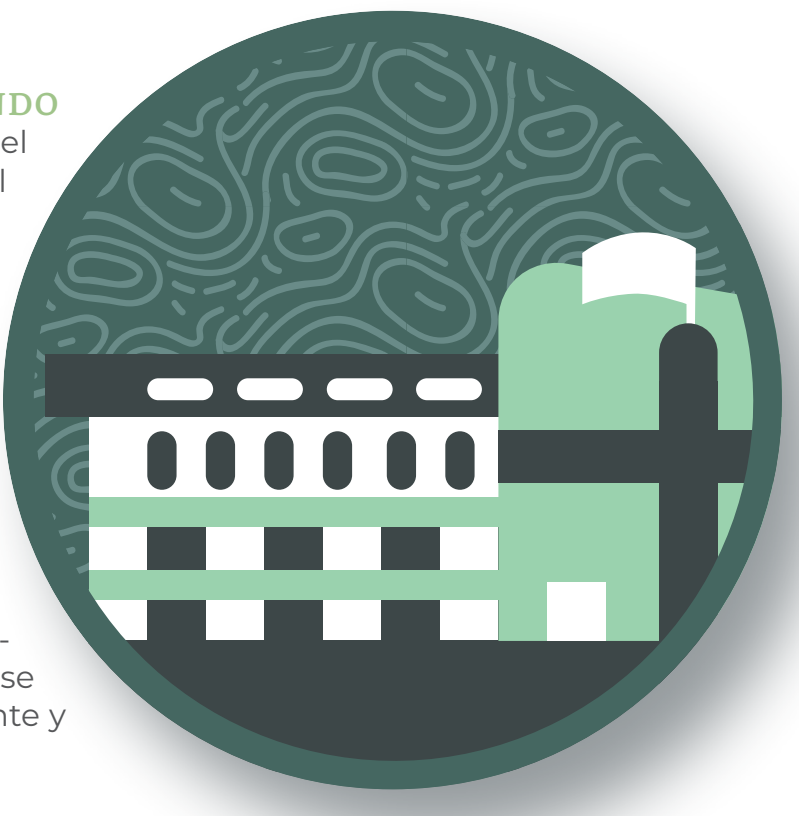




\section{IMTA}

\section{TRANSVERSAL}

\section{Programa Institucional}

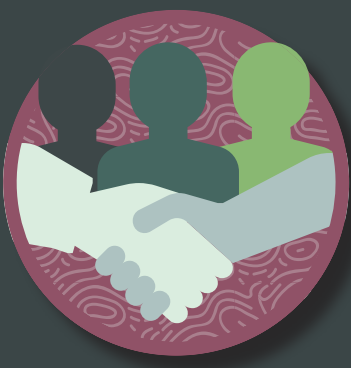

Propone una nueva visión en cuanto a su organización y objetivos de su trabajo. Las opiniones y propuestas de su comunidad se incorporaron en la definición de objetivos, estrategias y líneas de acción.

\section{Conacyt}

Durante 2020 se acordaron 13 proyectos financiados con fondos del Conacyt.
10

$\circ \bullet$

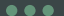

\section{Tzolkin}

Herramienta de acceso libre para Mesoamérica, cuyo objetivo es contribuir a la seguridad alimentaria y el manejo de información de sequías.

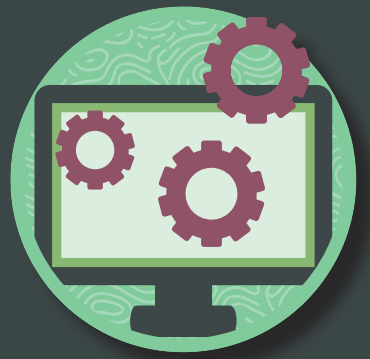

Ley Modelo de Sistemas

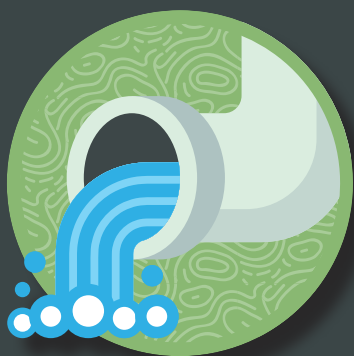
Comunitarios de Agua y Saneamiento

Propuesta que permita cerrar las brechas de desigualdad y sentar las bases de un marco jurídico para los países de Latinoamérica y el Caribe.

\section{Transparencia hídrica}

Espacio para la discusión rigurosa sobre el acceso a la información, la transparencia y la rendición de cuentas en relación con el agua.

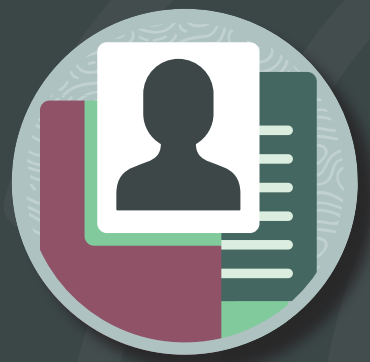

\section{Consejo de Ciencia y Tecnología}

Convenio entre el IMTA y el Consejo de Ciencia y Tecnología del Estado de Morelos para impulsar el desarrollo, la ciencia, la tecnología y la divulgación del conocimiento.

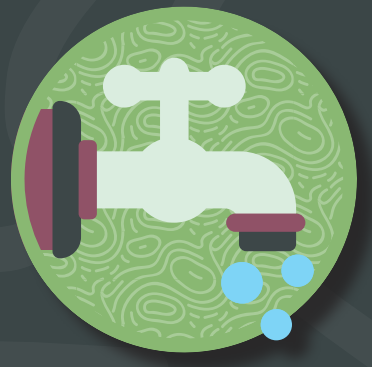

El IMTA está comprometido con la construcción colectiva de soluciones fundamentadas en principios éticos que fortalezcan la vida y el bienestar de todos. 


\subsection{PROGRAMA INSTITUCIONAL}

El Programa Institucional del IMTA emana del Programa Sectorial de Medio Ambiente y Recursos Naturales 2020-2024 (Promarnat), derivado, a su vez, del Plan Nacional de Desarrollo 2019-2024 (PND). La comunidad del Instituto, en colaboración con la Comisión Nacional del Agua (Conagua), organizó el 16 de julio de 2019 el foro Programa Nacional Hídrico 2019-2024: Ciencia y Tecnología como Eje Transversal y participó en los foros regionales de consulta sobre el PND, organizados en agosto de 2019, por la Secretaría de Medio Ambiente y Recursos Naturales (Semarnat).

Durante el 2020, el IMTA concluyó la elaboración de su Programa Institucional, que propone una nueva visión en cuanto a su organización y a los objetivos de su trabajo. Para ello se realizó una consulta interna con el fin de conocer las opiniones y propuestas de su comunidad, mismas que se incorporaron en la definición de objetivos, estrategias y líneas de acción.

Se espera la aprobación del Programa Institucional del IMTA por parte de su Órgano de Gobierno en la primera sesión ordinaria de 2021 y su posterior publicación en el Diario Oficial de la Federación.
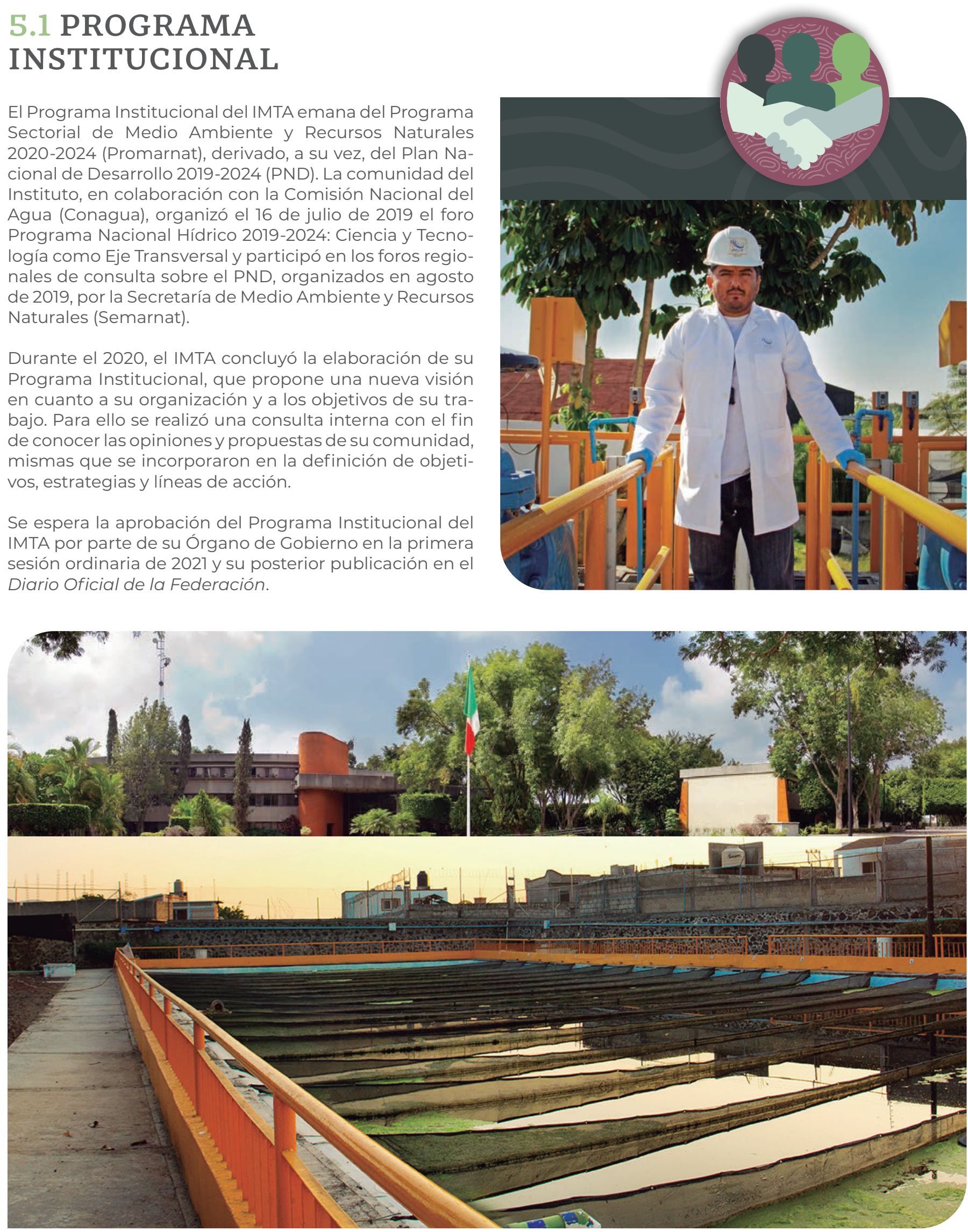


\subsection{TZOLKIN: MONITOR MESOAMERICANO DE SEQUÍA}

El Instituto Mexicano de Tecnología del Agua, con apoyo de la Agencia Mexicana de Cooperación Internacional para el Desarrollo y la Organización de las Naciones Unidas para la Alimentación y la Agricultura, construyó la herramienta Tzolkin, de acceso libre y abierto para Mesoamérica, cuyo objetivo es contribuir a la seguridad alimentaria de la región mediante la disponibilidad y el manejo de información diversa para la caracterización de sequías y con ello apoyar la toma de decisiones encaminadas a reducir los riesgos asociados a este fenómeno hidrometeorológico.

La sequía que, entre otras regiones del mundo, afecta a Centroamérica, especialmente a las zonas asociadas al corredor seco (principalmente Guatemala, El Salvador, Nicaragua y Honduras) amenaza la producción de cultivos como el maíz y el frijol, base de la alimentación de la población en situación de pobreza. En este contexto, mejorar el monitoreo y caracterización de la sequía permitirá disminuir sus consecuencias.

Tzolkin es una palabra maya que significa "la cuenta ordenada de los días", versión del ciclo sagrado de esa población ancestral utilizado en la Mesoamérica precolombina, entre otras finalidades, para la calendarización del cultivo del maíz.

Esta herramienta de consulta en línea se encuentra disponible en: http:// galileo.imta.mx/Sequias, presenta datos de precipitación, humedad de suelo y escurrimiento de la base de datos MERRA-2 (Modern-Era Retrospective Analysis for Research and Applications versión 2 (MERRA-2; Rienecker, et al., 2011) y calcula los siguientes índices:

- índice estandarizado de precipitación (SPI)

- índice estandarizado de humedad del suelo (SSI)

- índice estandarizado de escurrimiento (SRI)

- índice estandarizado multivariado de precipitación y humedad del suelo (MSDI-PreSMo)

- índice estandarizado multivariado de precipitación y escurrimiento (MSDI-PreRun)

- índice estandarizado multivariado de precipitación, humedad del suelo y escurrimiento (MSDI-PreSMoRun)

Estos índices pueden visualizarse mediante mapas georreferenciados. Las escalas temporales disponibles son de 1, 3, 6, 9 y 12 meses, lo que ayuda a identificar la proporción de los periodos secos. Además, se pueden realizar consultas dinámicas de series de tiempo de intensidad, magnitud de sequía y porcentaje de área afectada para cada país de Mesoamérica.

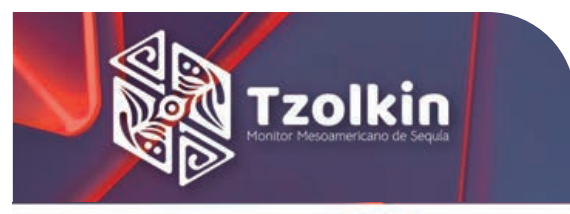

Gráfica

Seleccione una característica del índice MSDla a graficar $\%$ de Área afectada

\begin{tabular}{|l|l|l}
\hline División politica & Administración del Agua & Hidrografia
\end{tabular}

Seleccione un País

México

Seleccione un Estado de México

Todo México

Cargar grafica
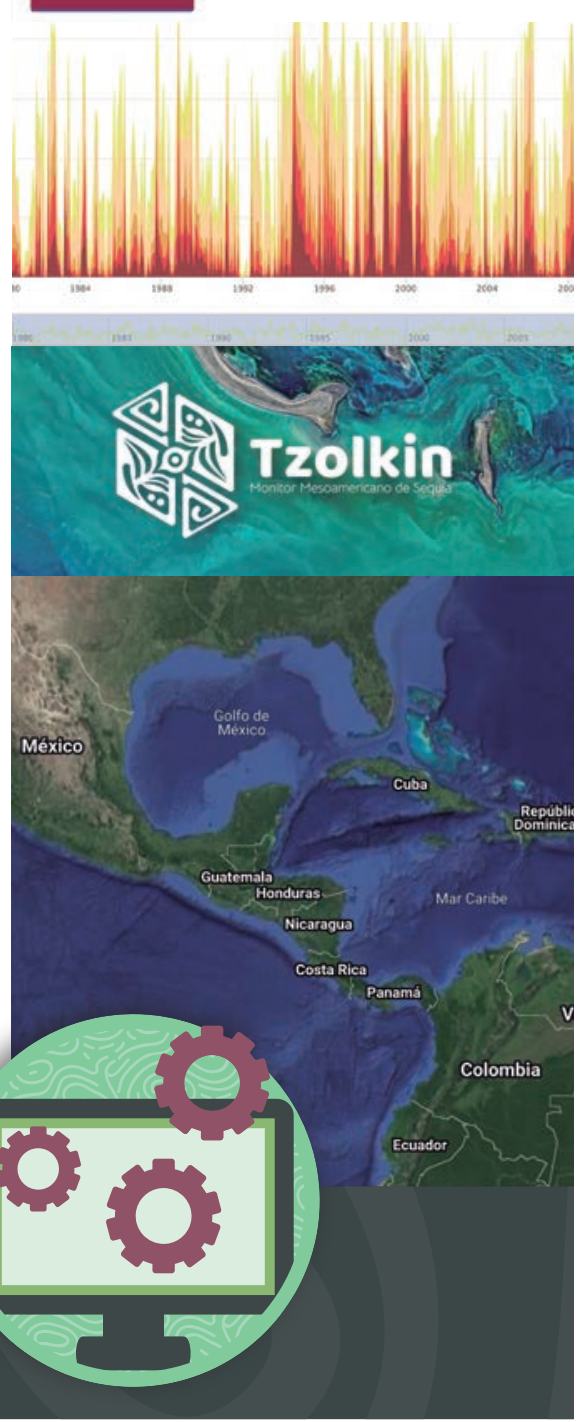
5.3 LEY MODELO DE SISTEMAS COMUNITARIOS DE AGUA Y SANEAMIENTO PARA AMÉRICA LATINA Y EL CARIBE

El IMTA presentó al Parlamento Latinoamericano una propuesta, con sustento sociotécnico, de una Ley Modelo de Sistemas Comunitarios de Agua y Saneamiento que permita cerrar las brechas de desigualdad y sentar las bases de un marco jurídico para los países de Latinoamérica y el Caribe.

En esta labor internacional inédita, el IMTA, en colaboración con el Frente Parlamentario Contra el Hambre, la Amexcid y el apoyo de la FAO, proporcionó apoyo técnico a las reuniones y consultas del Frente Parlamentario Contra el Hambre, Capítulo México, para diseñar la propuesta de ley. Con ello, México se coloca al frente del cierre de brechas de desigualdad regionales.

La recepción positiva de la propuesta permite reconocer, dentro del marco jurídico, la posibilidad de que pequeñas comunidades se organicen para garantizar su acceso al agua y al saneamiento.

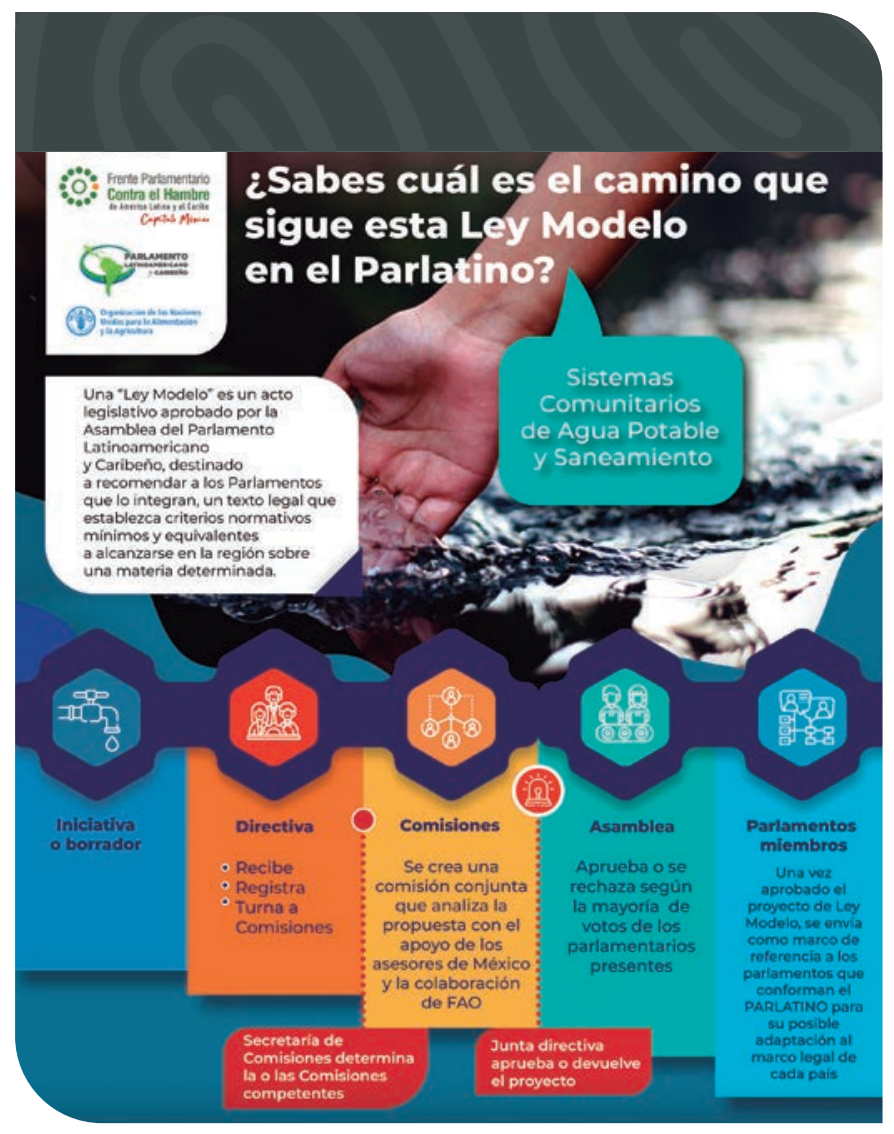

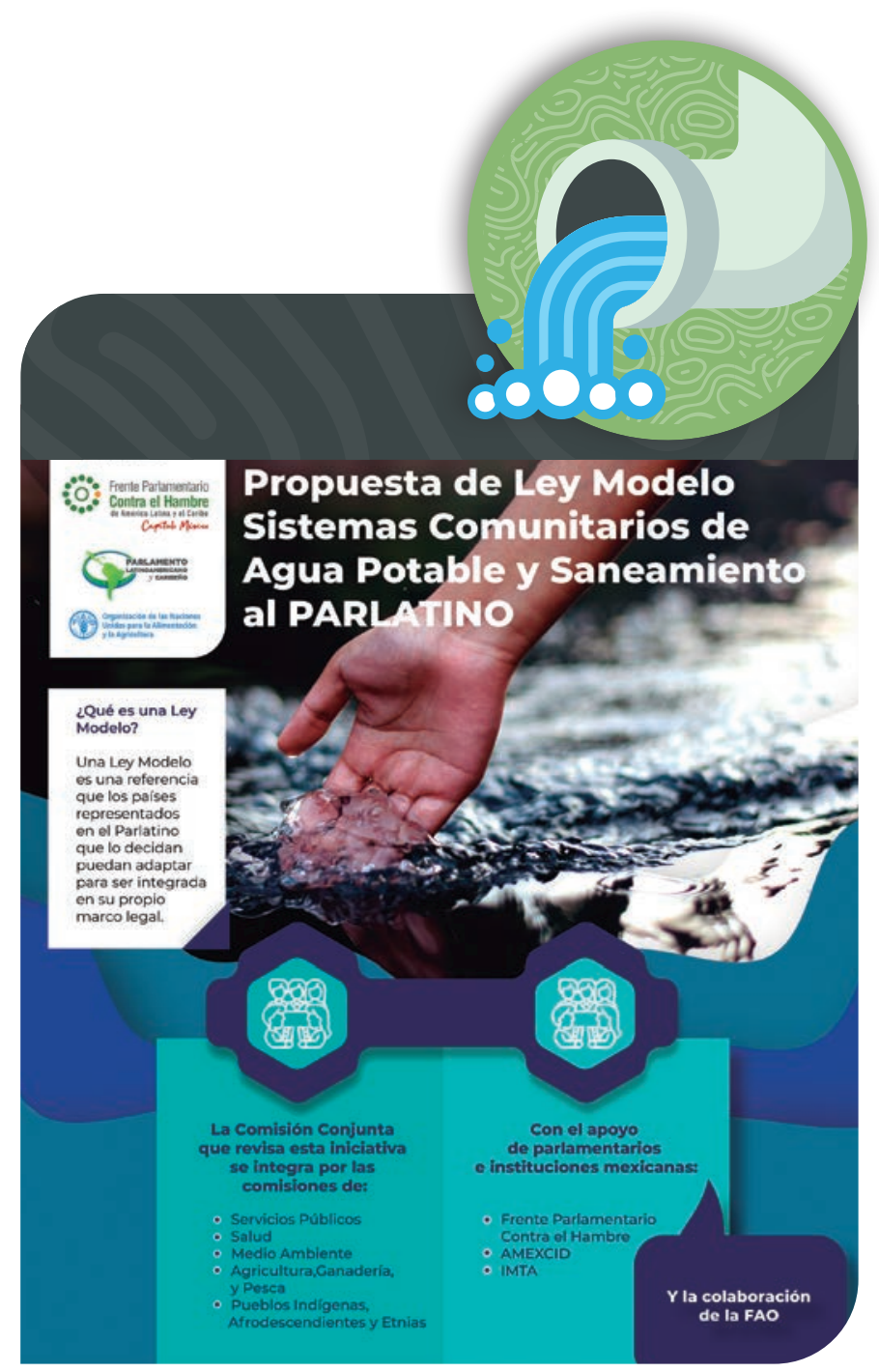

La Ley Modelo de Sistemas Comunitarios de Agua y Saneamiento reconoce los sistemas comunitarios de agua y saneamiento y la necesidad de ayudarlos a realizar una gestión eficiente. Asimismo, establece reglas para su operación y considera la posibilidad de que las comunidades sean responsables del servicio de agua potable local y de garantizar el recurso a sus miembros.

Destaca también el reconocimiento al derecho de los pueblos y las comunidades indígenas y equiparables sobre las aguas de los territorios que habitan y fomenta la participación responsable, informada y organizada de la sociedad para garantizar la disponibilidad y una buena calidad del agua en el presente y para las futuras generaciones.

Se espera que la Ley Modelo de Sistemas Comunitarios de Agua y Saneamiento, con apoyo de México y la FAO, sea aprobada en los primeros meses del 2021. 


\subsection{TRANSPARENCIA HÍDRICA}

Con el objetivo de habilitar un espacio para la discusión rigurosa sobre el acceso a la información, la transparencia y la rendición de cuentas en relación con el agua y así contribuir a la formación de un gobierno abierto, se realizaron, en colaboración con Oxfam México, las acciones siguientes:

- Un seminario interdisciplinario con la participación de académicos, organizaciones de la sociedad civil, periodistas y especialistas en el tema.

- La Semana de la Transparencia Hídrica, la cual logró convocar a más de 400 personas, contó con más de 15 horas de transmisión y los videos de la transmisión suman más de 6 mil reproducciones (corte al 1 de diciembre).

- La transferencia de un Sistema de Información Geográfica sobre concesiones y agua, que coadyuva al entendimiento del tema.

En este proyecto, además de Oxfam México, participan Causa Natura, A.C.; Proyecto Poder, A.C.; Fan Mex; Contralínea; Animal Político; El Colegio de San Luis, y Flor y Canto, A.C.

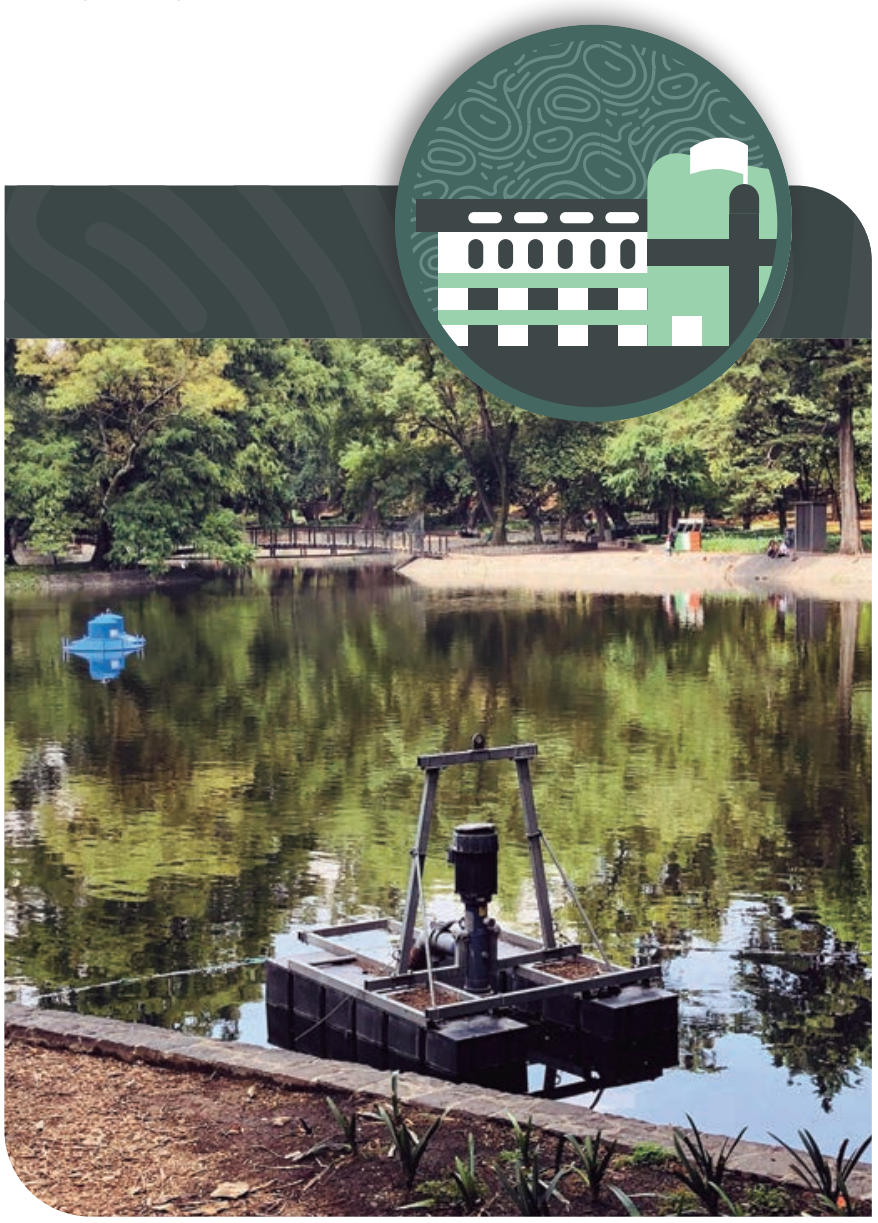

\subsection{CONACYT}

El IMTA ha fortalecido su relación con el Consejo Nacional de Ciencia y Tecnología (Conacyt). Además de la invitación a participar en el proyecto Bosque de Chapultepec: Naturaleza y Cultura, cada año se concursa para acceder al financiamiento de los fondos para el desarrollo científico, tecnológico y de innovación del Consejo.

Durante 2020 se acordaron 13 proyectos financiados con fondos del Conacyt:

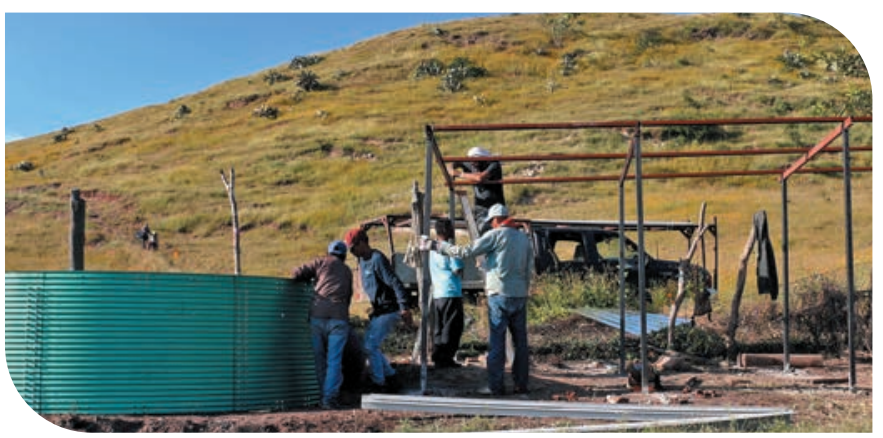




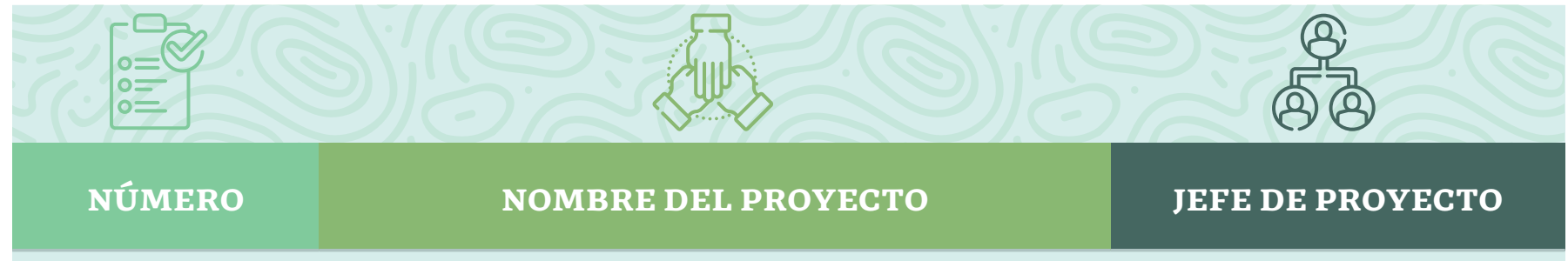

1

Modelo Interdisciplinario para ejercer el derecho humano al agua y al saneamiento en zonas rurales.

2

Fortalecimiento de comunidades de tres estados de la República.

Estrategias para la garantía de los derechos humanos asociados al agua en regiones rurales de difícil acceso: la sierra Wixárika, en la cuenca baja del río Santiago.

Generación de un inventario nacional de corrientes marinas, mareas y procesos asociados (dinámica sedimentaria) y su variabilidad bajo distintas condiciones ambientales.

Plataforma web informativa sobre usos del agua en la agricultura nacional.

Implementación de sistemas de desalinización mediante tecnología fotovoltaica y nanofiltración en la mesa central de México.

Dinámica poblacional de consorcios microbianos en celdas de biocombustible usadas para el tratamiento de desechos líquidos con alto contenido de materia orgánica.

Evaluación de la disponibilidad de la energía y la potencia de las olas: determinación de las condiciones medias y extremas de oleaje en la zona costera.

\section{Denise Soares}

Alejandra Peña

Carolina Escobar Neira

Efraín Mateos Farfán

Alberto González Sánchez

Eduardo Venegas Reyes

Petia Mijaylova

José Antonio Salinas Prieto 


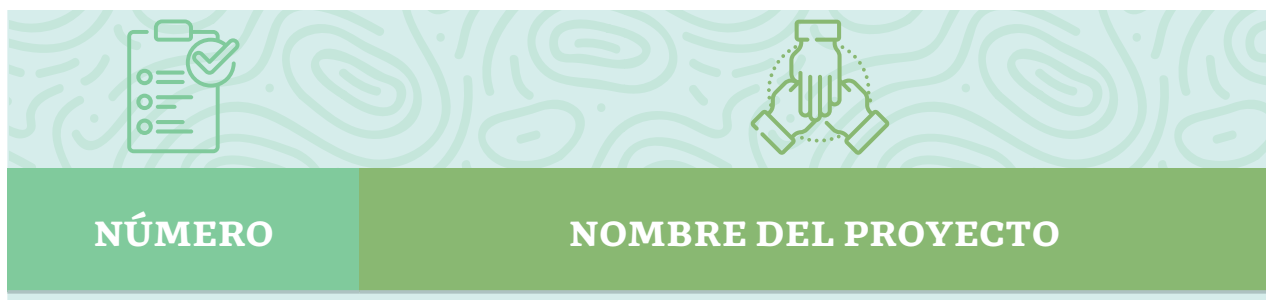

9

10

11

12
Vigilancia de la sequía agrícola y evaluación de su probabilidad de ocurrencia en zonas áridas de México mediante el sistema del índice de estrés agrícola (ASIS) de la FAO.

Diagnóstico y propuestas para la gestión de los recursos hídricos en las cuatro secciones del bosque de Chapultepec.

Análisis y proyección de inundaciones y sequías en la cuenca Grijalva-Usumacinta y evaluación de sus potenciales impactos hidrológicos y socioambientales.

Evaluación y atención integral del deterioro ambiental y productivo de las lagunas de Mitla, Coyuca y Tres Palos y sus cuencas en el estado de Guerrero.
Modelo interdisciplinario para el ordenamiento territorial de cuencas, basado en la cooperación entre actores, el manejo sostenible de los recursos hídricos y
JEFE DE PROYECTO
David Ortega Gaucín

Julio César Soriano Monzalvo

Martín Montero Martínez

Agustín Breña Naranjo el ejercicio de los derechos humanos.

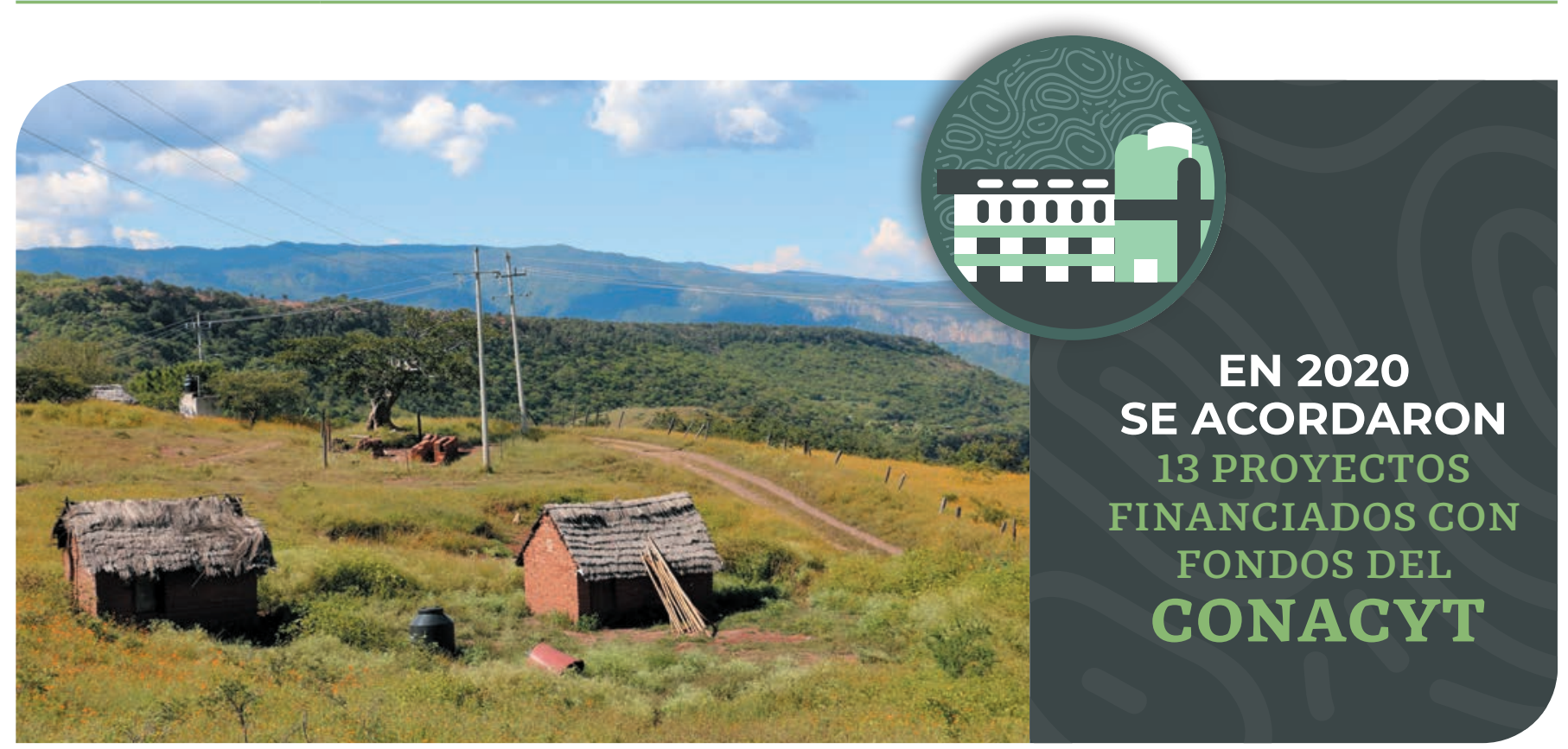




\subsection{CONSEJO DE CIENCIA Y \\ TECNOLOGÍA DEL ESTADO DE MORELOS}

$\int$ Acercamos el conocimiento del agua para el beneficio de la población en
Morelos.

En 2020 se formalizó, con la firma de un convenio de colaboración, la realización de actividades conjuntas entre el IMTA y el Consejo de Ciencia y Tecnología del Estado de Morelos (CCyTEM) para impulsar el desarrollo de la innovación, la ciencia, la tecnología y la divulgación del conocimiento, así como la superación académica y la formación y capacitación profesional.

En el marco de este convenio, el Instituto lleva el conocimiento científico al lugar en donde se encuentran las personas, mediante intervenciones técnicas dirigidas a superar diversos problemas relativos al agua, la divulgación de conocimiento socialmente útil y el fomento de una cultura hídrica.

Uno los primeros pasos de esta colaboración es concretar un nuevo enfoque para la Sala del Agua en el Museo de Ciencias de Morelos, con el fin de que se convierta en un referente en todo el país.

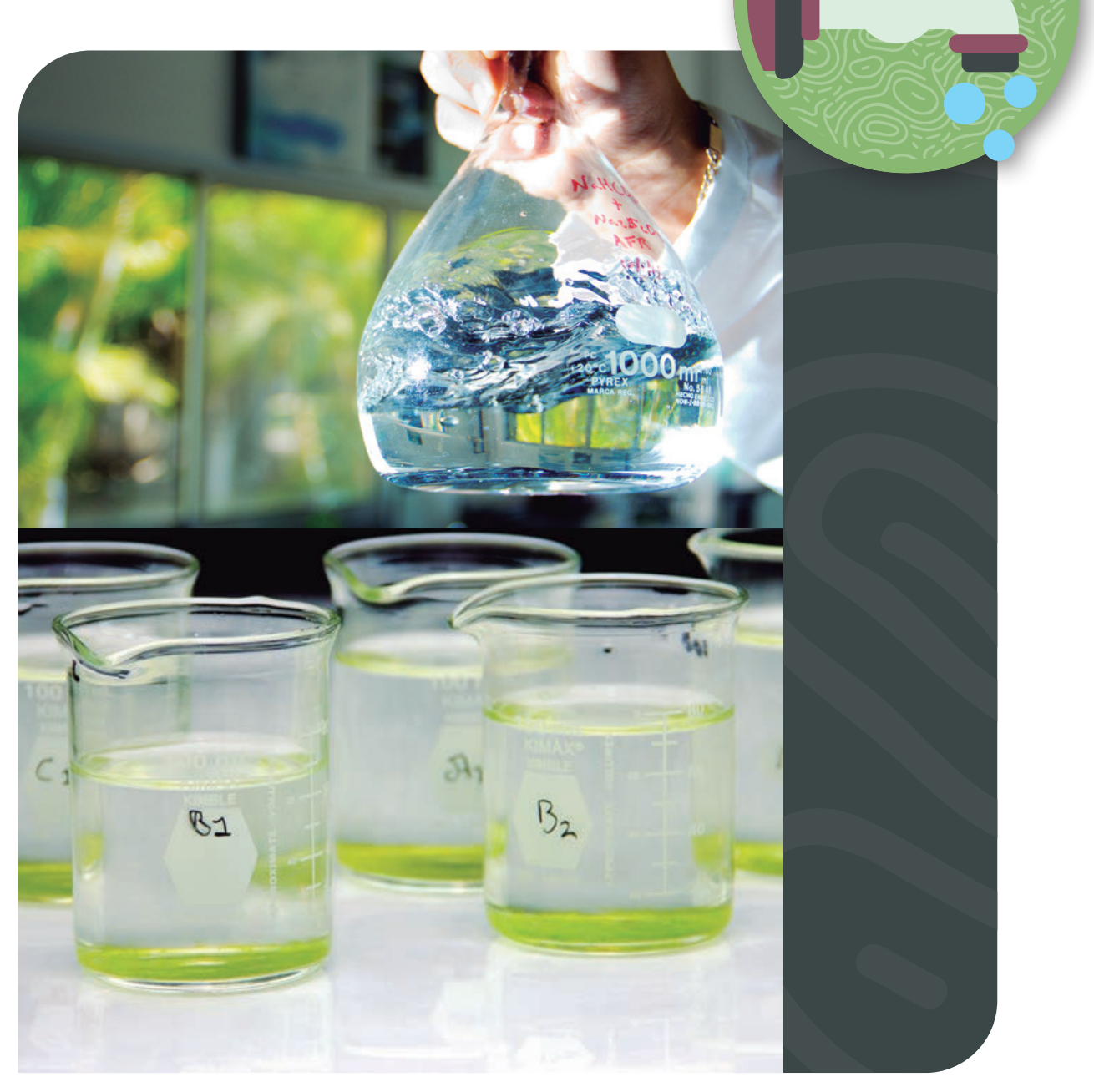




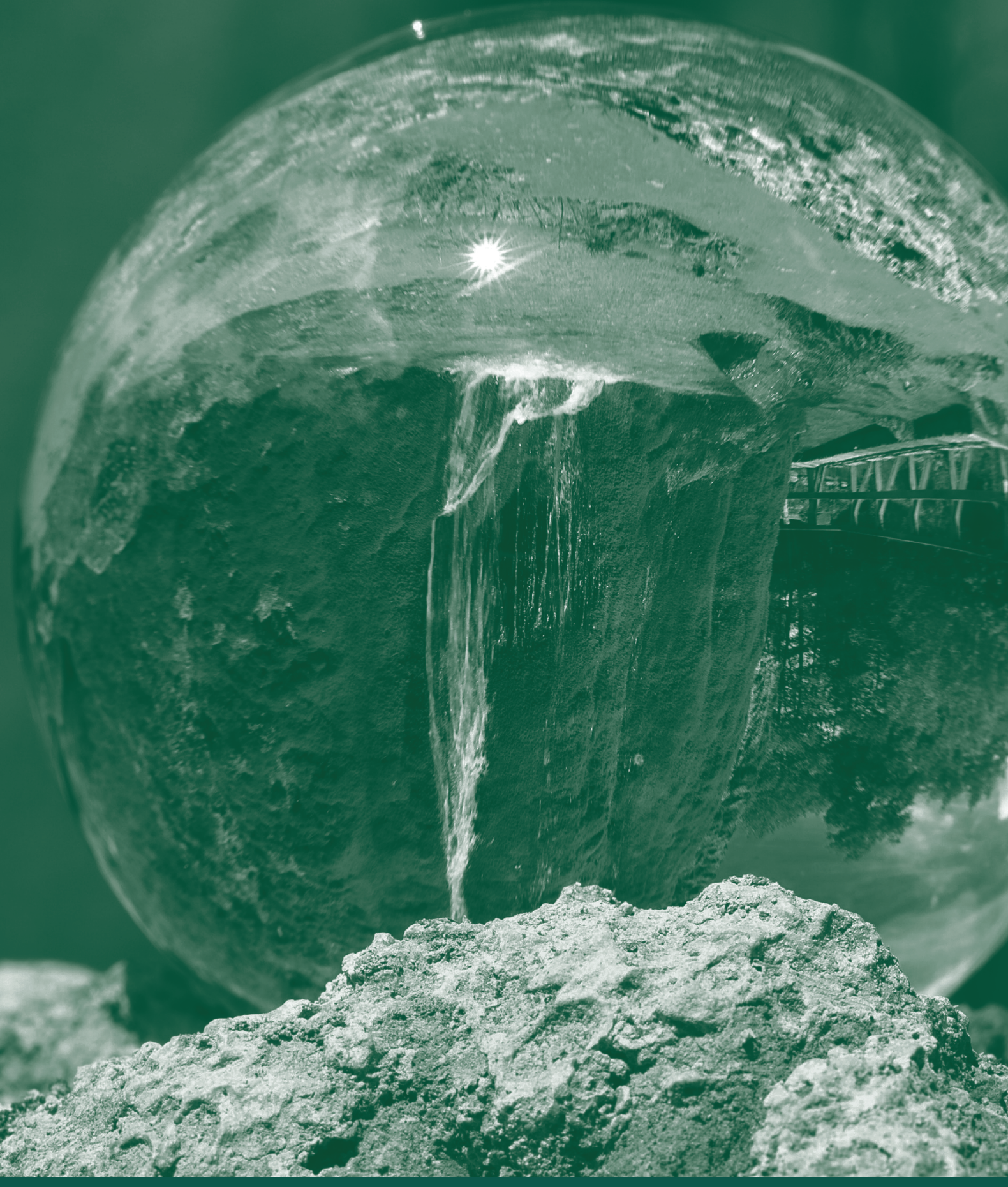




\section{IMTA GLOBAL}

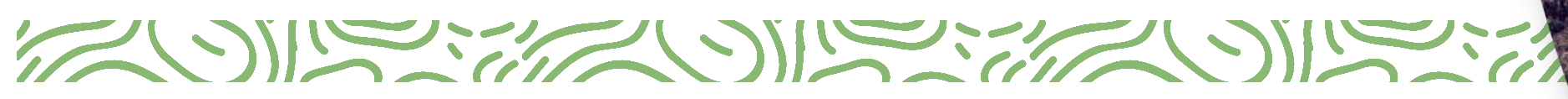

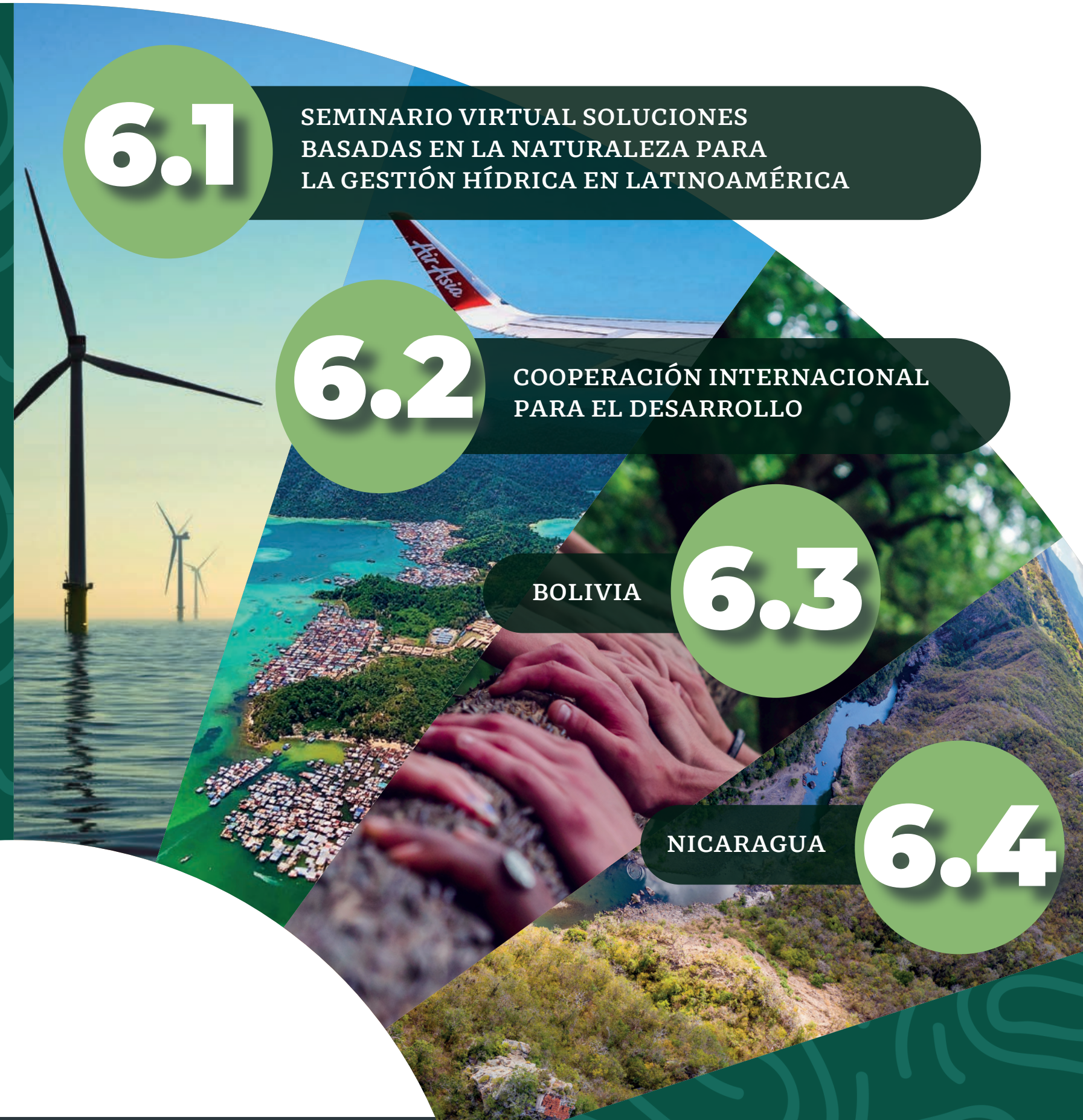





\subsection{SEMINARIO VIRTUAL SOLUCIONES BASADAS EN LA NATURALEZA PARA LA GESTIÓN HÍDRICA EN LATINOAMÉRICA}

Este seminario contribuyó a la difusión, discusión y ampliación del conocimiento en México y en diversos países de América Latina en torno a las soluciones basadas en la naturaleza (SBN) para la gestión hídrica, así como, al intercambio de experiencias y casos de éxito en la región mediante la divulgación de las ponencias siguientes:

- Mejorando los servicios ecosistémicos a través de infraestructura verde en la ciudad de Hermosillo

Las áreas naturales protegidas como soluciones naturales para la resiliencia hídrica

\section{Espacio público como infraestructura hídrica}

Infraestructura verde para el control del escurrimiento pluvial y beneficios térmicos

Desafíos y oportunidades de implementación de las soluciones en la naturaleza en la gestión del agua en América Latina

Durante el evento se contó con la participación de expertos nacionales e internacionales, provenientes del Instituto Tecnológico de Sonora; el Instituto Municipal de Planeación Urbana de Hermosillo; la Comisión Nacional de Áreas Naturales Protegidas; el Programa de las Naciones Unidas para el Desarrollo; la Universidad Nacional Autónoma de México; la Universidad Federal de Santa María, Brasil, y la Universidad Nacional de Córdoba, Argentina.

Los invitados coincidieron en que los múltiples beneficios ambientales derivados de las SBN son las mejoras en la cantidad y calidad del agua, la regulación de la temperatura, el sumidero de contaminantes, las mejoras en la calidad del aire y del paisaje, y la mitigación y adaptación al cambio climáti$\mathrm{co}$, entre otros.

El Seminario ha sentado las bases para continuar generando conocimiento y ampliar las discusiones sobre este tema.

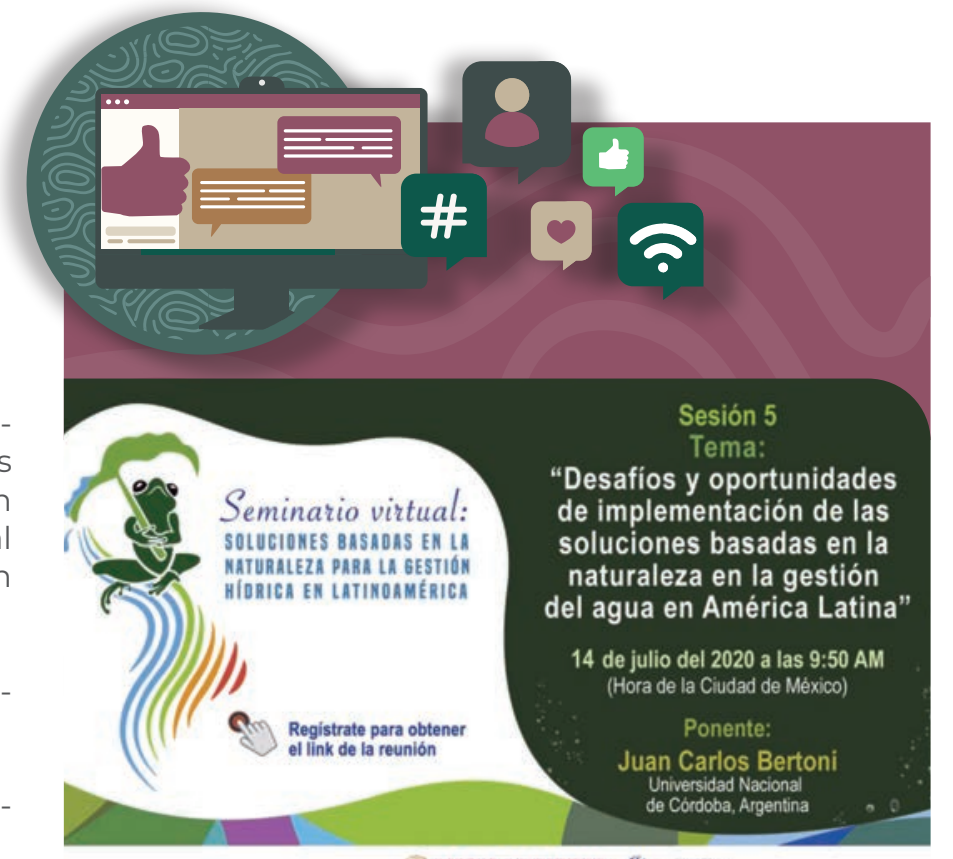

(6) MEDIO AMBIENTE | (GIMTA

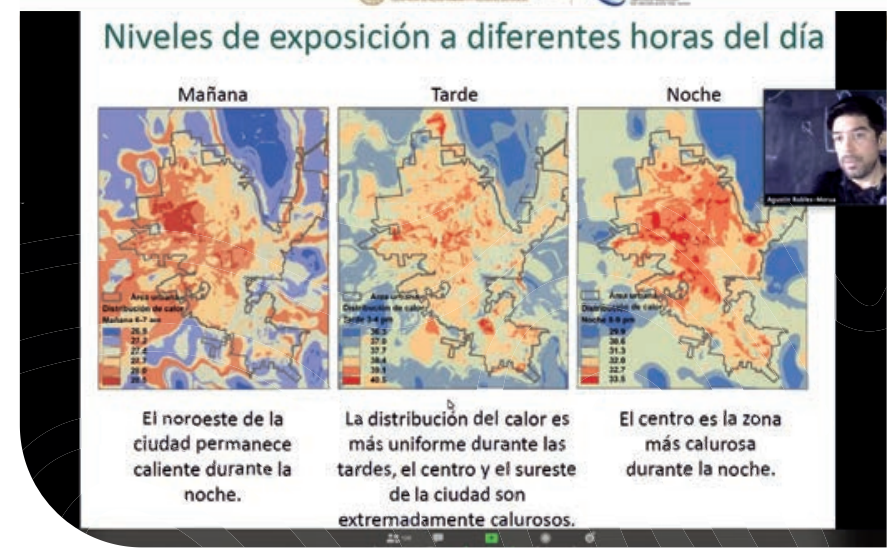

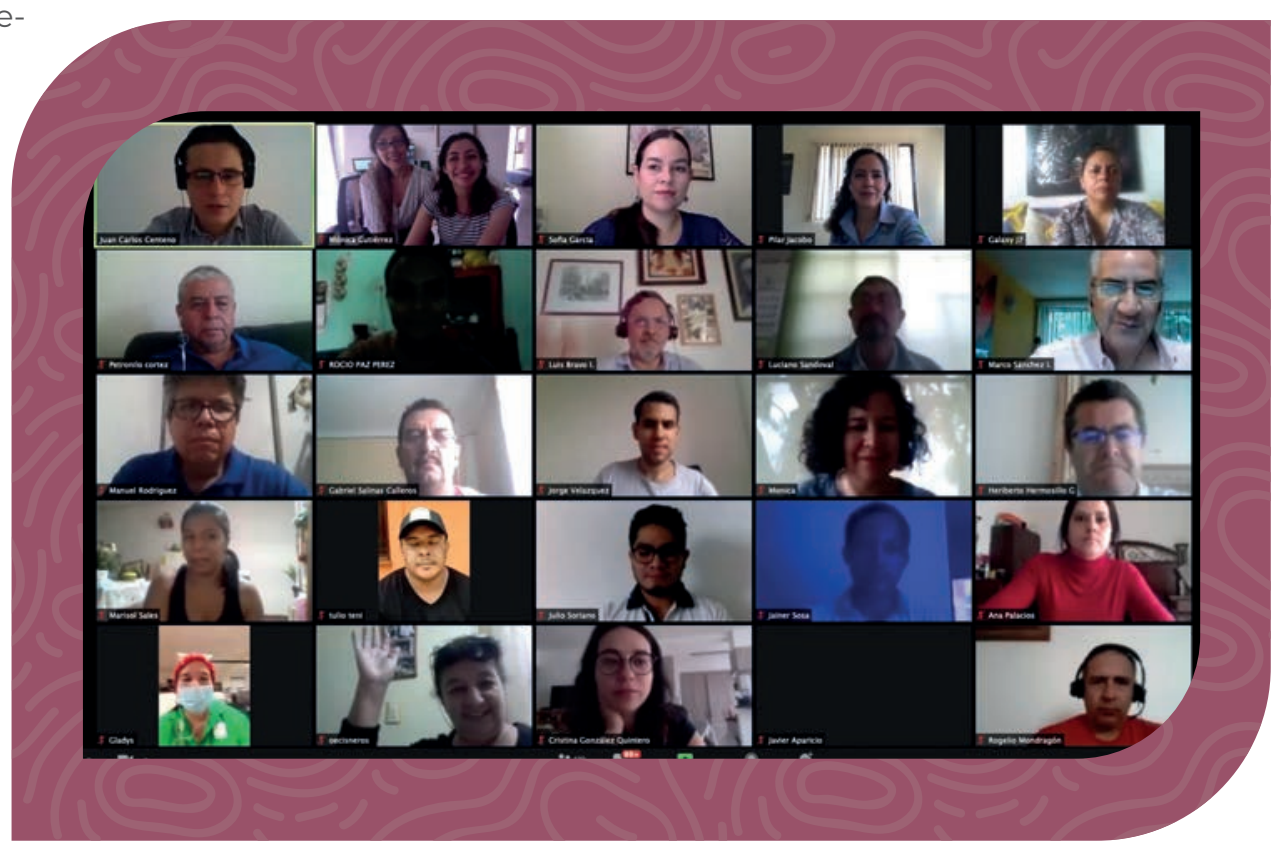




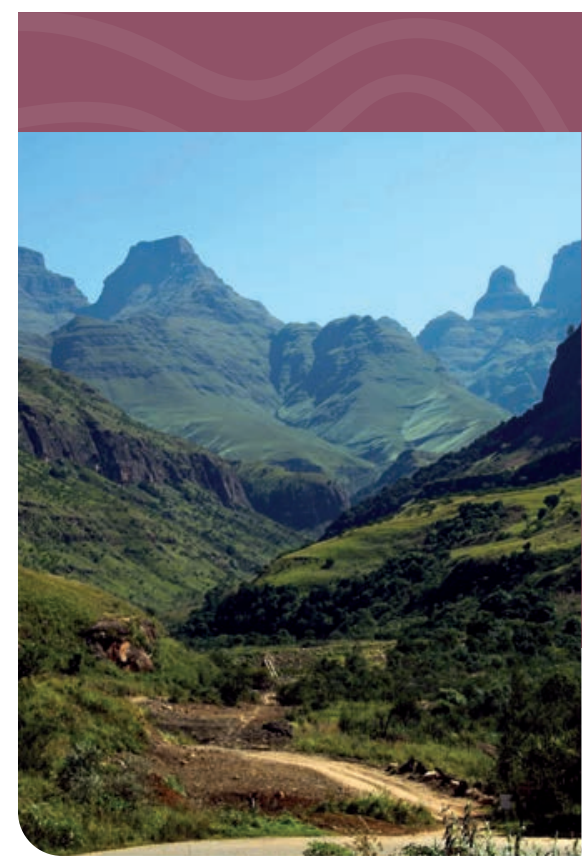
dades de discusión. biodiversidad.

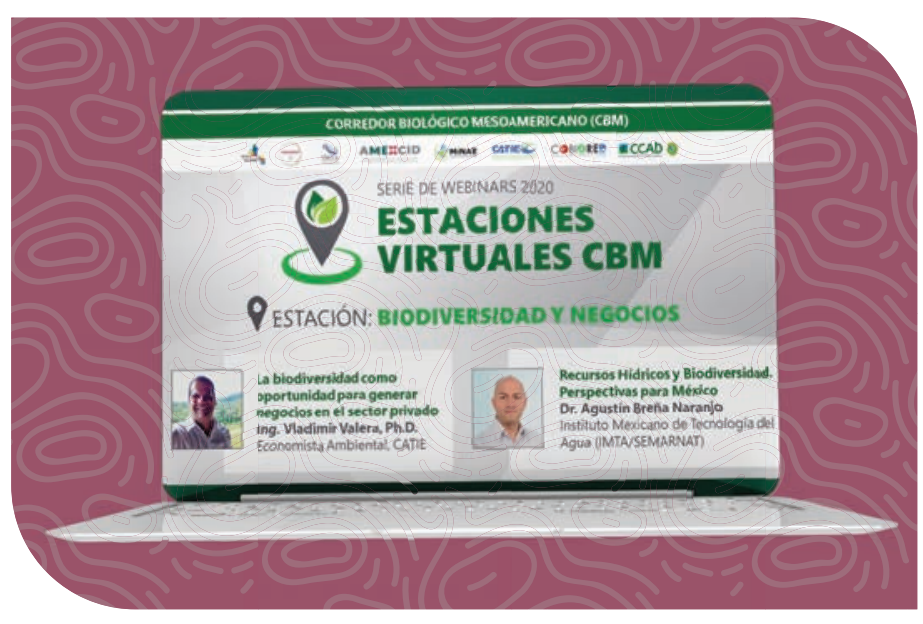

\subsection{COOPERACIÓN INTERNACIONAL PARA EL DESARROLLO}

Las actividades de cooperación internacional se realizan en colaboración con la Agencia Mexicana de Cooperación Internacional para el Desarrollo (Amexcid). Además de desarrollar proyectos con a contrapartes de seis países de la región Latinoamericana y el Caribe, el IMTA participo en diversas activi-

\section{ESTACIONES VIRTUALES: CORREDOR BIOLÓGICO MESOAMERICANO}

Con la finalidad de contribuir al fortalecimiento de capacidades institucionales en temas de interés para los coordinadores nacionales y enlaces de los diez países que integran el Corredor Biológico Mesoamericano (CBM), el IMTA participó en una serie de seminarios denominados Estaciones Virtuales CBM, compartiendo su conocimiento en temas hídricos vinculados con la

El evento fue coordinado por el Sistema Nacional de Áreas de Conservación (Sinac), dependencia del Ministerio de Ambiente y Energía de Costa Rica (Minae); el Centro Agronómico Tropical de Investigación y Enseñanza (Catie); la Dirección Ejecutiva del Proyecto de Integración y Desarrollo de Mesoamérica, y la Agencia Mexicana de Cooperación Internacional para el Desarrollo.

Perla Alonso Eguía, de la Coordinación de Tratamiento y Calidad del Agua del IMTA, destacó la importancia de los ecosistemas dulceacuícolas tropicales por su enorme riqueza y contribución al mantenimiento de la biodiversidad y señaló las amenazas que enfrentan. Mientras que la Maricela Martínez Jiménez, de la misma área técnica, compartió casos de éxito en el control de plagas a través de agentes de control biológico y su beneficio para la conservación de la biodiversidad, versus el uso de plaguicidas en la agricultura que inciden en la disminución de insectos polinizadores, como las abejas, e impactan negativamente en la salud humana y en la de los
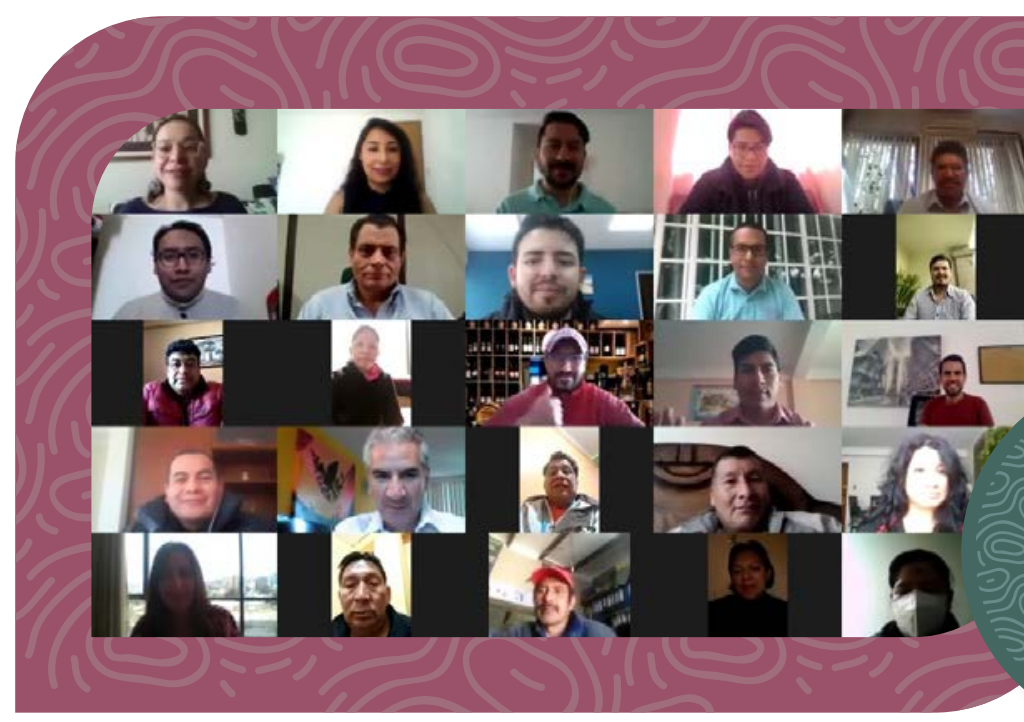
ecosistemas.

Por su parte el, coordinador de Hidrología, Agustín Breña Naranjo, abordó el papel de esta ciencia en la biodiversidad de plantas terrestres y las tecnologías emergentes para la gestión de la biodiversidad y compartió algunas perspectivas para el caso de México. 
El IMTA participó en la XX Reunión de la Comisión del Mar Caribe de la AEC, celebrada de manera virtual el 14 de agosto de 2020. Derivado de dicha reunión, el IMTA colabora compartiendo el conocimiento y las experiencias de México con naciones hermanas.

En el marco de dichos compromisos, Yolanda Pica Granados impartió la conferencia virtual La nueva naturaleza. Macro y microplásticos: una brevísima historia de calamidades, el 30 de noviembre de 2020 , dirigida a funcionarios e investigadores de los países miembros de la AEC.

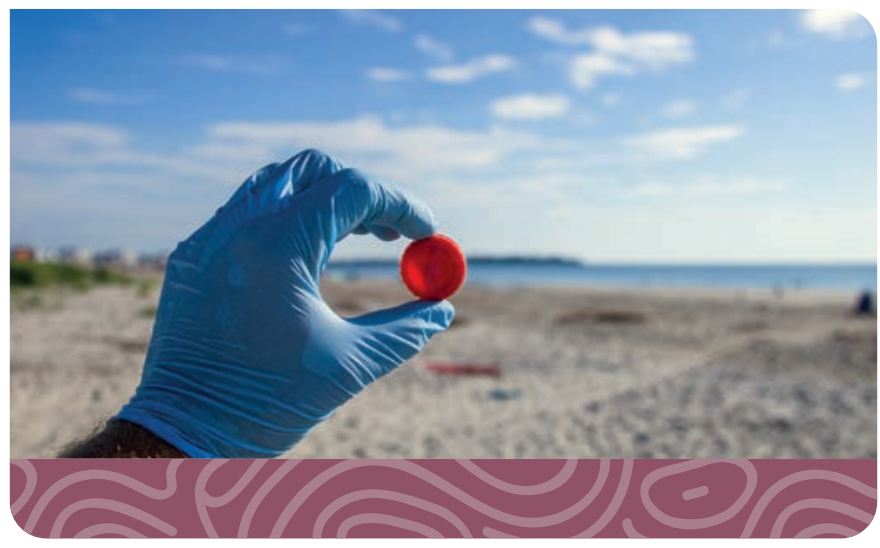

\section{EVENTOS INTERNACIONALES}

Seminario Hacia una Nueva Política del Agua: Inclusión de la Ética y la Diversidad Cultural en un Futuro de Precariedad Hídrica

El Instituto Mexicano de Tecnología del Agua celebró este seminario virtual con la conferencia magistral de David L. Feldman, profesor de la Universidad de California en Irvine, EUA, y la participación de la senadora Alejandra León Gastélum y el diputado Diego Eduardo del Bosque Villareal, con el objetivo de continuar promoviendo la ética y la justicia hídricas en la toma de decisiones y en la formulación de políticas públicas.

El ponente invitado enfatizó que para soslayar los conflictos sociales hídricos es necesario incorporar la ética y los valores culturales en la política del agua. Asimismo, subrayó que se debe abandonar el actual paradigma de justicia ambiental, basado en el utilitarismo y transitar hacia una concepción en la que converjan la justicia social y la justicia económica, usualmente vinculadas al bienestar social y a la justicia ambiental, como lo plantea la ecojusticia.

Por su parte, la senadora Alejandra León añadió que desde el Senado se trabaja para proteger el medio ambiente, marcando límites al consumismo y buscando siempre la justicia ambiental y la justicia por el agua. El diputado Diego del Bosque reconoció que las comunidades y los ejidos son la reserva moral del país, cuyos valores comunitarios y concepción de los recursos naturales aporta a la conservación del medio ambiente en muchos estados de México.

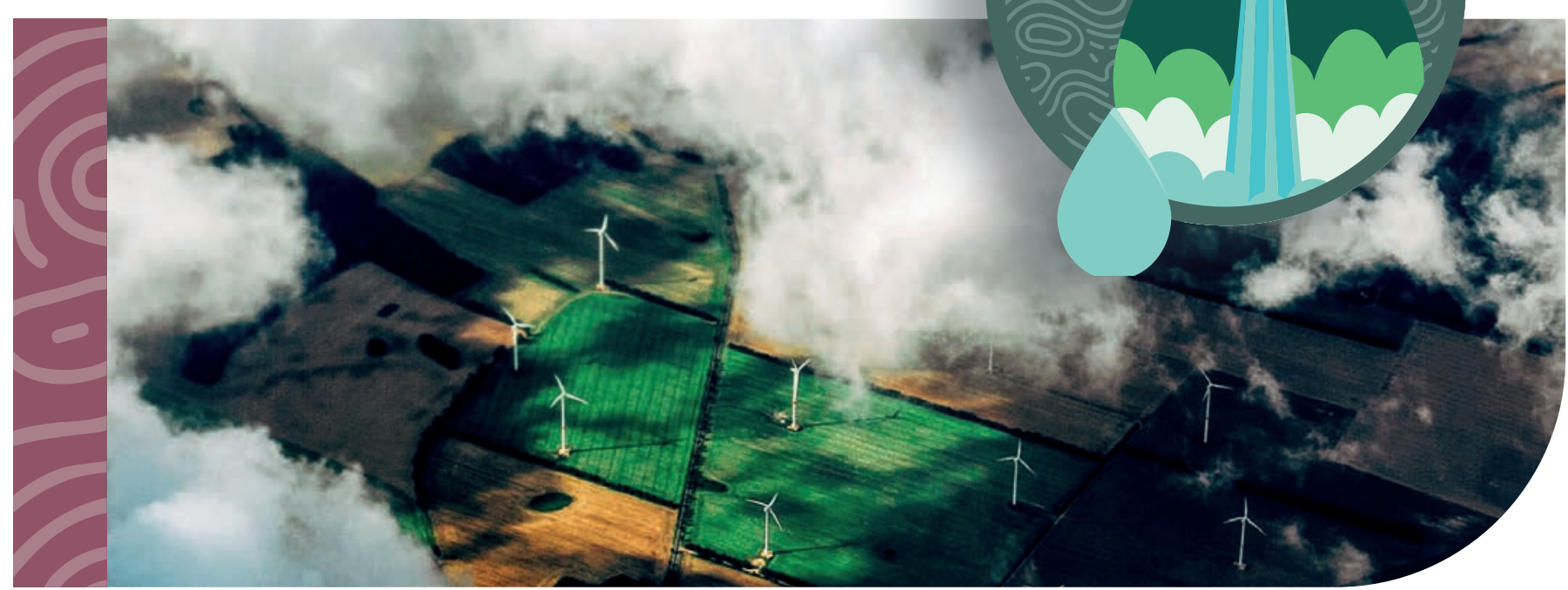


En el marco de la cooperación entre Quebec, Canadá, y México, se celebró el 19 de noviembre un taller para presentar los avances del actual trabajo conjunto entre el IMTA y la Escuela de Tecnología Superior (ÉTS, por sus siglas en francés) de Quebec y discutir nuevos temas de colaboración, como son vulnerabilidad, impacto y adaptación al cambio climático.

Asimismo, al amparo de la celebración del taller, se suscribió el convenio de colaboración entre la ÉTS y el Instituto Mexicano de Tecnología del Agua, con la participación del director general del IMTA, el director general de la ÉTS, el cónsul de México en Montreal, el director de Asociaciones de Innovación Canadienses e Internacionales del Ministerio de Economía e Innovación de Quebec, y la directora de Experiencia en Agua y Atmósfera en Quebec.

\section{CHILE}

El IMTA y la Agencia Mexicana de Cooperación Internacional para el Desarrollo suscribieron un convenio de colaboración que permitirá iniciar la implementación del proyecto Alianza estratégica entre la Comisión Nacional de Riego y el IMTA, para fortalecer capacidades y conocimientos en la implementación de programas de desarrollo productivo con captación de agua de lluvia en zonas rurales vulnerables de las regiones de la Araucanía en Chile y de la Sierra Tarahumara en México, aprobado en el marco del Fondo Conjunto de Cooperación México-Chile.

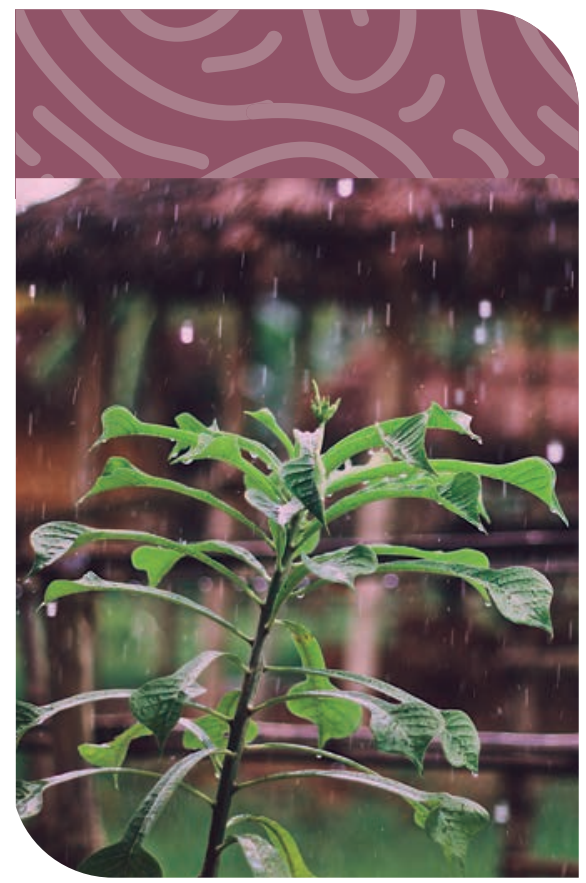

\section{HONDURAS}

PARTICIPANTES: Óscar Jesús Llaguno Guilberto, Juan

Maldonado Silvestre, Vladimir Contreras González

y Héctor Giovanni Rodríguez Vázquez.

En seguimiento a las capacitaciones brindadas por el IMTA en 2019, se realizaron ciclos de asesorías virtuales con el objetivo de revisar y retroalimentar los avances que ha tenido la Alcaldía Municipal del Distrito Central (AMDC) de Tegucigalpa, Honduras, en la implementación de las herramientas computacionales SWMM y HEC-HMS.

El primer ciclo de asesorías a distancia se celebró en torno a la herramienta computacional SWMM, el 23 y 30 de septiembre y el 2, 7 y 9 de octubre, con una duración total de 8 horas. Se contó con la asistencia de 12 expertos de la AMDC. Durante el encuentro se realizó una revisión de la información base, construcción y escenarios del modelo de simulación de la colonia Duarte de Tegucigalpa y una propuesta de mejora del alcantarillado.

Durante el segundo ciclo de asesorías relativas a la herramienta HEC-HMS, que tuvo lugar el 15, 22, 29 de octubre y el 3 de diciembre con una duración total de 8 horas, se efectuó una revisión de las subcuencas de la cuenca de aportación a la ciudad de Tegucigalpa, se validaron los números de escurrimiento, se realizó el cálculo de las tormentas de diseño, se actualizó el modelo

FORMACIÓN

DE RECURSOS HUMANOS PARA EI MANEJO DE DRENAJE URBANO 
FORTALECIMIENTO DE CAPACIDADES TÉCNICAS CENTRO

DE ENTRENAMIENTO

DE DESARROLLO

AGRÍCOLA

(CEDA)

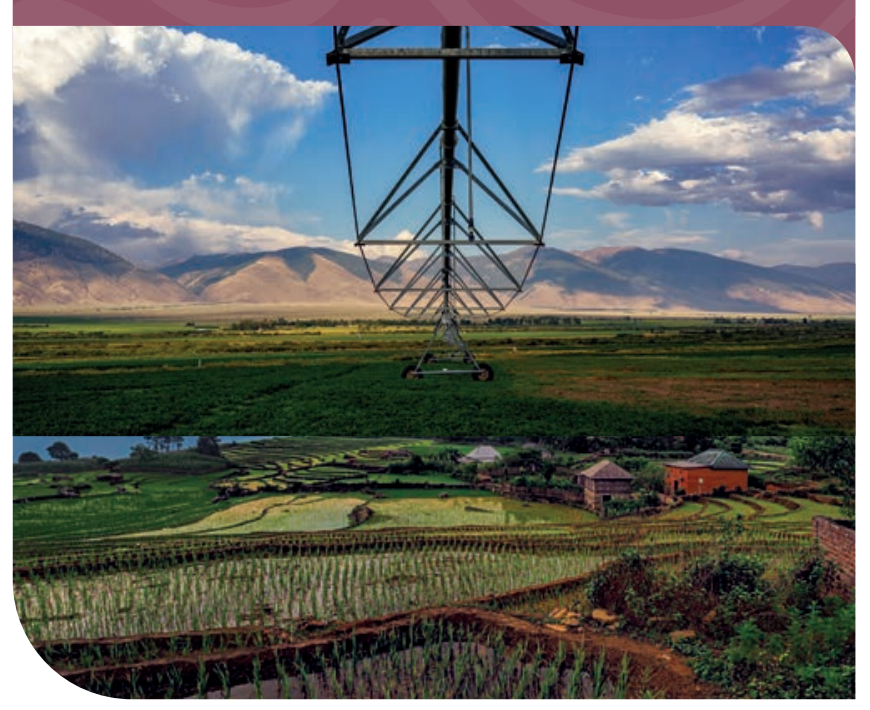

Iluvia-escurrimiento desarrollado en el curso de HECHMS de 2019 y se efectuó la simulación para los diferentes periodos de retorno, particularmente para aquellos en los que se requiera calcular mapas de riesgo por inundación en el software IBER.

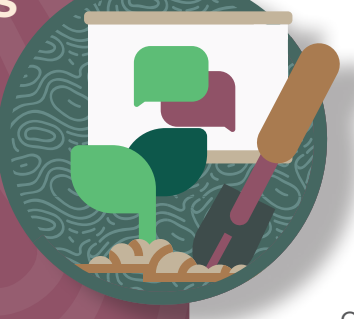

PARTICIPANTES: Antonio Quevedo Tiznado, Pedro Pacheco Hernández y Juan Carlos Herrera Ponce.

En el marco de este proyecto, el IMTA realizó una compilación de información de diversas publicaciones, generando el documento Manual práctico de operación y evaluación del riego parcelario, cuyo contenido servirá de base para las futuras actividades del proyecto, mismas que se reprogramaron para 2021 como consecuencia de la contingencia por COVID-19.

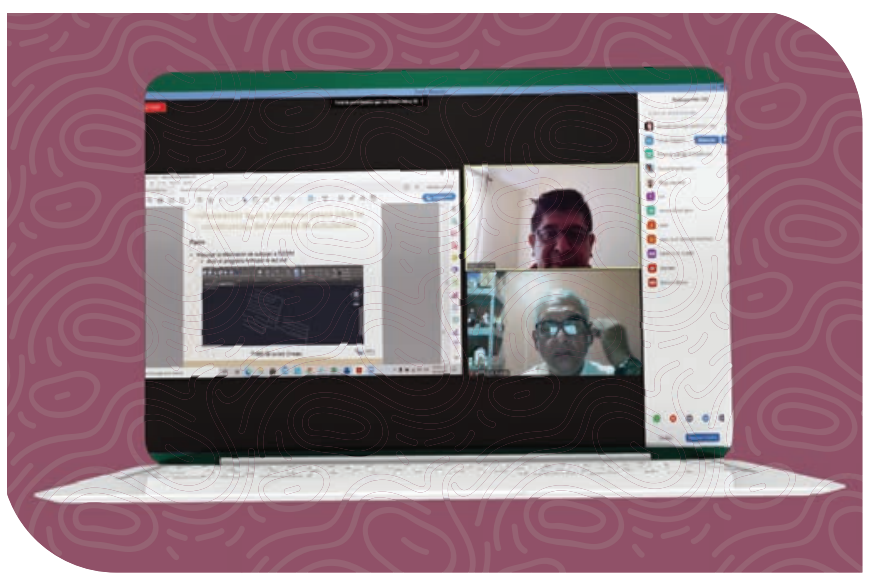

\section{REPÚBLICA DOMINICANA}

PARTICIPANTES: Carolina Escobar Neira, Jorge Velázquez Suárez, Liliana García Sánchez, Axel Falcón Rojas y Juan Gabriel García Maldonado.

Como parte de las actividades del proyecto Fortalecimiento de las capacidades técnicas para la implementación de servicios de agua potable y saneamiento con participación comunitaria organizada, tecnólogos del IMTA impartieron el curso virtual Transferencia Tecnológica para la Sustentabilidad Hídrica el 13, 14, 15, 22 y 23 de octubre de 2020, cuyo objetivo fue capacitar a promotores y personal de Instituto Nacional de Aguas Potables y Alcantarillados (Inapa) en el proceso de transferencia en la selección y adopción de tecnologías alternativas para la recolección, tratamiento, abastecimiento, consumo y disposición final de agua.

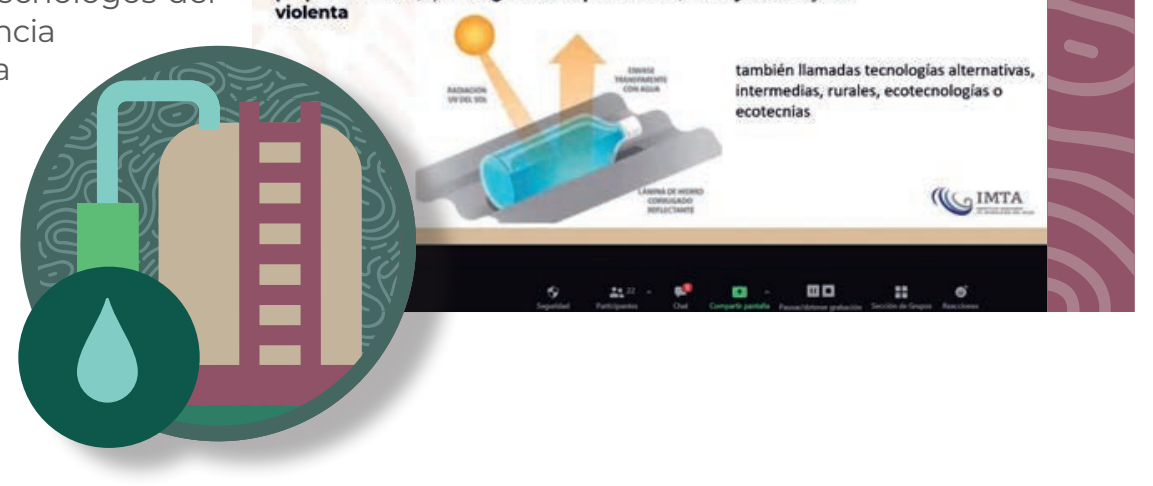

- Concepto formulado por E.F. Schumacher en su libro "Lo pequeño es hermoso" 1973

tecnologías a pequeña escala

mejorar el nivel de vida

Se definió la tecnología apropiada como una tecnología simple, de pequeña escala, que no genera dependencia, de bajo costo y no

\section{¿Qué son las tecnologías apropiadas?}

\section{$P$

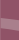

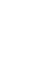




\subsection{BOLIVIA}

\section{COOPERACIÓN TRIANGULAR \\ MÉXICO-ALEMANIA-BOLIVIA}

PARTICIPANTES: Alberto Güitrón de los Reyes, Citlalli Astudillo Enríquez, Ana Wagner, Alexis Cervantes Carretero, Héctor Sanvicente Sánchez, Javier Ramírez Luna y Mario Montiel Gutiérrez.

El proyecto de cooperación triangular Desarrollo de capacidades para la gestión eficiente del agua en sistemas multipropósito concluyó con éxito el $17 \mathrm{sep}$ tiembre de 2020 y se llevó a cabo una sesión de cierre de proyecto coordinada por la Agencia Alemana de Cooperación Internacional (GIZ), con la participación de la Agencia Mexicana de Cooperación Internacional para el Desarrollo, la Comisión Nacional del Agua, el Instituto Mexicano de Tecnología del Agua y el Ministerio de Medio Ambiente y Agua de Bolivia.

Esta cooperación contó con tres líneas de acción: 1) planificación hídrica en sistemas multipropósito, 2) institucionalización de la gestión del agua en el sistema múltiple de Misicuni y 3) capacitación de los actores vinculados a sistemas multipropósito.

El IMTA colaboró de manera específica en la línea de acción tres, proporcionando una serie de capacitaciones y pasantías durante el 2019 en riego mayor, planeación hídrica en sistemas multipropósito y modelación hidrológica y de gestión de recursos hídricos con la plataforma de simulación WEAP.

Durante 2020, tecnólogos del IMTA contribuyeron en la sistematización de los resultados del proyecto con base en las
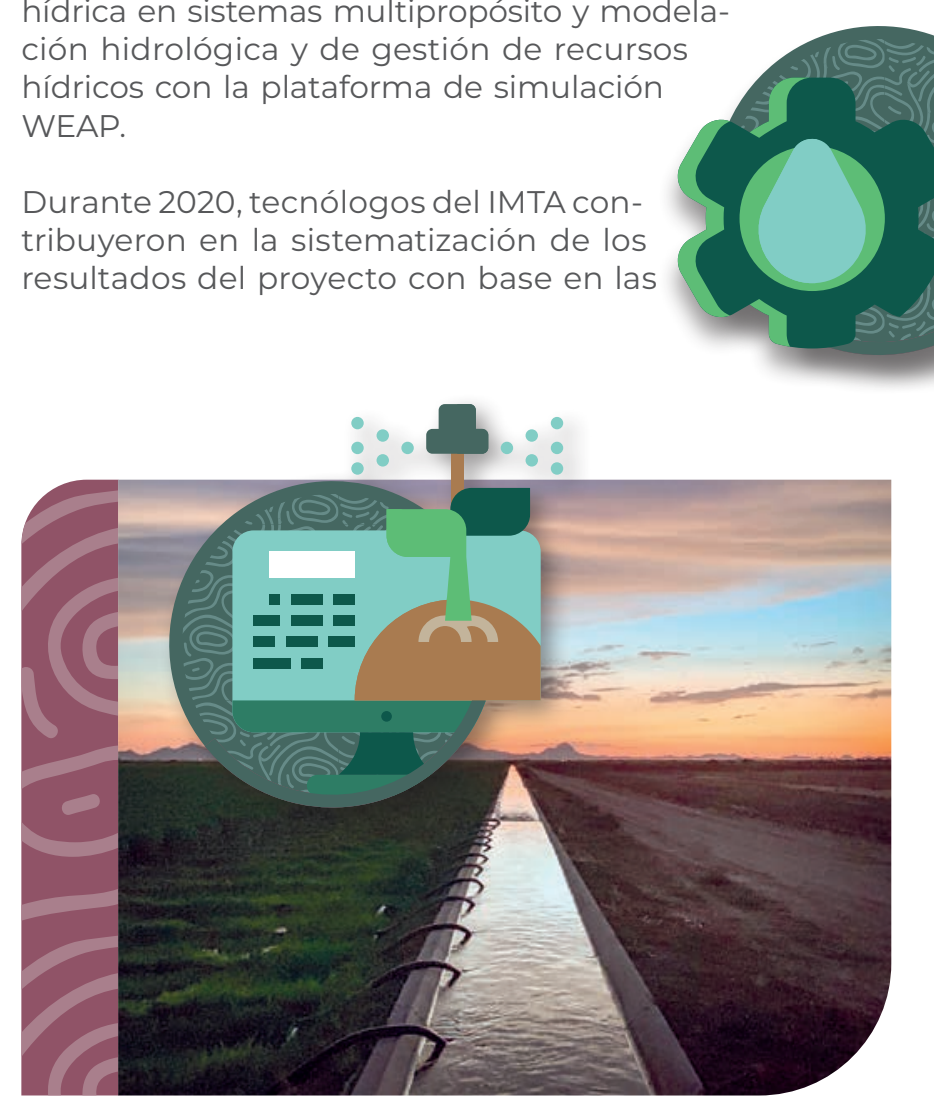

temáticas de capacitación y participaron en la elaboración de los siguientes entregables:

- Memoria del desarrollo y resultados del proyecto. Disponible en https://www.bivica.org/file/view/id/5699

- Reglamento General para la Gestión de Distritos de Riego en Bolivia. Disponible en https://www.bivica. org/file/view/id/5695

- Metodología para la distribución de agua en distritos de riego. Disponible en https://www.bivica.org/file/ view/id/5697

- Guía para la elaboración de plan de cultivos y riego. Disponible en https://www.bivica.org/file/view/ $\mathrm{id} / 5696$

- Guía para la formulación de una estrategia de planeación y administración del agua en proyectos multipropósito. Disponible en https://www.bivica.org/file/ view/id/5698

El evento de cierre del proyecto contó con una dramatización que explica el inicio y conclusión del proyecto triangular (https://www.youtube.com/watch?v=OqVQySA50IO\&feature=youtu.be) y con un video que resume las actividades desarrolladas en el marco del proyecto (https://www.youtube.com/watch?v=a8bj4SBN9UA).

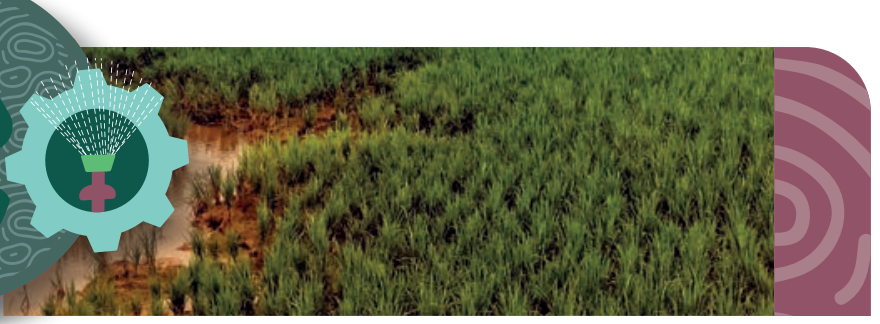

\section{COOPERACIÓN BILATERAL MÉXICO-BOLIVIA}

PARTICIPANTES: Antonio Quevedo Tiznado, Mario Alberto Montiel Gutiérrez, Juan Manuel Ángeles Hernández, Jorge Castillo González, Javier Ramírez Luna y Alberto González Sánchez.

En el marco del proyecto Desarrollo de capacidades e intercambio de experiencias en el sector riego se impartieron dos cursos virtuales: Operación, Distribución y Mantenimiento de Sistemas de Riego, del 17 al 21 de agosto de 2020, y Formulación, Seguimiento y Ajuste de Planes de Riego, del 7 al 16 de diciembre de 2020, se proporcionó una asesoría vía remota en sistemas de riego el 2 y 27 de noviembre y se brindó asesoría en la realización del Programa de Revitalización de Sistemas de Riego en Bolivia. 


\subsection{NICARAGUA}

Durante la X Reunión de la Comisión Mixta de Cooperación Técnica y Científica entre México y Nicaragua, ambos gobiernos acordaron la cartera de proyectos de cooperación bilateral para el período 2020-2022. El IMTA colaborará en dos iniciativas en conjunto con instituciones nicaragüenses:
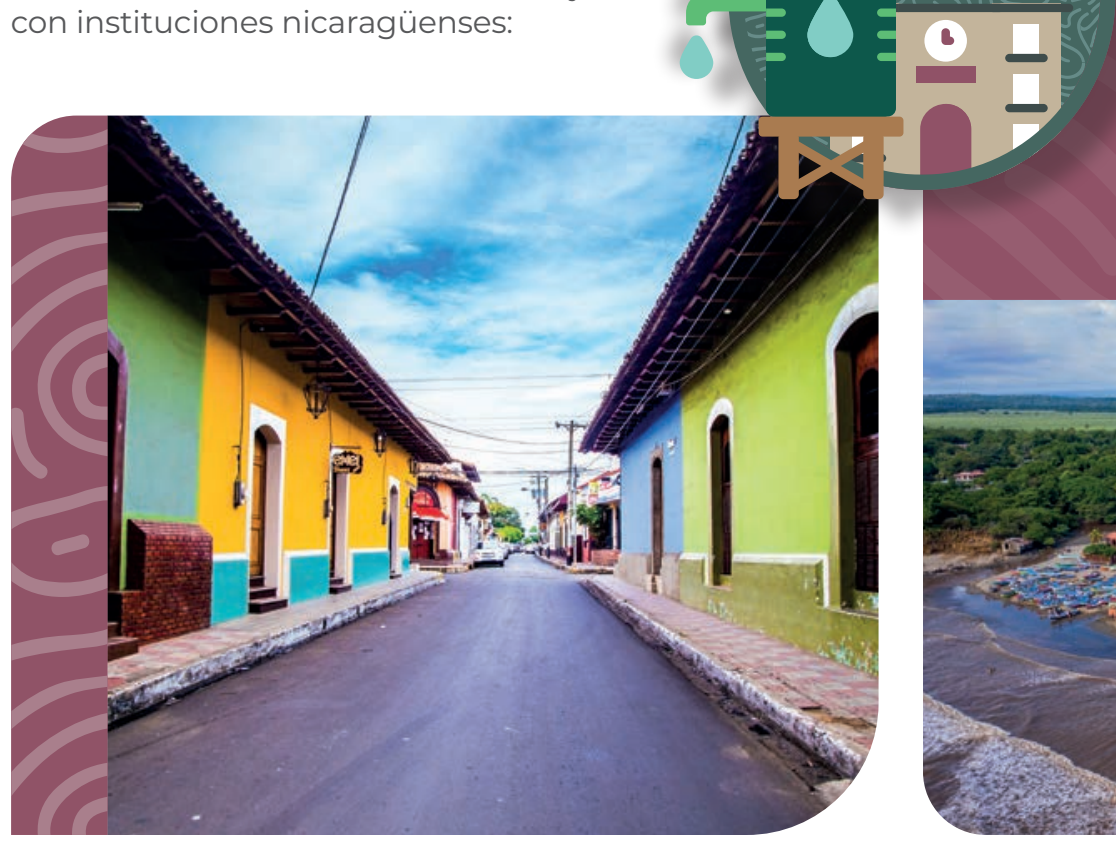

DESARROLLO DE TÉCNICAS Y HERRAMIENTAS PARA EL MANEJO, CUIDADO Y ALMACENAMIENTO DE AGUA EN CENTROS ESCOLARES DE NICARAGUA 


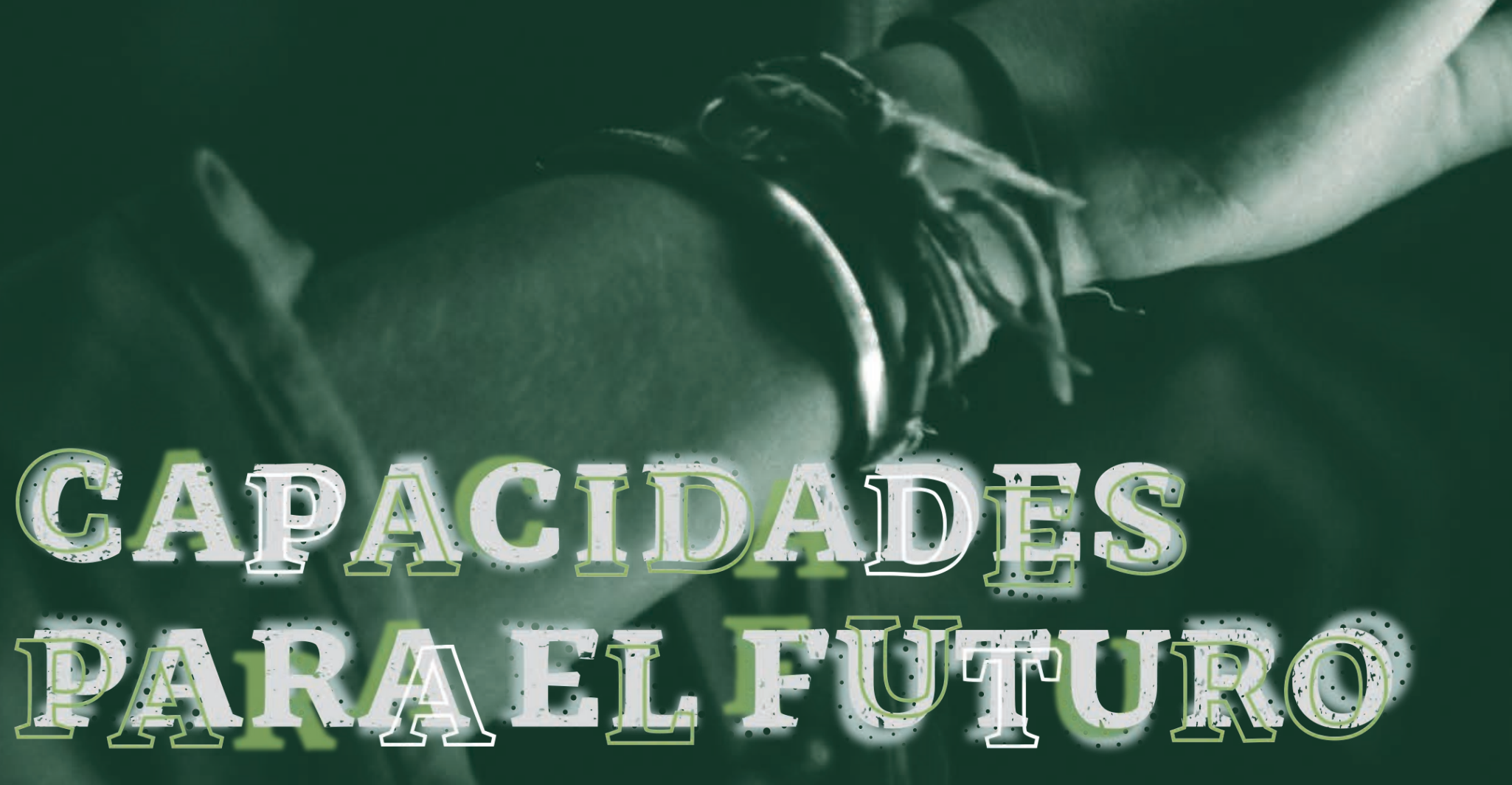




\section{CAPACIDADES}

PARA EL FUTURO

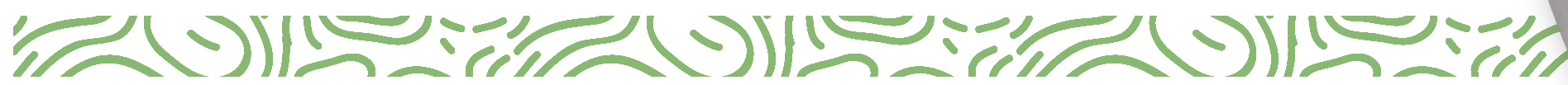

\section{6]}

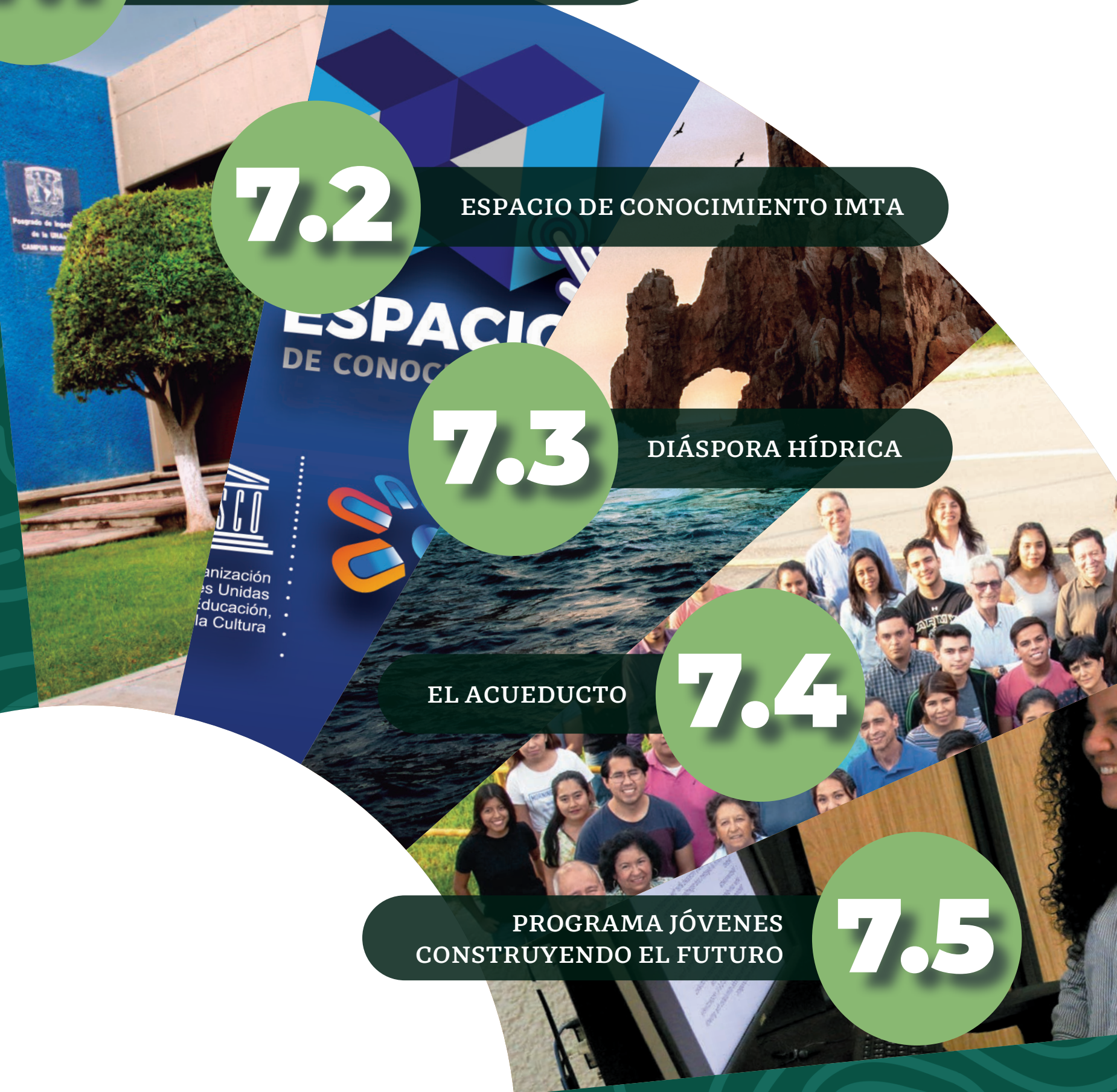



rritorio nacional.
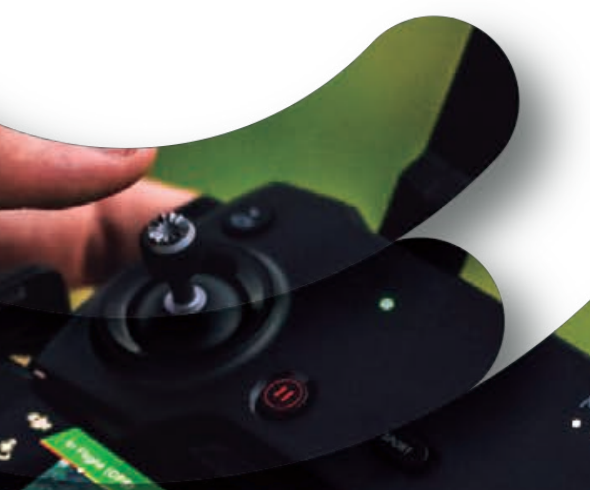

ब.
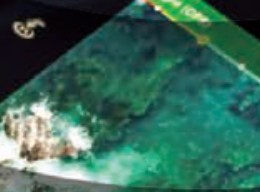

.
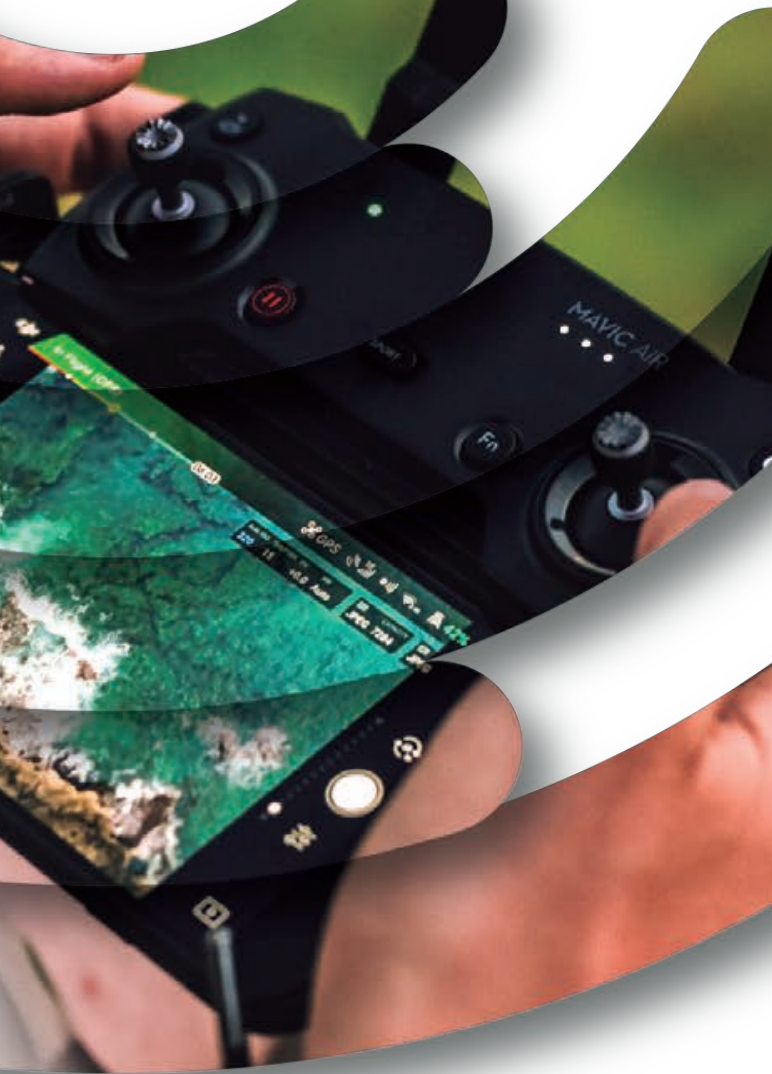

\begin{abstract}
UNA TAREA FUNDAMENTAL DEL IMTA ES PREPARAR especialistas capaces de enfrentar los retos asociados al agua mediante una visión interdisciplinaria, con dimensión social, que expanda su marco teórico e involucre conceptos de ingeniería avanzada a través de programas de educación formal, educación continua y actividades académicas. Con ello se les habilita para entender los efectos que una decisión técnica puede tener sobre las personas y para prever la necesidad de alentar y propiciar la participación ciudadana en los temas hídricos del país.
\end{abstract}

La generación de capacidades adecuadas a los tiempos que vivimos es fundamental para el futuro de México, considerando las cada vez más complejas interacciones entre los usuarios del agua que se aprecian a lo largo del te-

Ante las nuevas condiciones de trabajo impuestas por la pandemia que padecemos actualmente, impulsamos la creación de dinámicas y eventos en línea, así como el empleo de diversas plataformas digitales con temas y formatos variados de divulgación de la ciencia y difusión del conocimiento asociado al agua. Como decía Albert Einstein, "No podemos resolver nuestros problemas con la misma forma de pensar que usábamos cuando los creamos". Solo con esta nueva manera de actuar, acompañada de jóvenes bien preparados, podremos construir un futuro próspero para México. 


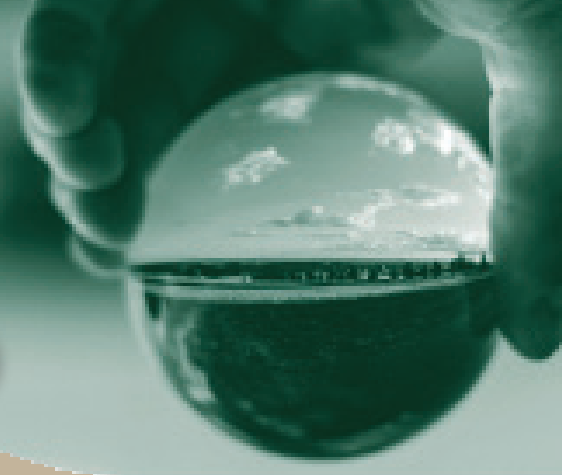

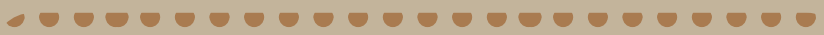

○。० (1)

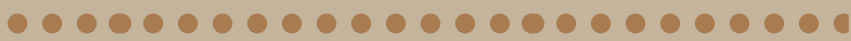

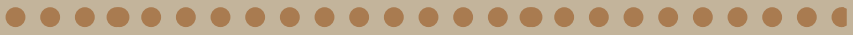

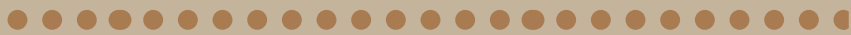

00010000000000000000000 10000000

1000000000

10

10 0 1 $00000000000000000 \%$

000100000000000000000

000000000000000000000

$0001000000000001000 \%$

0 100 0000 $\Delta \circ+00000$

10000000000000

000000000

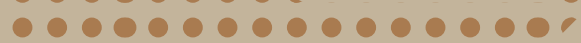

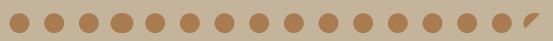

$000000000000 \%$ .

$100001000000 \%$

0.0000000000,

-

000 1 9000

- 100000 00000100001

1000000000

- (1)

100000

100

$-100000$

00000000

1000

1001001

1000000

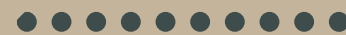

000000000

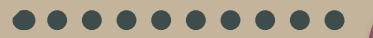

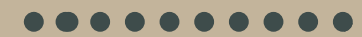

-

$\circ \circ \circ \bigcirc$

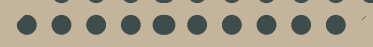

,

$\circ \bullet$

,

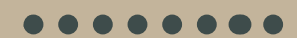

, 1000000

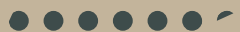

100

$\bullet$

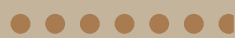

-

100

$\circ \circ$ 2000000000000

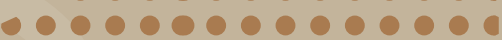

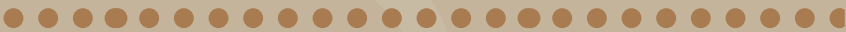

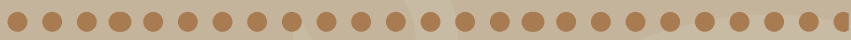

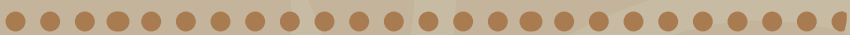

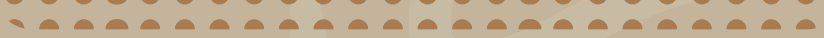

100000

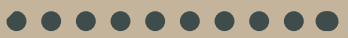

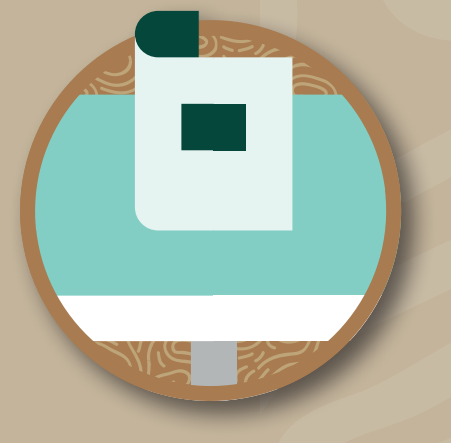

EL ACUEDUCTO 4 NÚMEROS líneas de investigación Orientados en las cuatro

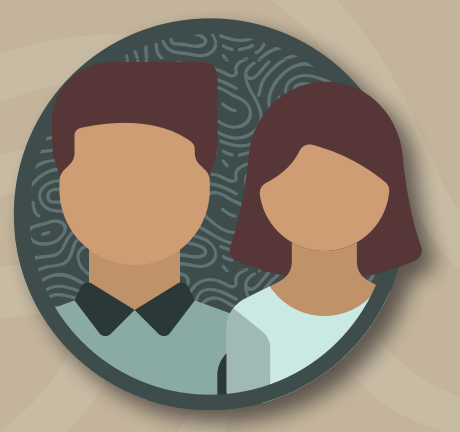

JÓVENES CONSTRUYENDO EL FUTURO

Este programa favorece el diálogo intergeneracional para la transformación del país en el manejo y conservación del agua 129 JóvENES INSCRITOS
POSGRADO

18 alumnos GRADUADOS

Se impartieron 183 cursos de 12,230 horas con una duración conjunta

\section{ESPACIO}

\section{DE CONOCIMIENTO}

Se llevaron a cabo 14 eventos especiales con temas relevantes del sector ambiental

\section{0}

participantes registrados
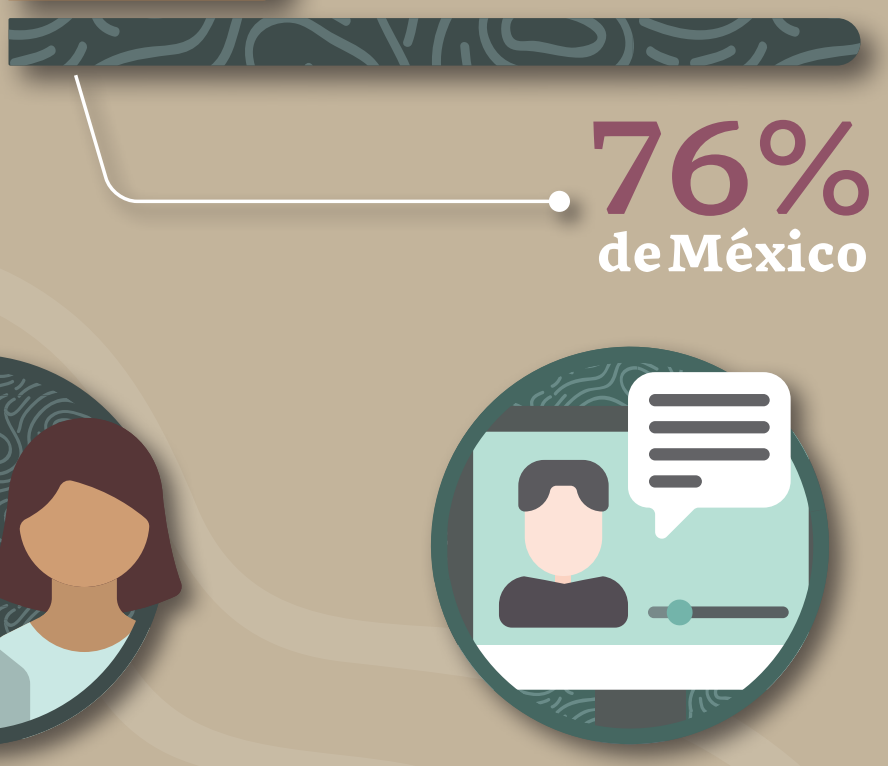

DIÁSPORA HÍDRICA

Se organizó el seminario virtual Diáspora Hídrica: Jóvenes Mexicanos Explorando las Fronteras del Conocimiento del Agua CONTAMOS CON LA
PARTICIPACIÓN DE

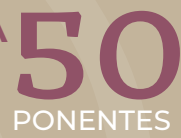




\subsection{POSGRADO Y NUEVO PROGRAMA EN SEGURIDAD HÍDRICA}

El año 2020 impuso nuevos desafíos que fueron enfrentados adecuadamente con resultados satisfactorios para el IMTA.

Los programas de posgrado del IMTA así como los cursos, seminarios de investigación, evaluaciones, graduaciones y procesos administrativos se desarrollaron, a partir de abril de 2020, bajo condiciones especiales a las que se adecuó el proceso de formación presencial y de tiempo completo a una versión a distancia. Si bien en el primer trimestre se realizaron actividades presenciales, a partir de esa fecha se generalizó el uso de plataformas virtuales.

Los registros escolares indican que se impartieron 183 cursos, con una duración conjunta de 12,230 horas, en los que participaron 73 alumnos, y no se reportaron deserciones ni atrasos en el desarrollo de los programas de posgrado.

Asimismo, se llevaron a cabo las convocatorias de ingreso a los programas de maestría en Ciencias y Tecnología del Agua, Gestión Integrada de los Recursos Hídricos, Ingeniería Civil/Hidráulica e Ingeniería Ambiental/Agua, con un ingreso de 28 alumnos y 2 alumnos para el Doctorado en Ingeniería Civil/Hidráulica e Ingeniería Ambiental/Agua. Los registros para el 2020 indican 18 alumnos graduados: 14 de nivel maestría y cuatro de doctorado, con una eficiencia terminal de $65 \%$ por cohorte global para todos los programas.

Desde hace más de un año, el cuerpo de profesores y tutores del IMTA han trabajado en la adecuación de un nuevo programa de doctorado, denominado Seguridad Hídrica, con fundamento en una dimensión y una visión interdisciplinarias para abordar el manejo del agua, considerando un entorno medioambiental sano, pero también los requerimientos que impone el desarrollo humano.
En la última sesión de la Junta de Gobierno del IMTA, desarrollada en noviembre de 2020, se aprobó este nuevo programa, con lo cual da inicio su registro en la Direcciones General de Profesiones, con la posibilidad de ser inscrito en el PNPC-Conacyt en el año 2021.

Este nuevo posgrado considera líneas de generación y aplicación de los conocimientos siguientes:

\section{- Sistemas ambientales \\ - Hidrometeorología \\ - Sistemas hídricos \\ - Gobernanza del agua}

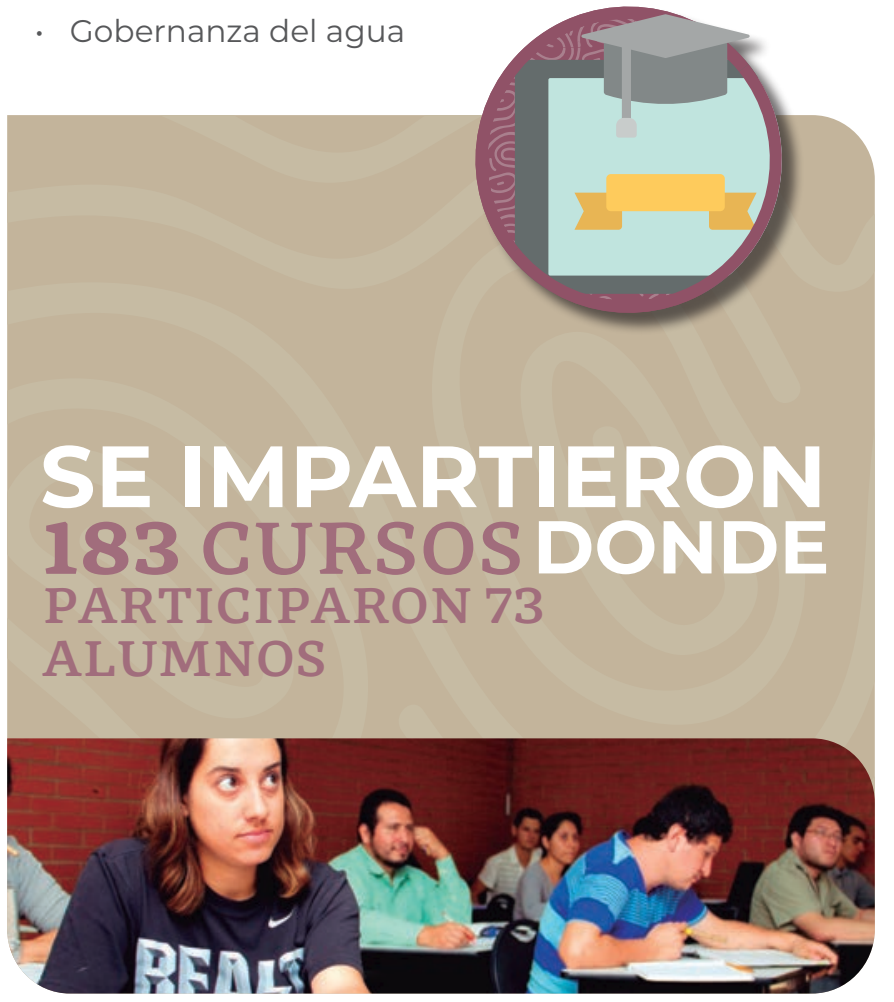

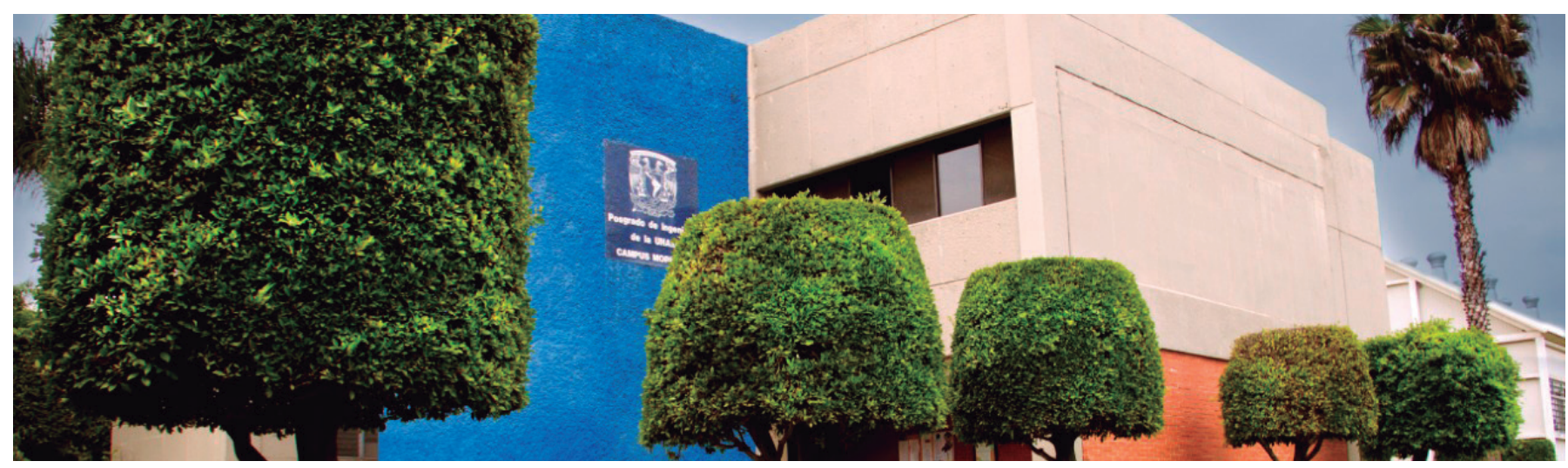




\subsection{ESPACIO DE CONOCIMIENTO IMTA}

Este año realizamos diversos eventos académicos y de divulgación en línea, denominados en conjunto Espacio de Conocimiento IMTA, enfocados a compartir ideas e investigaciones con participantes y ponentes de México y del resto del mundo.

La generación de conocimiento hídrico y la creación de espacios para compartirlo son líneas de acción sustantivas para el quehacer del Instituto que se orientan a crear las capacidades que requerimos para el futuro que deseamos en materia de agua y medio ambiente.

La Cátedra Unesco-IMTA, incluida en este Espacio del Conocimiento, brinda a la población en general información relacionada con el agua mediante una plataforma de difusión sustentada en redes sociales, en las que se publican boletines electrónicos mensuales para promover eventos y seminarios nacionales e internacionales, cursos, talleres y concursos de fotografía, entre otras actividades. La Unesco aprobó la renovación del acuerdo respectivo para que el IMTA sea el responsable de la Cátedra Unesco-IMTA por un periodo de cuatro años más, hasta julio de 2023.

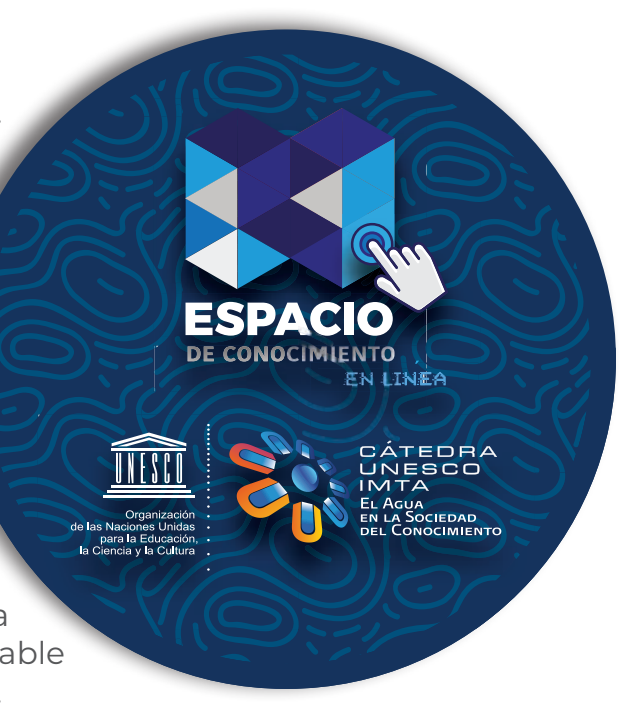

Las publicaciones que integra este Espacio del Conocimiento se enfocan al fortalecimiento de un trabajo de vinculación entre las áreas del Instituto con otras instituciones, sectores y organizaciones afines para ofrecer un sustento tecnológico y científico para la toma de decisiones en torno al agua y al medio ambiente.

En el marco de la pandemia, que tiene un impacto prácticamente en todas las esferas del quehacer humano, en 2020 nos enfocamos a llevar a cabo dinámicas y espacios de conocimiento en línea que incluyeron 53 seminarios, impartidos por 120 ponentes (93 mexicanos y 27 extranjeros), a los que acudieron 13,070 participantes registrados (76 \% mexicanos y $24 \%$ extranjeros).

Además, se llevaron a cabo 14 eventos especiales con temas relevantes del sector, como hidrología forestal, ecología política y agua, agua y derechos humanos, transparencia hídrica, pequeñas centrales hidroeléctricas, agua y minería, y soluciones basadas en la naturaleza, entre otros.

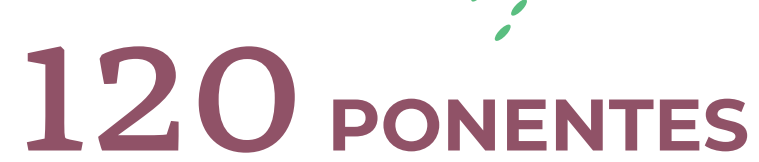

DE 15 PAÍSES: BRASIL, ARGENTINA, SUIZA, ITALIA, ESTADOS UNIDOS, FRANCIA, ALEMANIA, CANADÁ, COLOMBIA, COSTA RICA, CHILE, CHINA, HONDURAS, AUSTRALIA Y ARABIA SAUDITA.

\section{Promedio de $\mathbf{2 5 6}$ participantes por seminario}

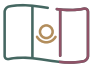
$76 \%$ participantes mexicanos (2⿰氵⿹丁口) $24 \%$ participantes extranjeros
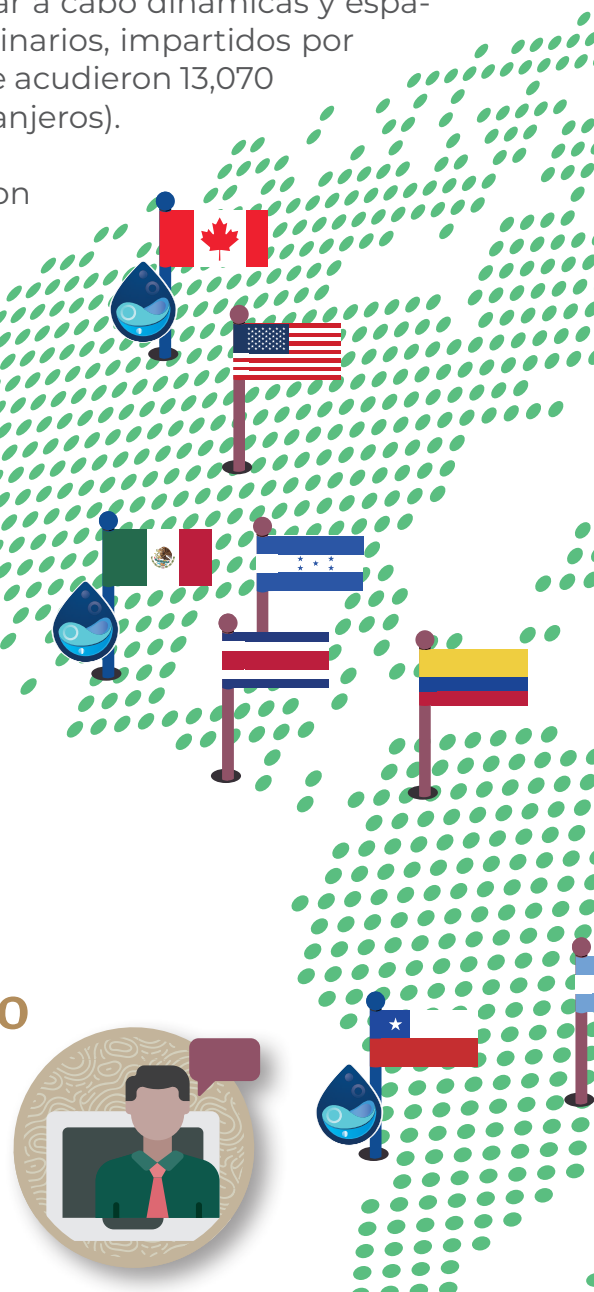

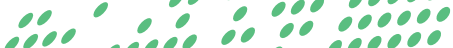

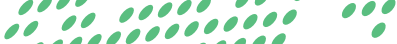

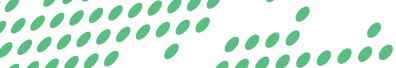
1000000.00000000

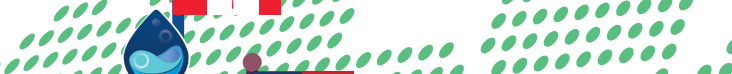
$000000 \mathrm{CP} 1000000000000.000000000$

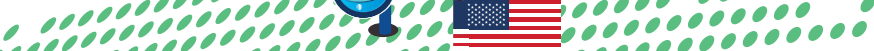

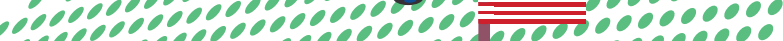

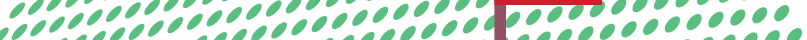

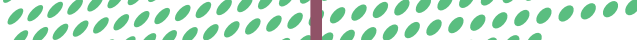
0000000000000000000000

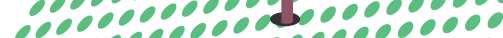

10000000000000000000

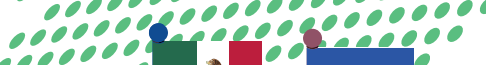

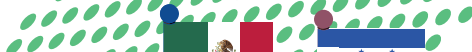
10 000000 : $\because 0$ .
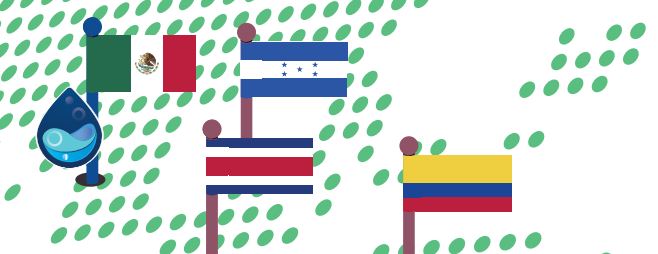

10

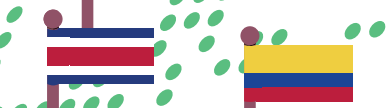

100

10 1000

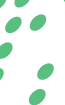

I

- 100000000

1000000

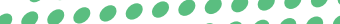

-

- 000000000000

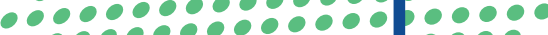

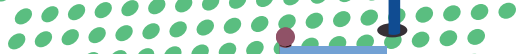

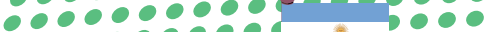

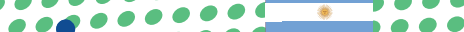

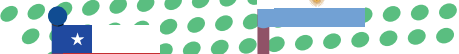

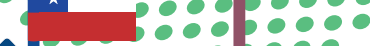

60000001500

90000000

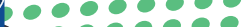

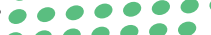

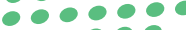

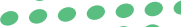

60

2000

우웅

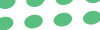

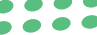

28

10 


\subsection{EL ACUEDUCTO}

Se inició la publicación trimestral de la quinta época del boletín de co municación interna El Acueducto, que durante 2020 constó de cuatro números, orientados desde las cuatro líneas de investigación del Instituto: calidad del agua y ecología, sistemas hídricos, seguridad hídrica y gobernanza del agua.

Mediante artículos, notas y diversos contenidos de carácter general, la ac tual gaceta refleja la vida institucional, académica, y científica del IMTA y tiene el doble propósito, primero, de difundir tanto al interior, principalmente, como al exterior, los resultados generados en el IMTA, pero sobre todo distinguir a las personas que los hacen posible y, segundo, de fortalecer los lazos de interacción interna para reafirmar la identidad institucional entre los colaboradores del Instituto.

Los cuatro números pueden consultarse en www.gob.mx/imta, y la información es abierta a la sociedad interesada en el quehacer del Instituto.
Colaboración en PeRspectivas con:

PROGRAMA DE COMPENSACIONES POR LA PÉRDIDA DE BIENESTAR SOCIOAMBIENTAL

Ángel CarRizales López

DIRECTOR EJECUTIVO DE ASEA

LA MESETA P'UREPECHA HACIA LA GESTIÓN TERRITORIAL INTEGRAL Y A FAVOR DE LAS COMUNIDADES Y LA NATURALEZA

Jorge CASTAÑos MARTÍNeZ DIRECTOR GENERAL DE LA CONAFOR

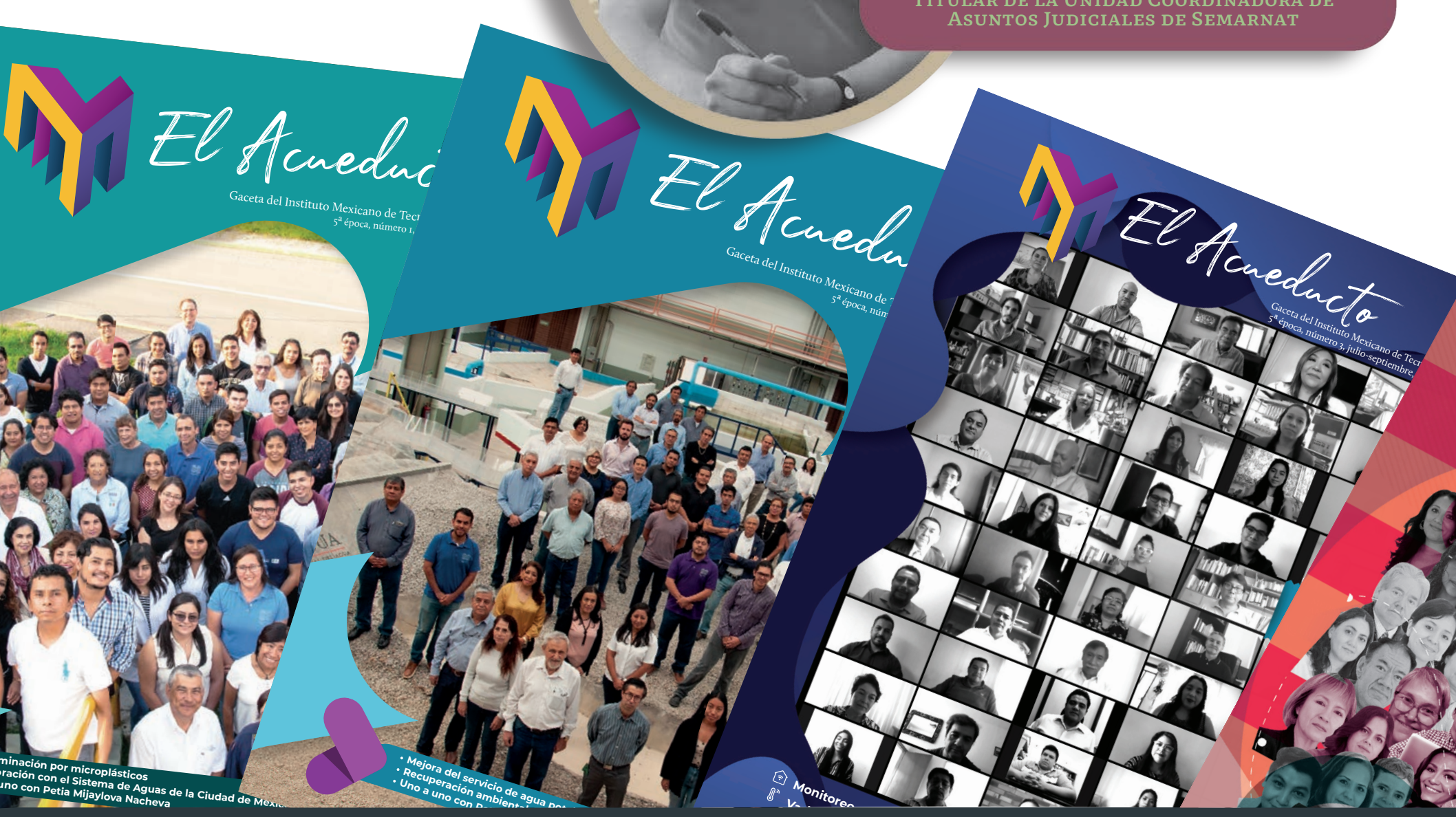

Colaboración en PERs Pectivas con:

LEY GENERAL DE AGUAS CONFLICTOS SOCIOAMBIENTALES

\section{Y DERECHOS HUMANOS}

\section{GUADALUPE ESPINOZA SAUCEDA}

TITULAR DE LA UNIDAD COORDINADORA DE ASUNTOS JUDICIALES DE SEMARNAT 

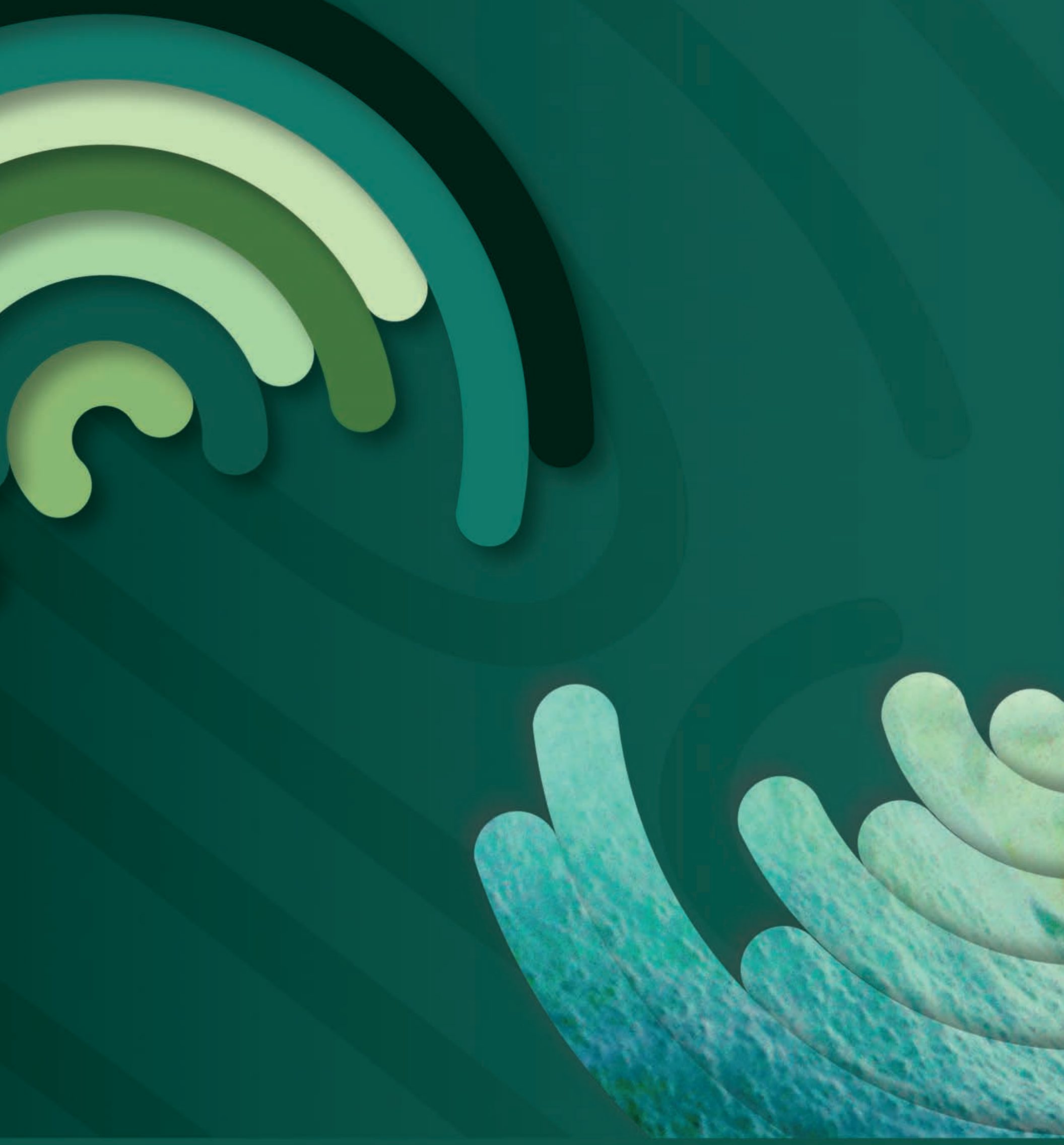